Prepared for $\mathrm{CH} 2 \mathrm{M}$ HILL Plateau Remediation Company

and the U.S. Department of Energy

under Contract DE-AC05-76RL01830

\title{
Spatial Analysis of Contaminants in 200 West Area Groundwater in Support of the 200-ZP-1 Operable Unit Pre-Conceptual Remedy Design
}

\author{
CJ Murray \\ Y-J Bott
}

December 2008

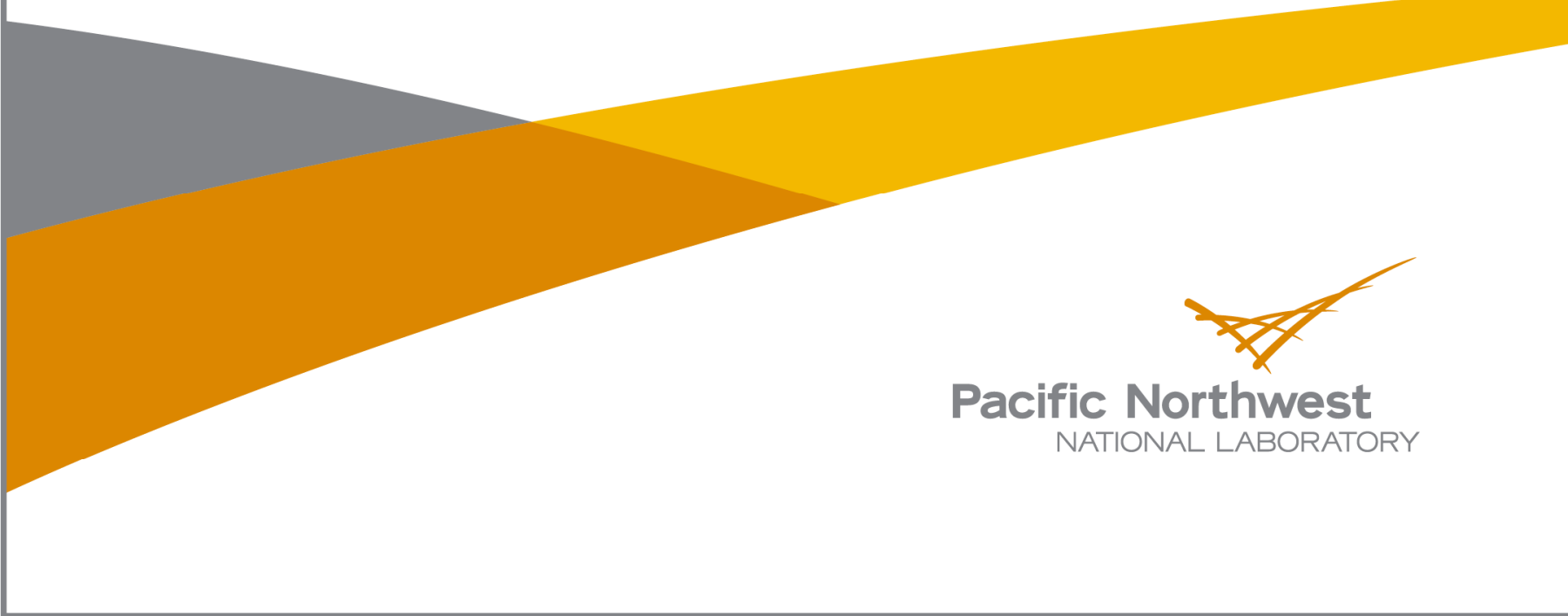




\title{
DISCLAIMER
}

This report was prepared as an account of work sponsored by an agency of the United States Government. Neither the United States Government nor any agency thereof, nor Battelle Memorial Institute, nor any of their employees, makes any warranty, express or implied, or assumes any legal liability or responsibility for the accuracy, completeness, or usefulness of any information, apparatus, product, or process disclosed, or represents that its use would not infringe privately owned rights. Reference herein to any specific commercial product, process, or service by trade name, trademark, manufacturer, or otherwise does not necessarily constitute or imply its endorsement, recommendation, or favoring by the United States Government or any agency thereof, or Battelle Memorial Institute. The views and opinions of authors expressed herein do not necessarily state or reflect those of the United States Government or any agency thereof.

\author{
PACIFIC NORTHWEST NATIONAL LABORATORY \\ operated by \\ BATTELLE \\ for the \\ UNITED STATES DEPARTMENT OF ENERGY \\ under Contract DE-AC05-76RL01830 \\ Printed in the United States of America \\ Available to DOE and DOE contractors from the \\ Office of Scientific and Technical Information, \\ P.O. Box 62, Oak Ridge, TN 37831-0062; \\ ph: (865) 576-8401 \\ fax: $(865) 576-5728$ \\ email: reports@adonis.osti.gov \\ Available to the public from the National Technical Information Service, \\ U.S. Department of Commerce, 5285 Port Royal Rd., Springfield, VA 22161 \\ ph: (800) 553-6847 \\ fax: $(703) 605-6900$ \\ email: orders@ntis.fedworld.gov \\ online ordering: http://www.ntis.gov/ordering.htm
}

This document was printed on recycled paper. 


\section{Spatial Analysis of Contaminants in 200 West Area Groundwater in Support of the 200-ZP-1 Operable Unit Pre-Conceptual Remedy Design}

CJ Murray

Y-J Bott

December 2008

Prepared for

CH2M HILL Plateau Remediation Company

and the U.S. Department of Energy

under Contract DE-AC05-76RL01830

Pacific Northwest National Laboratory

Richland, Washington 99352 



\section{Summary}

This report documents a preliminary spatial and geostatistical analysis of the distribution of several contaminants of interest (COIs) in groundwater within the unconfined aquifer beneath the 200 West Area of the Hanford Site. The contaminant plumes of interest extend within the 200-ZP-1 and 200-UP-1 groundwater operable units. CH2M HILL Plateau Remediation Company (CHPRC) currently is preparing a plan that identifies locations for groundwater extraction wells, injection wells, transfer stations, and one or more treatment facilities to address the contaminants of concern identified in the 200-ZP-1 CERCLA Record of Decision. To accomplish this, Fluor Hanford, Inc. (the previous site contractor) requested that Pacific Northwest National Laboratory (PNNL) provide numerical models of the three-dimensional distribution of selected COIs throughout the 200 West Area groundwater. The COIs included in the PNNL study were carbon tetrachloride (CTET), technetium-99 (Tc-99), iodine-129 (I-129), chloroform, plutonium, uranium, trichloroethylene (TCE), and nitrate.

The project included three tasks. Task 1 involved the development of a database that includes all relevant depth-discrete data on the distribution of COIs in the study area. The database includes well construction information, well sample data for the COIs named above, fields describing the sources of the data, and data quality flags. The database includes all forms of the COIs identified above-for example, all plutonium and uranium isotopes included in the Hanford Environmental Information System, as well as total uranium and all forms of nitrate and chromium. The concentration and activity values summarized in the resulting tables of the Microsoft Access database are considered final for carbon tetrachloride, chloroform, and Tc-99 and were used in the subsequent analysis and mapping (Tasks 2 and 3). However, further work will be needed to transform and select concentrations for some of the other COIs when multiple forms of a COI are present in the database (e.g., chromium, nitrate, and uranium are present in multiple forms). In addition, some uranium and uranium-238 data in the database are measured in picocuries per liter and will need to be converted to micrograms per liter. The appendix to this report contains several electronic files that document in detail the data sources, transformations, and selections that were performed in assembling the database, as well as a copy of the database itself.

The second task involved a spatial analysis of the three-dimensional (3D) distribution of data for the COIs in the study area. The main focus of the task was to determine if sufficient data are available for geostatistical mapping of the COIs in 3D. The results of that study indicate that sufficient data are available for 3D mapping of CTET, chloroform, and Tc-99 using geostatistical methods. Although the conclusions are preliminary, the number of data that appear to be available for the other COIs is much lower; geostatistical mapping of those COIs in 3D may not be possible unless correlations can be established with data that are more numerous and widely distributed in the study area. As an alternative, simpler models may need to be used to characterize the distributions of those COIs with depth in the study area.

Task 3 involved the generation of numerical grids of the concentration of CTET, chloroform, and Tc-99. Multiple realizations were created using a geostatistical simulation approach. Two different suites of realizations were generated for CTET, based on two variogram models known as the CTET 3D model and the CTET 2D model. Although both models were fully three-dimensional, one was based on a variogram model fit to the $3 \mathrm{D}$ concentration data, while the variogram for the CTET $2 \mathrm{D}$ model was fit to 2D data representative of concentrations at the water table. The CTET 3D model was considered the base case for later processing. 
The suites of realizations for each COI were post-processed to provide information about the spatial distribution of the COIs. This included the generation of 3D maps of the median and average concentrations and the probability of exceeding various concentration thresholds. The median concentration provides an estimate of the most probable concentration value at each grid node and can be used as the initial condition for input to flow and transport models. The average of the simulated values also was provided as an alternative base case for the initial conditions. Methods also were developed to rank the realizations and select a subset of realizations for flow and transport modeling for CHPRC by personnel from S.S. Papadopulos \& Associates, Inc. to provide a preliminary investigation of the effect of the spatial uncertainty in concentration distributions on flow and transport predictions.

Complete results of the geostatistical study are documented on compact discs (CDs) provided as the Appendix to this report. The CDs contain electronic files produced during the mapping study, including the COI database and supporting documentation. The geostatistical realizations of CTET (3D model) and chloroform were used to update the carbon tetrachloride inventory in the unconfined aquifer within the 200-ZP-1 and 200-UP-1 groundwater operable units. The updated inventory results, which include an assessment of the uncertainty in the inventory, are reported in a companion document, PNNL-18118. 


\section{Acknowledgments}

The authors thank Matt Tonkin (S.S. Papadopulos \& Associates, Inc.); Mark Byrnes, Virginia Rohay, and Duane Horton (CH2M HILL Plateau Remediation Company); Craig Arola (Vista Engineering Technology, LLC); and Paul Thorne (Pacific Northwest National Laboratory) for their cooperation and collaboration on the performance of this project. We also acknowledge George Last, who provided a technical review of the report, and Andrea Currie, who provided editorial support for the document. 



\title{
Acronyms and Abbreviations
}

\author{
$2 \mathrm{D}$ \\ $3 \mathrm{D}$ \\ BWT \\ CERCLA \\ CHPRC \\ COI \\ CTET \\ DBWT \\ DOE \\ Ecology \\ EPA \\ FY \\ HEIS \\ HWIS \\ I-129 \\ IQR \\ PNNL \\ RUI \\ SSPA \\ TCE \\ Tc-99 \\ VET \\ two-dimensional \\ three-dimensional \\ below water table \\ Comprehensive Environmental Response, Compensation, and Liability Act of \\ 1980 \\ CH2M HILL Plateau Remediation Company \\ contaminant of interest \\ carbon tetrachloride \\ depth below water table \\ U.S. Department of Energy \\ Washington Department of Ecology \\ U.S. Environmental Protection Agency \\ fiscal year \\ Hanford Environmental Information System \\ Hanford Well Information System \\ iodine-129 \\ interquartile range \\ Pacific Northwest National Laboratory \\ reference uncertainty index \\ S.S. Papadopulos \& Associates, Inc. \\ trichloroethylene \\ technetium-99 \\ Vista Engineering Technology, LLC
}





\section{Contents}

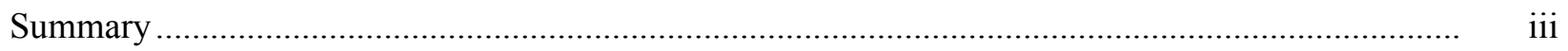

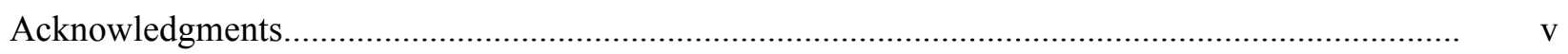

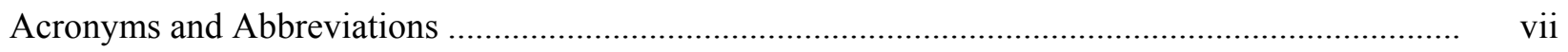

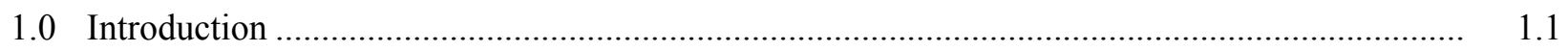

2.0 Compilation of Depth-Discrete Contaminant of Interest Database ....................................... 2.1

2.1 Data Sources and Documentation ............................................................................ 2.1

2.2 Treatment of Non-Detects and Duplicates ................................................................ 2.1

2.3 Calculation of the Depth Below the Water Table ........................................................... 2.2

2.4 Selection of Depth-Discrete COI Data for Analysis and Mapping .................................... 2.2

3.0 Spatial Analysis of Depth Discrete Data ......................................................................... 3.1

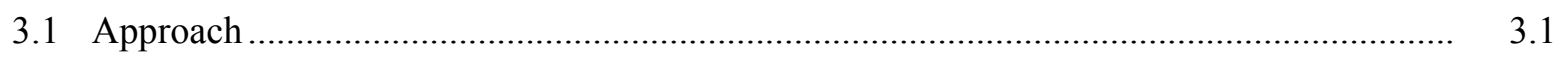

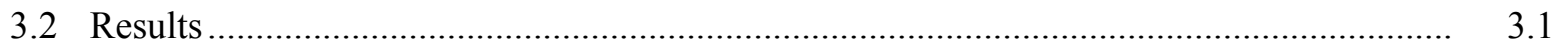

3.3 Preliminary Conclusions on Spatial Distribution of the COI Data ................................. 3.14

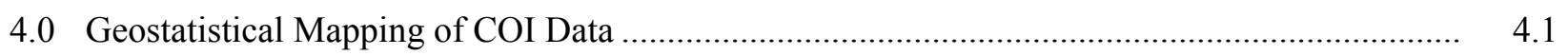

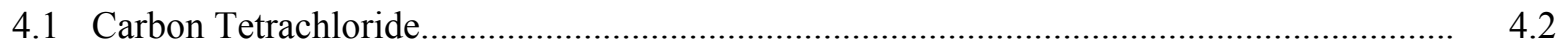

4.1.1 3D Variogram Model ................................................................................... 4.2

4.1.2 2D Variogram Model ......................................................................... 4.12

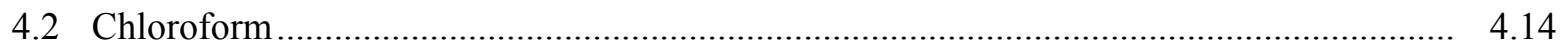

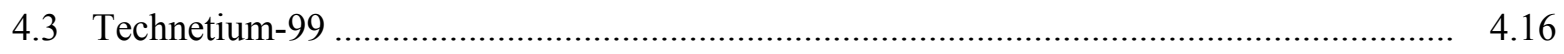

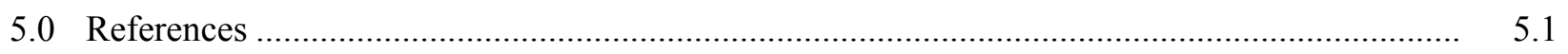

Appendix - Electronic Files for Contaminant Database and Geostatistical Mapping ....................... 1

\section{Figures}

3.1 Frequency Distributions of CTET, Chloroform, and Tc-99 Depth-Discrete Groundwater

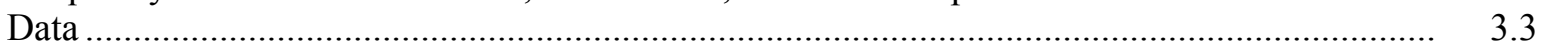

3.2 Spatial Distribution of Average CTET Concentration Data for Intervals

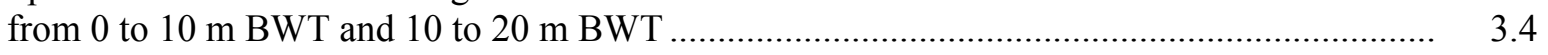

3.3 Spatial Distribution of Average CTET Concentration Data for Intervals from 20 to $30 \mathrm{~m} \mathrm{BWT}$ and 30 to $40 \mathrm{~m} \mathrm{BWT} \mathrm{............................................................................} 3.5$

3.4 Spatial Distribution of Average CTET Concentration Data for Intervals

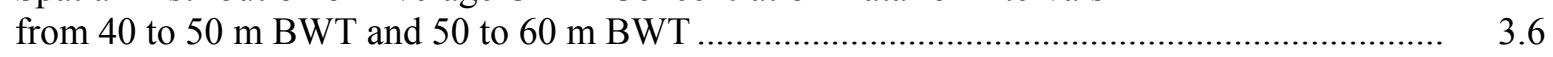

3.5 Spatial Distribution of Average Chloroform Concentration Data for Intervals

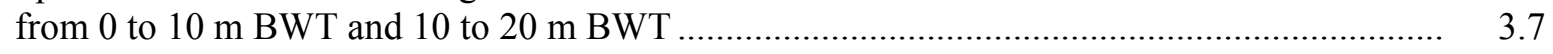

3.6 Spatial Distribution of Average Chloroform Concentration Data for Intervals from 20 to $30 \mathrm{~m}$ BWT and 30 to $40 \mathrm{~m} \mathrm{BWT} \mathrm{..........................................................................}$

3.7 Spatial Distribution of Average Chloroform Concentration Data for Intervals from 40 to $50 \mathrm{~m} \mathrm{BWT}$ and 50 to $60 \mathrm{~m} \mathrm{BWT}$. 
3.8 Spatial Distribution of Average Tc-99 Activity Data for Intervals

from 0 to $10 \mathrm{~m} \mathrm{BWT}$ and 10 to $20 \mathrm{~m} \mathrm{BWT}$....

3.9 Spatial Distribution of Average Tc-99 Activity Data for Intervals from 20 to $30 \mathrm{~m} \mathrm{BWT}$ and 30 to $40 \mathrm{~m} \mathrm{BWT}$

3.10 Spatial Distribution of Average Tc-99 Activity Data for Intervals from 40 to $50 \mathrm{~m} \mathrm{BWT}$ and 50 to $60 \mathrm{~m} \mathrm{BWT}$....

3.11 Concentrations of CTET and Chloroform as a Function of Depth BWT

3.12 Activity of Tc-99 as a Function of Depth BWT

4.1 Experimental Variogram and Model for the Depth-Discrete CTET Data ....

4.2 Variance of Mean of Simulations vs. the Number of Simulations of CTET .

4.3 Median CTET Concentration of Simulations Based on the 3D Variogram Model

4.4 Median CTET Concentration Based on 3D Variogram Model at Depth BWT of 5 and $15 \mathrm{~m}$.....

4.5 Median CTET Concentration Based on 3D Variogram Model at Depth BWT of 25 and $35 \mathrm{~m}$.

4.6 Median CTET Concentration Based on 3D Variogram Model at Depth BWT of 45 and $55 \mathrm{~m}$.

4.7 E-Type CTET Concentration of Simulations Based on the 3D Variogram Model.

4.8 Probability of CTET Exceeding $5 \mu \mathrm{g} / \mathrm{L}$ and $100 \mu \mathrm{g} / \mathrm{L}$ for the Simulations Based on the 3D Variogram Model

4.9 Probability of CTET Exceeding $1000 \mu \mathrm{g} / \mathrm{L}$ and $2000 \mu \mathrm{g} / \mathrm{L}$ for the Simulations Based on the 3D Variogram Model

4.10 RUI with Respect to a Threshold of $100 \mu \mathrm{g} / \mathrm{L}$ as Based on 500 Realizations of CTET Generated Using the 3D Variogram Model .

4.11 Experimental Variogram and Model for the 2D Horizontal Variogram Based on CTET Data from the FY 2007 Annual Groundwater Report.

4.12 Median CTET Concentration of Simulations Based on the Variogram Model of 2D Data........

4.13 Comparison of Global Average Concentrations for Realizations Generated Using the 3D and 2D Variogram Models

4.14 Experimental Variograms and Fitted Models for the Normal Scores of the Depth-Discrete Chloroform Data.

4.15 Experimental Variogram and Fitted Model for 2D Chloroform Data.

4.16 Median Simulated Chloroform Concentration over 500 Realizations

4.17 Median Chloroform Concentration at Depth BWT of 5 and $15 \mathrm{~m}$..

4.18 Median Chloroform Concentration at Depth BWT of 25 and $35 \mathrm{~m}$......

4.19 Median Chloroform Concentration at Depth BWT of 45 and $55 \mathrm{~m}$.

4.20 Experimental Variograms and Models for the Normal Scores of 3D Tc-99 Data and the Horizontal Variogram Model for 2D Tc-99 Data.

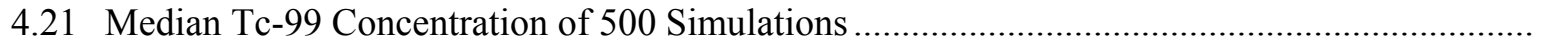

4.22 Median Tc-99 Concentration at Depth BWT of 5 and $15 \mathrm{~m}$....

4.23 Median Tc-99 Concentration at Depth BWT of 25 and $35 \mathrm{~m}$.

4.24 Median Tc-99 Concentration at Depth BWT of 45 and $55 \mathrm{~m}$. 
4.25 E-type Tc-99 Concentration for 500 Simulations .

4.26 Probability of Tc-99 Exceeding $900 \mathrm{pCi} / \mathrm{L}$ from the Suite of Realizations for Depths BWT of 5 and $15 \mathrm{~m}$..

4.27 Probability of Tc-99 Exceeding $900 \mathrm{pCi} / \mathrm{L}$ from the Suite of Realizations for Depths BWT of 25 and $35 \mathrm{~m}$.

\section{Tables}

3.1 Counts of Depth-Discrete Samples for Each COI

3.1

3.2 Summary Statistics of 3D CTET, Chloroform, and Tc-99 Data ...

4.1 Variogram Models Fit to the Normal Score Data of the Three COIs

4.2 Grid Parameters Used in Generation of the Geostatistical Realizations.

4.3 Statistics for Global Means of CTET Realizations Generated Using the 3D and 2D Variogram Models

4.4 Statistics of Global Means for 500 Tc-99 Realizations. 



\subsection{Introduction}

This report documents a preliminary spatial and geostatistical analysis of the distribution of contaminants of interest (COIs) in groundwater within the unconfined aquifer beneath the 200 West Area of the Hanford Site. The contaminant plumes of interest extend within the 200-ZP-1 and 200-UP-1 groundwater operable units.

CH2M HILL Plateau Remediation Company (CHPRC) currently is preparing a plan identifying locations for groundwater extraction wells, injection wells, transfer stations, and one or more treatment facilities to address COIs identified in the 200-ZP-1 CERCLA Record of Decision. To accomplish this, Fluor Hanford, Inc. (the previous site contractor) requested that Pacific Northwest National Laboratory (PNNL) provide numerical models of the three-dimensional distribution of selected COIs throughout the 200 West Area groundwater. The COIs included in the PNNL study were carbon tetrachloride (CTET), technetium-99 (Tc-99), iodine-129 (I-129), chloroform, plutonium, uranium, trichloroethylene (TCE), and nitrate.

The preliminary spatial and geostatistical analysis project included three tasks. Task 1 involved the development of a database that included all relevant depth-discrete data on the distribution of COIs in the study area. The database includes well construction information; well sample data for the COIs named above; fields describing the sources of the data; and data quality flags. The database includes all forms of the COIs identified above - for example, all plutonium and uranium isotopes included in the Hanford Environmental Information System, as well as total uranium and all forms of nitrate. Development of the depth-discrete database was a collaborative effort among interdisciplinary researchers and scientists from PNNL, S.S. Papadopulos \& Associates, Inc. (SSPA), CH2M HILL Plateau Remediation Company (CHPRC) (previously Fluor Hanford, Inc.), and Vista Engineering Technologies LLC (VET).

Task 2 called for a spatial analysis of the three-dimensional (3D) distribution of data for the COIs in the study area. The main focus of the task was to determine if sufficient data were available for geostatistical mapping of the COIs in 3D. The primary focus of the spatial analysis was on the distribution of CTET, chloroform, and Tc-99 data, although preliminary conclusions on the spatial distribution of data for the other COIs also are presented.

Task 3 involved the generation of numerical grids of the concentration of CTET, chloroform, and Tc-99. Multiple realizations were created using a geostatistical simulation approach. The suites of realizations for each COI were post-processed to provide information about the spatial distribution of the COIs. This included the generation of 3D maps of the median and average concentrations and the probability of exceeding various concentration thresholds. Methods also were developed to rank the realizations and select a subset of realizations for flow and transport modeling for CHPRC by personnel from SSPA to provide a preliminary investigation of the effect of the spatial uncertainty in concentration distribution on the flow and transport predictions. The geostatistical realizations of CTET (3D model) and chloroform created for Task 3 were used to update the carbon tetrachloride inventory in the unconfined aquifer within the 200-ZP-1 and 200-UP-1 groundwater operable units. The updated inventory results, which include an assessment of the uncertainty in the inventory, are reported in PNNL-18118. 
This report contains five sections. Section 2 presents information on the compilation of the COI database. Section 3 provides preliminary results on the spatial distribution of the COI data. The generation and processing of the geostatistical realizations are described in Section 4. Literature sources cited in the report are listed in Section 5.

The Appendix, on a set of two compact discs (CDs) bound inside the back cover of this report, contains several folders documenting the results of the geostatistical study. Included are

- a folder, Median Grids, containing the grids of the median simulated values for the CTET 3D and CTET 2D models and Tc-99

- a folder, etype grids, with the grids of the average simulated value (i.e., E-type estimate) for the CTET 3D model and Tc-99

- a folder, alternative realizations, containing subfolders with the alternative realizations for the CTET 3D model and Tc-99 selected based on ranking the realizations on the volume above specified threshold values

- simulation folders for CTET (both the 3D and 2D models), Tc-99, and chloroform that include the SGSIM parameter files, data files, and executable files used to generate the realizations - Each simulation folder contains archived copies of the 500 realizations retained for the study. 


\subsection{Compilation of Depth-Discrete Contaminant of Interest Database}

A database of depth-discrete concentration data was compiled in Microsoft Access for use in the spatial analysis and geostatistical mapping tasks. The database includes well sample data for the COIs of interest; well construction information; water table elevations; fields describing the sources of the concentration data; and data quality flags. The data were drawn from several sources, all of which can be traced back to standard Hanford Site data sources, including the Hanford Environmental Information System (HEIS) and the Hanford Well Information System (HWIS). The database was compiled by personnel from SSPA, CHPRC, and VET. The Appendix to this report contains a copy of the database as well as electronic files that document in detail the data sources, transformations, and selections performed in assembling the database. This section provides a brief description of that material.

\subsection{Data Sources and Documentation}

Data from several sources were included in the database, including the following data sets: the 200-ZP-1 Remedial Investigation data set and the 200-ZP-1 Feasibility Study data set, both provided by C. Arola at VET; depth-discrete CTET and chloroform data sets evaluated by V. Rohay at CHPRC; a depth-discrete Tc-99 data set evaluated by D. Horton at CHPRC; and a retrieval of the most recent data available in the HEIS. The file 200-ZP-1 Stretch PI DataSetDescription May20_2008.doc contains a detailed description of the initial manipulations performed by M. Tonkin at SSPA to assemble the series of Excel files containing the different retrievals mentioned above, as well as a brief description of those source files. The file $d b \_u p d a t e s \_08-11-08 . d o c$ contains a detailed description of revisions made at PNNL to the structure of the initial database provided by M. Tonkin, as well as calculations, selections, and transformations performed to produce the draft database Draft-200-ZP-1_08-11-08.mdb; the database is included in the Appendix.

In addition to the 3D depth-discrete concentration data, the database was supplemented by including the 2D data sets used to map the COIs in the FY 2007 Hanford Site groundwater monitoring report (Hartman and Webber 2008). The use of the supplemental 2D data sets follows the approach used by Murray et al. (2007), where the 2D data are used to provide additional constraints on the concentrations present near the water table and as supplemental data used for variogram analysis when sufficient data were not available to define the horizontal variogram. The methods used by CHPRC personnel working for the Soil and Groundwater Remediation Project to produce the annual report data sets can be found in Annual Report Groundwater Monitoring Data.doc contained in the Appendix. Data sets that were available from the FY 2007 Hanford Site groundwater monitoring report include CTET, chloroform, Tc99, TCE, nitrate, I-129, and uranium.

\subsection{Treatment of Non-Detects and Duplicates}

In many cases, the concentration for a COI was less than the detection limit, a fact that was noted in the Laboratory Qualifier field in the database. Non-detect concentrations were replaced in the database by one-half their stated value, a common practice in environmental analysis (Gilbert 1987). If radionuclide data were reported as less than zero, then those negative results were replaced with zeroes. 
On occasion, more than a single observation of the concentration was made at a given 3D location (e.g., duplicate samples from a single depth in a well). When this occurred, the maximum concentration value that was above detection was used to represent the concentration at that location. If all data from a given location were less than the detection limit, then one-half of the minimum non-detect value would be used; this decision was made because some instruments and laboratories have lower detection limits than others, and the result would be expected to be more representative of the true concentration.

\subsection{Calculation of the Depth Below the Water Table}

The geostatistical realizations of contaminant concentration were generated from the top of the aquifer down to a depth of $60 \mathrm{~m}$ below the water table, similar to the approach followed by Murray et al. (2007). As in the previous work by Murray and colleagues, this required conversion of sample depths below the ground surface to depth below the water table (DBWT).

A numerical grid of the elevation of the water table was created by P. Thorne (PNNL) in EarthVision (P. D. Thorne, PNNL, personal communication, 2008) with data supplied by J. McDonald (CHPRC) that had been used to contour the groundwater surface for the FY 2007 groundwater monitoring report (Hartman and Webber 2008). The elevation data were back-interpolated by M. Tonkin (SSPA) to provide estimates of the water table elevation for most wells in the database, and that table of water level elevations was imported into the Access database. The ground surface elevation, based on data retrieved from the HWIS, was set equal to Disc_Z when present and to ([Coord_Z] - 0.9144) when Disc_Z was not available. This assumes that [Coord_Z $]$ represents the top of casing with a 3-ft stickup. The surface elevation data at each well and the water table elevation were used within Access to convert sample depths below the surface to DBWT.

The sampling depths, water table elevation, and ground surface elevation for some concentration data resulted in the calculation of negative depths below the water table; i.e., they were above the FY 2007 water table. This can occur due to several causes, including recent changes in the elevation of the water table as well as inaccuracy in recording sampling depths and determining the elevation of the ground surface. In most of those cases, the depth of the sample data was within a short distance above the water table. If the distance above the water table was no more than $5 \mathrm{~m}$, then the calculated DBWT was set to zero so that the data were assumed to provide information about the concentrations at the water table. As noted in Section 2.4, if the DBWT was more than $5 \mathrm{~m}$ above the water table, then the sample values were not included in the mapping.

\subsection{Selection of Depth-Discrete COI Data for Analysis and Mapping}

Several criteria were used in selection of the depth-discrete COI data for use in the spatial analysis and geostatistical mapping tasks. These included sampling date, location relative to the water table, and geographic area.

The data were restricted so that only concentration data collected from 1999 or later were included in the final data used for analysis and mapping. This follows the approach used by Murray et al. (2007). The vast majority of the data incorporated in the final data set used for mapping were from 2003 or later. For example, $93 \%$ of the CTET data used for mapping were based on samples collected from 2003 or later. 
As mentioned in Section 2.3, the calculated DBWT for some samples was more than $5 \mathrm{~m}$ above the water table. Those data were excluded from the analysis and mapping because of uncertainty about the quality of the sample location information associated with those data (V. J. Rohay, CHPRC, personal communication, 2008).

The data were geographically restricted to lie between easting coordinates of $564000 \mathrm{~m}$ and $572200 \mathrm{~m}$ and northing coordinates of $132850 \mathrm{~m}$ and $139300 \mathrm{~m}$ (Washington State plane coordinates). This provided data coverage that extended slightly beyond the limits of the grid that was mapped using geostatistical methods, given in Section 4.

The concentration and activity values in the resulting table in the Access database, Table_draft_COC_selected_08-11-08, and the associated Excel spreadsheet, draft_COC_selected_08-1108.xls, are considered final for CTET, chloroform, and Tc-99 and were used in the subsequent spatial analysis and geostatistical mapping (Sections 3 and 4). However, further work will be needed to transform and select concentrations for some of the other COIs when multiple forms of a COI are present in the database (e.g., chromium, nitrate, and uranium are present in multiple forms). In addition, some uranium and uranium-238 data in the database are measured in picocuries per liter and will need to be converted to micrograms per liter. 



\subsection{Spatial Analysis of Depth Discrete Data}

Task 2 called for a spatial analysis of the $3 \mathrm{D}$ distribution of data for the COIs in the study area. The main focus of the task was to determine if sufficient data are available for geostatistical mapping of the COIs in 3D. The primary focus of the spatial analysis was on the distribution of CTET, chloroform, and Tc-99 data, although preliminary conclusions on the spatial distribution of data for the other COIs also are presented.

\subsection{Approach}

The primary data employed in the study consisted of contaminant concentration data from wells in which a discrete depth was recorded, so that a depth below the water table could be calculated for the sample. The vast majority of the data were for samples measured while drilling; a much smaller number were taken from discrete intervals in a wellbore after drilling, usually employing packers to isolate the interval (Murray et al. 2007). Table 3.1 shows the number of observations available for each COI in the study area. CTET had the most depth-discrete samples available. The 436 samples of CTET were distributed across 94 wells; 23 of those wells had samples from a single depth, and 39 wells had samples from five or more depths. The numbers of samples for chromium, nitrate, TCE, and uranium may increase slightly from those given in Table 3.1 because there are samples in the database with multiple forms of the COI present (e.g., both total chromium and chromium [VI]) and/or with both concentration and activity values reported. A procedure to transform and integrate those data needs to be developed before analysis of the spatial distribution of data can be performed for those COIs.

Table 3.1. Counts of Depth-Discrete Samples for Each COI

\begin{tabular}{lc}
\hline \multicolumn{1}{c}{ Contaminant of Interest } & Count \\
\hline CTET & 436 \\
Chloroform & 422 \\
Chromium & 80 \\
I-129 & 58 \\
Nitrate & 66 \\
Tc-99 & 372 \\
Trichloroethylene & 115 \\
Uranium & 64 \\
\hline
\end{tabular}

\subsection{Results}

Table 3.2 contains summary statistics for CTET, chloroform, and Tc-99, while Figure 3.1 shows the histograms of the three variables. All three variables are strongly skewed, with mean values much higher than the medians, and the coefficient of variation (i.e., the ratio of the standard deviation to the mean) is 
Table 3.2. Summary Statistics of 3D CTET, Chloroform, and Tc-99 Data

\begin{tabular}{lccr}
\hline & \multicolumn{3}{c}{ Contaminant of Interest } \\
\cline { 2 - 4 } \multicolumn{1}{c}{ Statistic } & CTET $(\mu \mathrm{g} / \mathrm{L})$ & Chloroform & $(\mu \mathrm{g} / \mathrm{L})$ \\
\hline Mean & 729.72 & 42.86 & Tc-99 $(\mathrm{pCi} / \mathrm{L})$ \\
Standard error & 48.55 & 5.99 & 5070.98 \\
Median & 211.50 & 11.00 & 916.71 \\
Standard deviation & 1013.78 & 123.08 & 96.55 \\
Sample variance & 1027745.53 & 15149.86 & 17680.84 \\
Coefficient of variation & 1.39 & 2.87 & 312612099.12 \\
Kurtosis & 2.64 & 36.06 & 3.49 \\
Skewness & 1.73 & 5.57 & 52.06 \\
Range & 5099.93 & 1099.97 & 6.48 \\
Minimum & 0.08 & 0.04 & 185000.00 \\
Maximum & 5100.00 & 1100.00 & 0.00 \\
Count & 436 & 422 & 185000.00 \\
\hline
\end{tabular}

high for each of the variables. The variability of Tc-99 is by far the greatest of the three variables, with an extremely wide range of data values and higher values for the standard deviation, skewness, and coefficient of variation.

Examination of Figure 3.1 shows that the histograms for chloroform and Tc-99 are somewhat symmetrical, while the CTET histogram is not. Given the logarithmic axis on which all three COIs are plotted, this suggests that chloroform and Tc-99 have univariate distributions that are approximately lognormal, but CTET does not. The normal score transform has more flexibility than the logarithmic transform (Goovaerts 1997), so in all three cases, the variables were mapped in Section 4 using the normal score transforms of the data, which transformed all three COIs to histograms that are exactly normal.

Figures 3.2 through 3.7 show the distribution of CTET and chloroform data for several depth intervals in the aquifer. The concentrations at each location within a given depth interval (e.g., 0-10 m below the water table [BWT]) were averaged for construction of these maps, which were generated to display the distribution of concentration data for a range of depths in the unconfined aquifer. The averaged values over those depth intervals were not used in the geostatistical analysis; the geostatistical analyses were based on the original depth-discrete data. These maps indicate that the highest CTET concentration values do not always occur near the water table but are often deeper within the aquifer, especially for locations in the eastern portion of the map area. For example, in the 299-W13-1 borehole several kilometers east of the assumed source areas, the highest concentrations for both CTET and chloroform occur in the 40- to 50-m-BWT depth interval. On the other hand, maps prepared in the same manner for Tc-99 (Figures 3.8-3.10) suggest that the highest concentrations for Tc-99 are near the top of the aquifer.

The conclusions regarding the distribution with depth for the three variables are supported by Figures 3.11 and 3.12, which plot the individual concentration or activity values for the three variables as a function of depth. The deep distribution of high concentrations of CTET and chloroform can be seen in Figure 3.11. On the other hand, all the high values for Tc-99 that occur deep within the aquifer (e.g., depths greater than $30 \mathrm{~m} \mathrm{BWT}$ ) are from a single well, the 299-W11-25B. At the rest of the wells, the maximum Tc-99 tends to decrease with depth (Figure 3.12). 

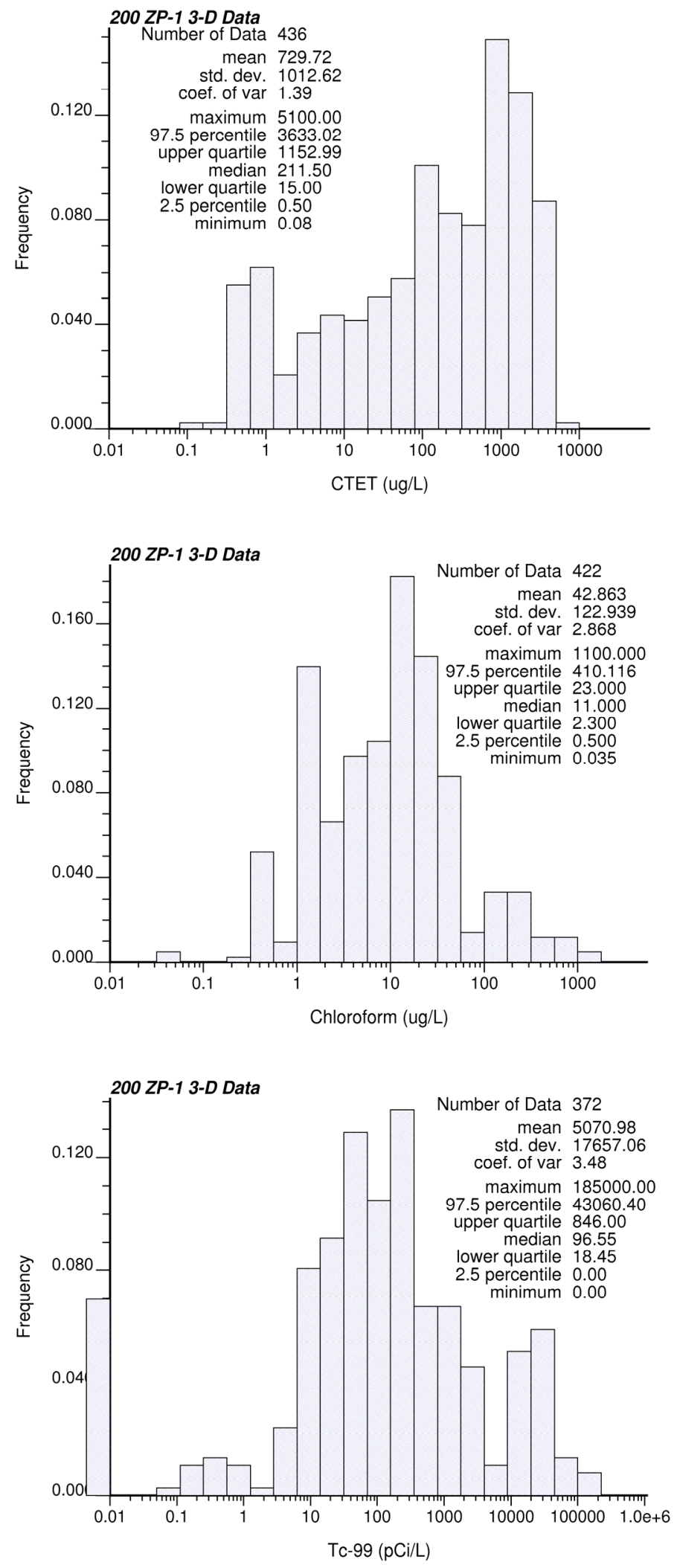

Figure 3.1. Frequency Distributions of CTET (upper), Chloroform (middle), and Tc-99 (lower) DepthDiscrete Groundwater Data. Note that all histograms are plotted on logarithmic scales. 


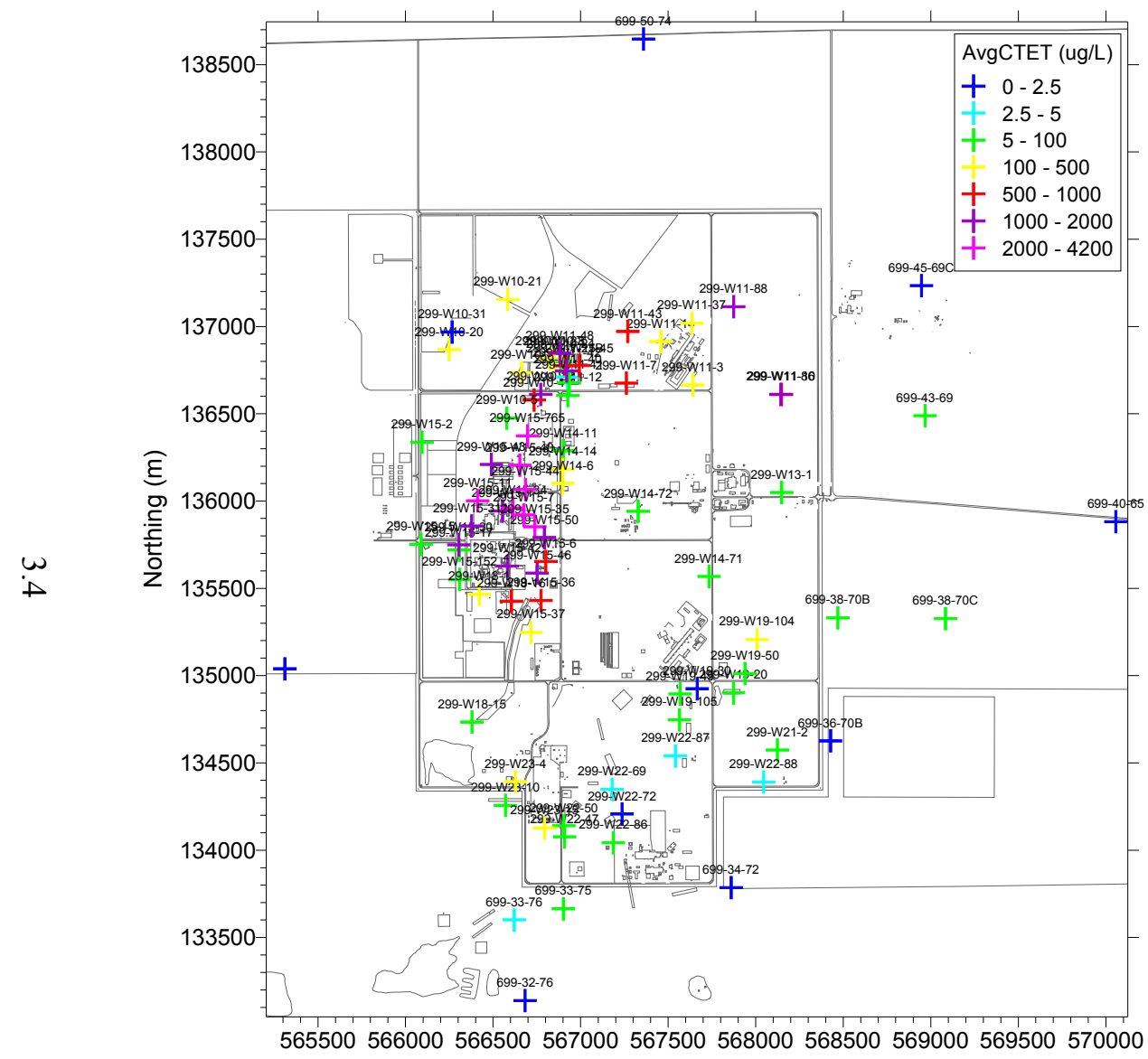

565500566000566500567000567500568000568500569000569500570000 Easting $(\mathrm{m})$

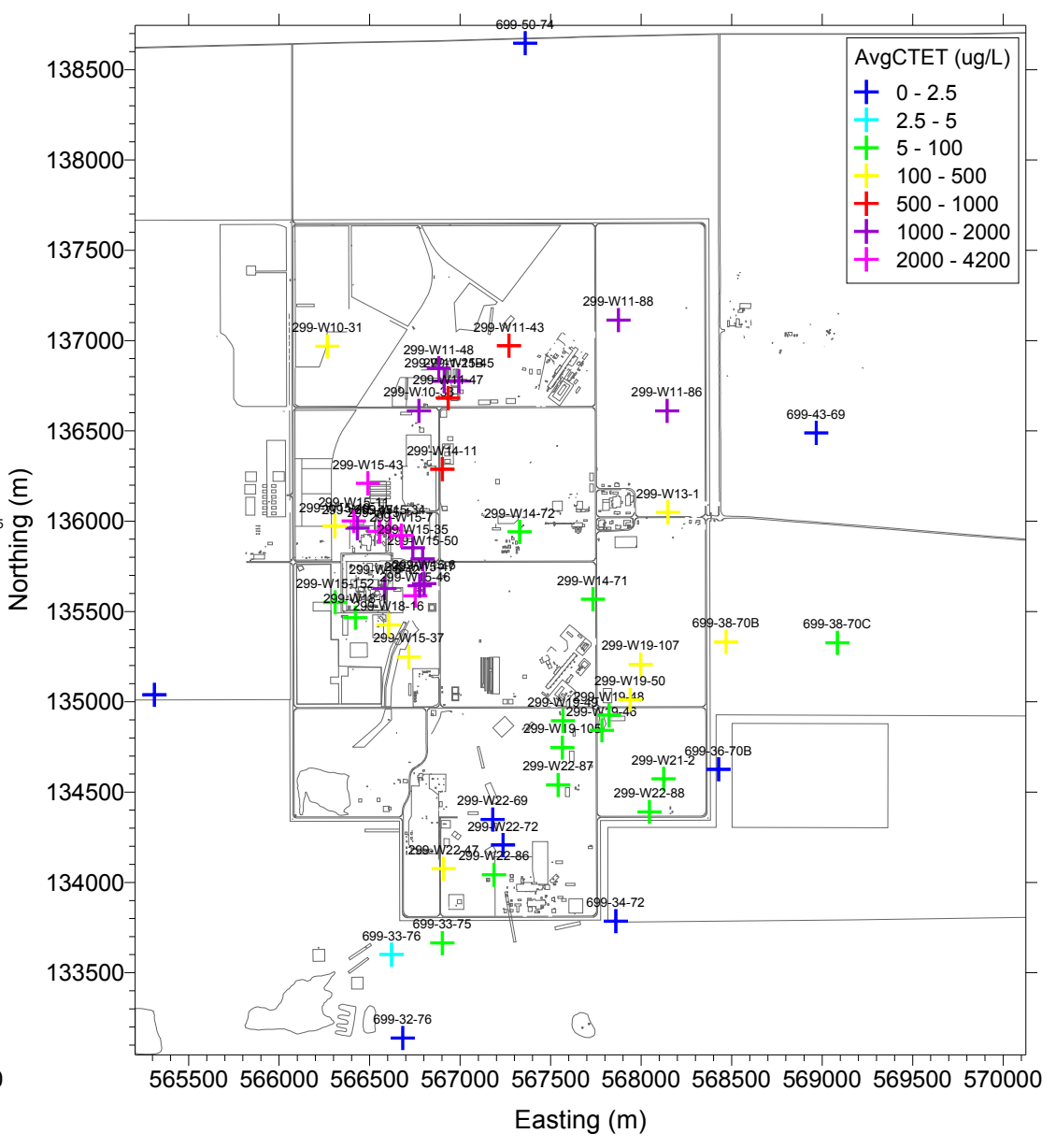

Easting $(m)$

Figure 3.2. Spatial Distribution of Average CTET Concentration Data for Intervals from 0 to $10 \mathrm{~m} \mathrm{BWT} \mathrm{(left)} \mathrm{and} 10$ to $20 \mathrm{~m} \mathrm{BWT}$ (right) 

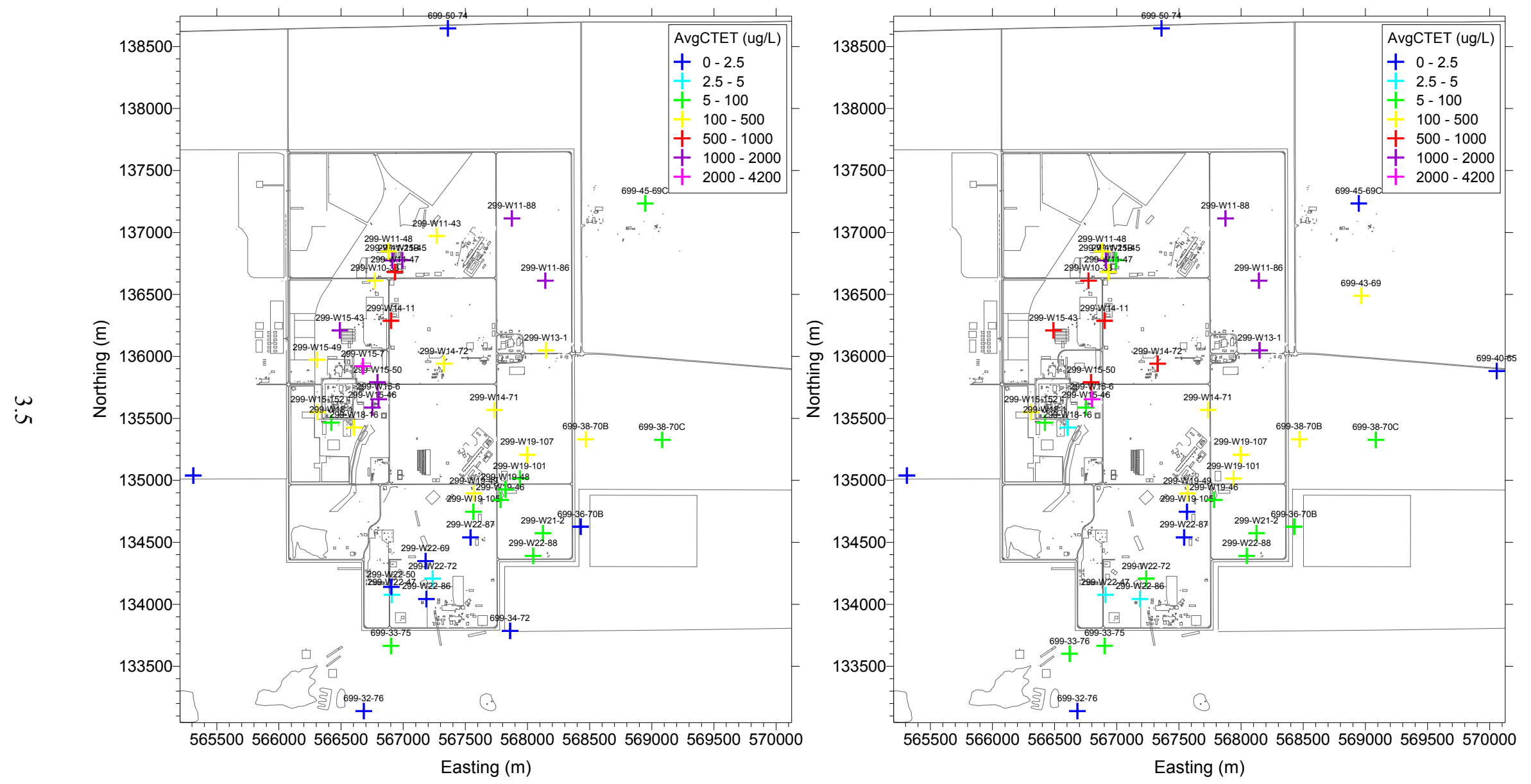

Figure 3.3. Spatial Distribution of Average CTET Concentration Data for Intervals from 20 to $30 \mathrm{~m} \mathrm{BWT} \mathrm{(left)} \mathrm{and} 30$ to $40 \mathrm{~m} \mathrm{BWT}$ (right) 

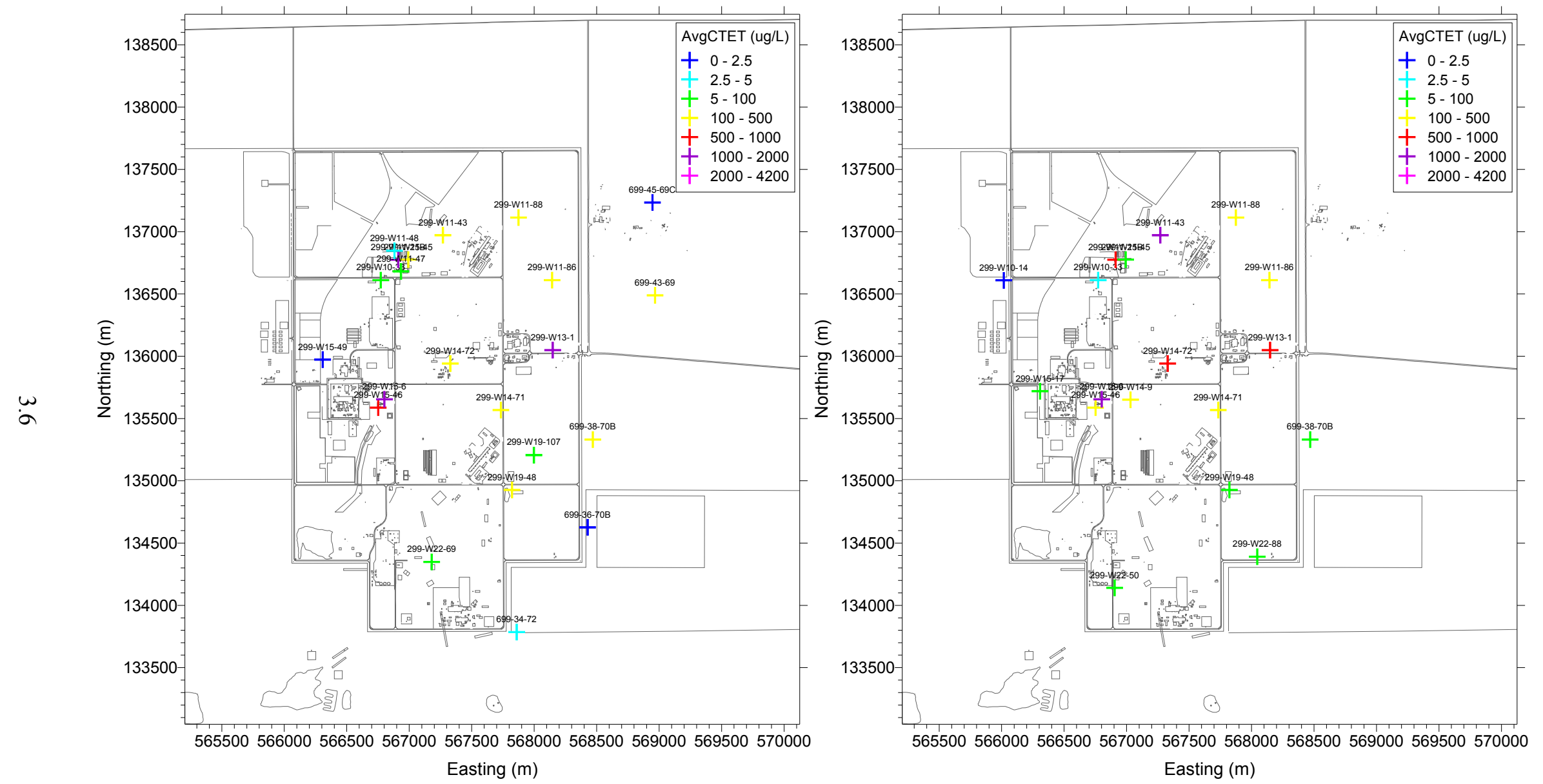

Figure 3.4. Spatial Distribution of Average CTET Concentration Data for Intervals from 40 to $50 \mathrm{~m} \mathrm{BWT}$ (left) and 50 to $60 \mathrm{~m} \mathrm{BWT}$ (right) 

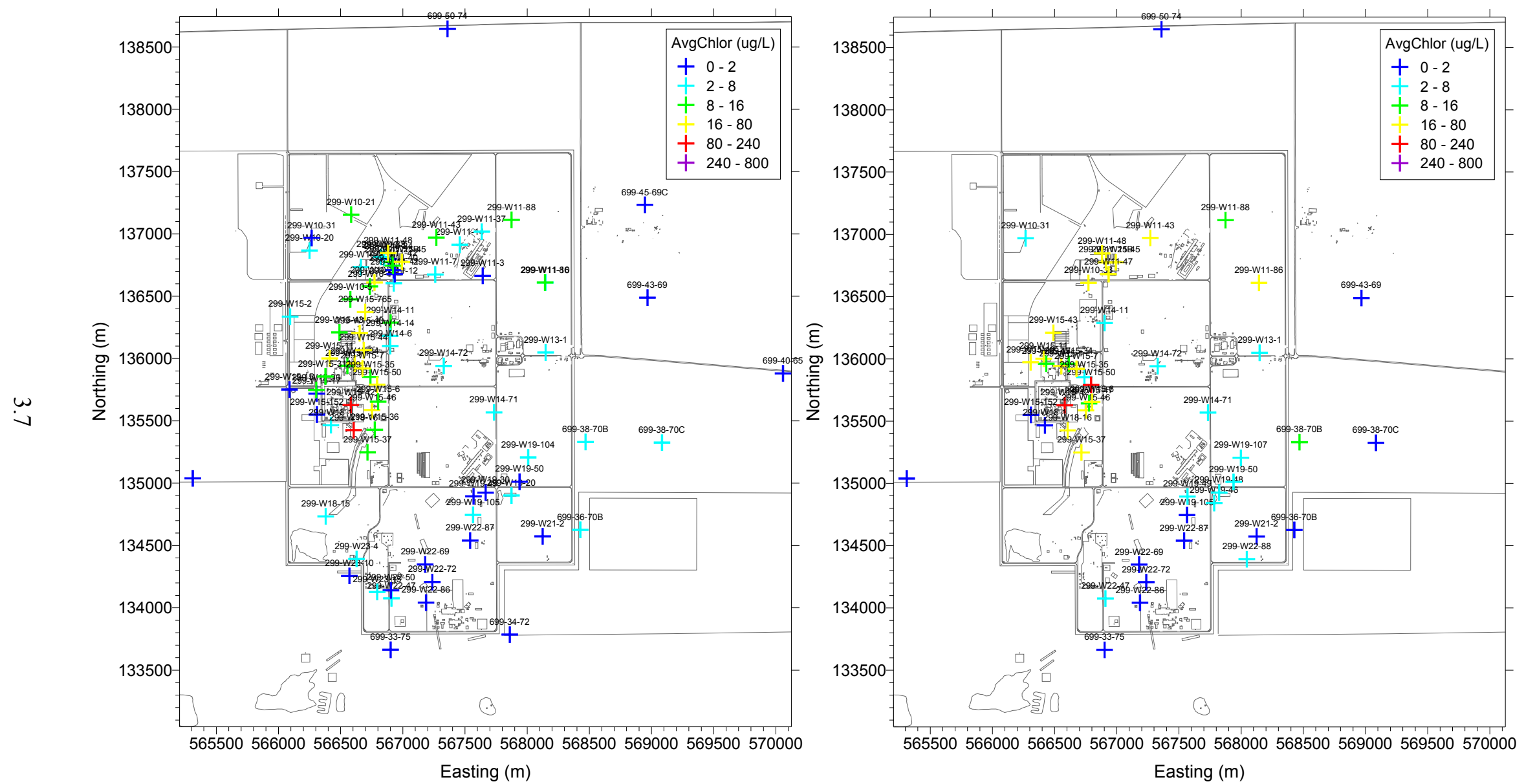

Figure 3.5. Spatial Distribution of Average Chloroform Concentration Data for Intervals from 0 to $10 \mathrm{~m} \mathrm{BWT}$ (left) and 10 to $20 \mathrm{~m} \mathrm{BWT}$ (right) 

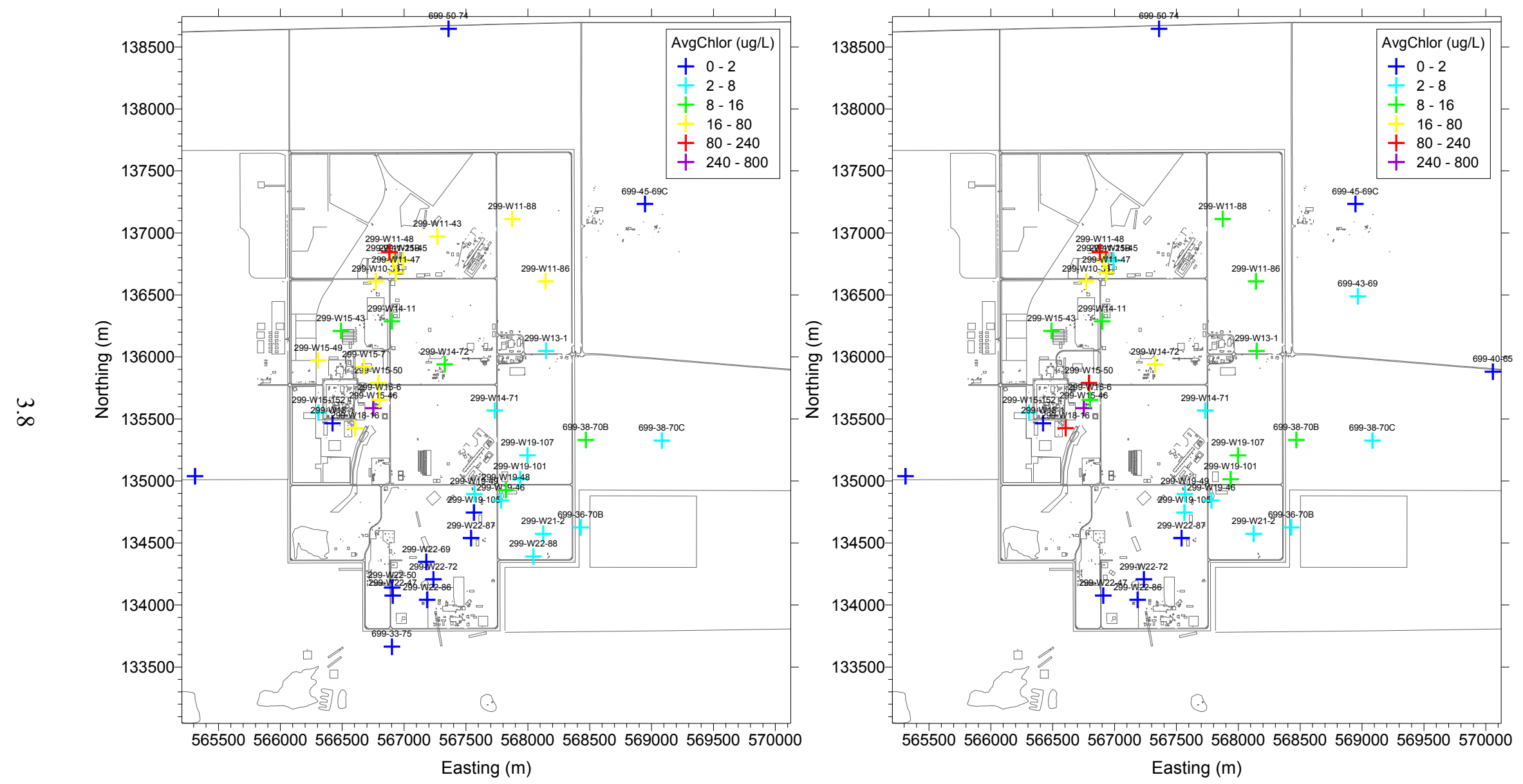

Figure 3.6. Spatial Distribution of Average Chloroform Concentration Data for Intervals from 20 to $30 \mathrm{~m} \mathrm{BWT}$ (left) and 30 to $40 \mathrm{~m} \mathrm{BWT}$ (right) 

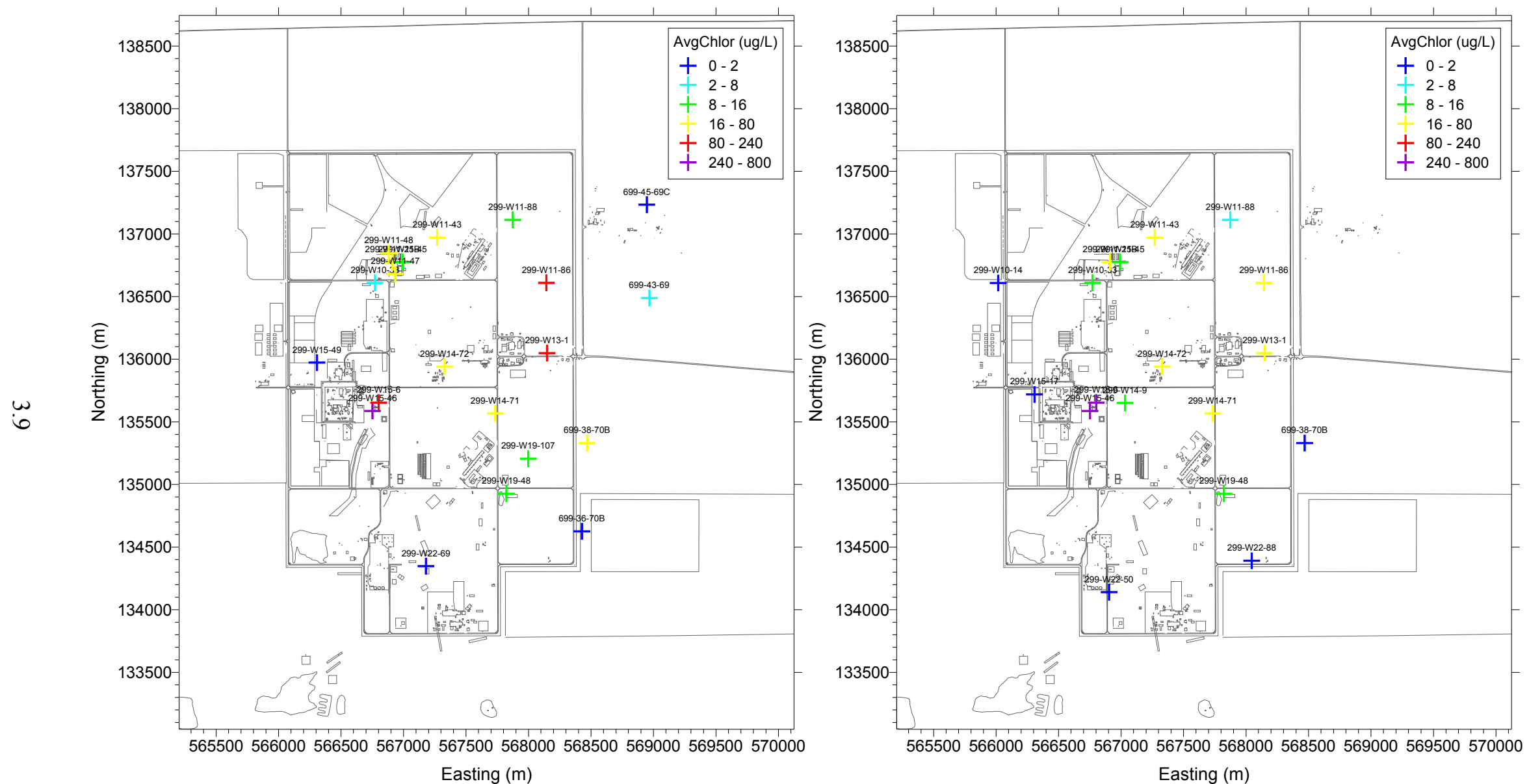

Figure 3.7. Spatial Distribution of Average Chloroform Concentration Data for Intervals from 40 to $50 \mathrm{~m} \mathrm{BWT} \mathrm{(left)} \mathrm{and} 50$ to $60 \mathrm{~m} \mathrm{BWT}$ (right) 

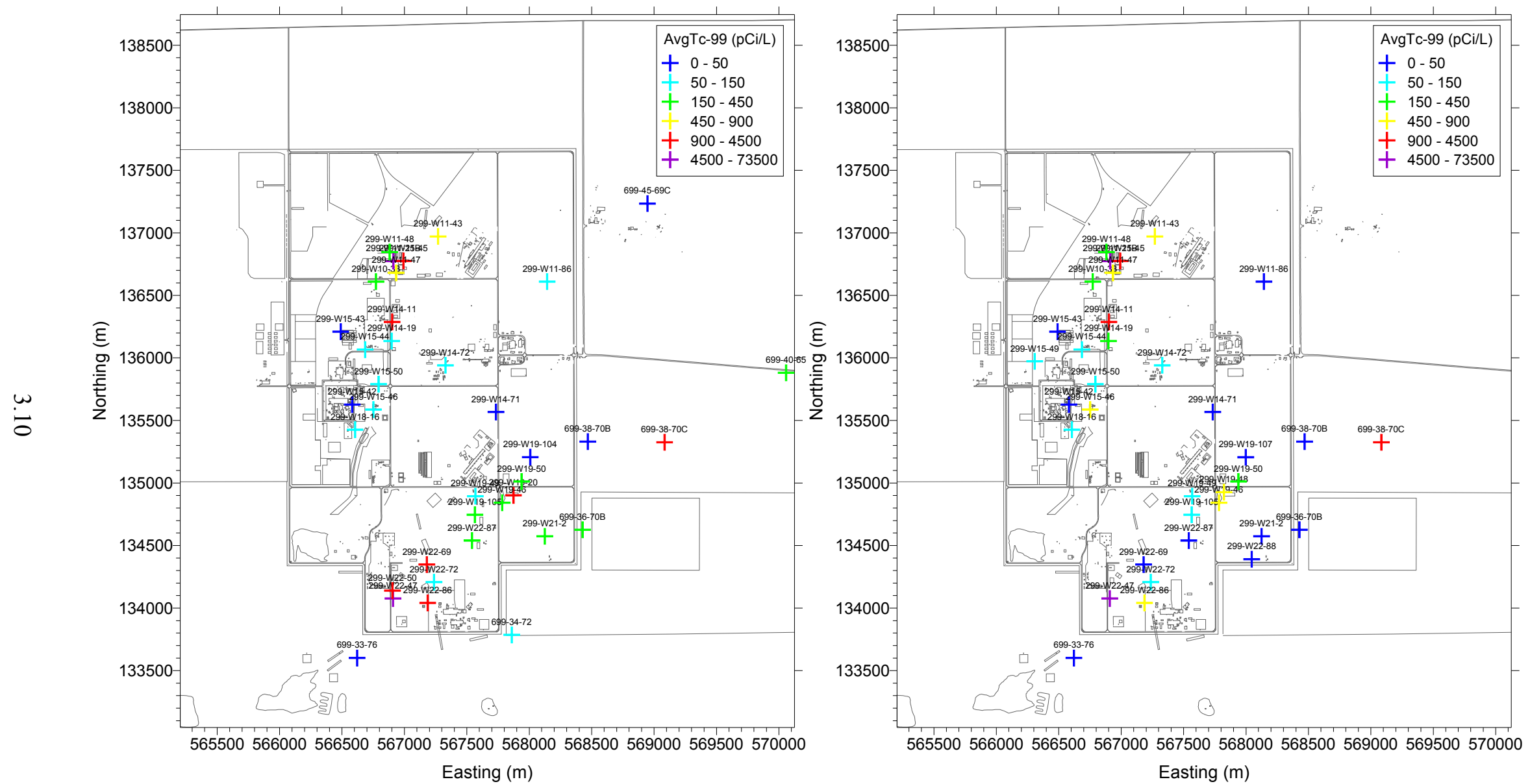

Figure 3.8. Spatial Distribution of Average Tc-99 Activity Data for Intervals from 0 to $10 \mathrm{~m}$ BWT (left) and 10 to $20 \mathrm{~m} \mathrm{BWT}$ (right) 

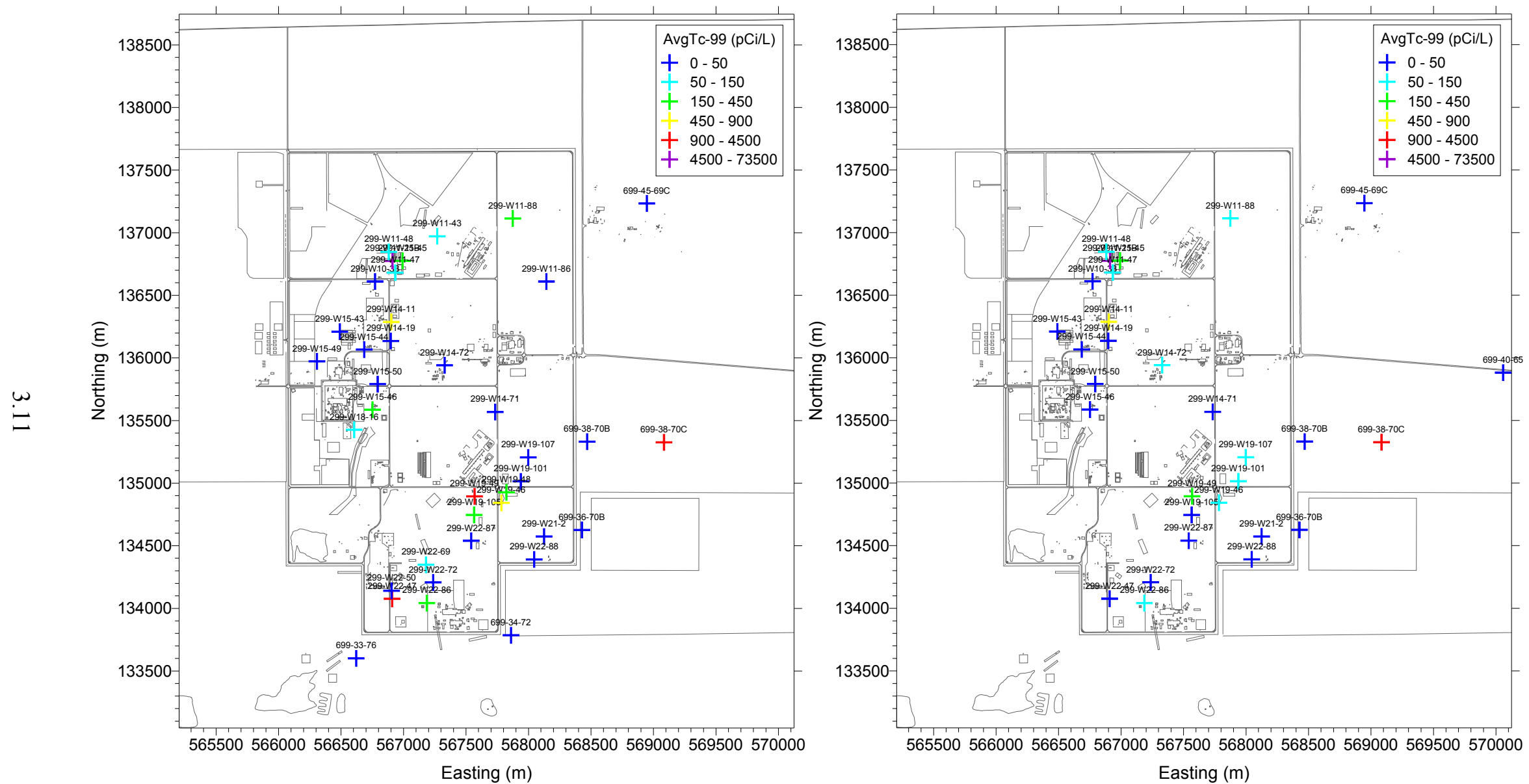

Figure 3.9. Spatial Distribution of Average Tc-99 Activity Data for Intervals from 20 to $30 \mathrm{~m}$ BWT (left) and 30 to $40 \mathrm{~m}$ BWT (right) 

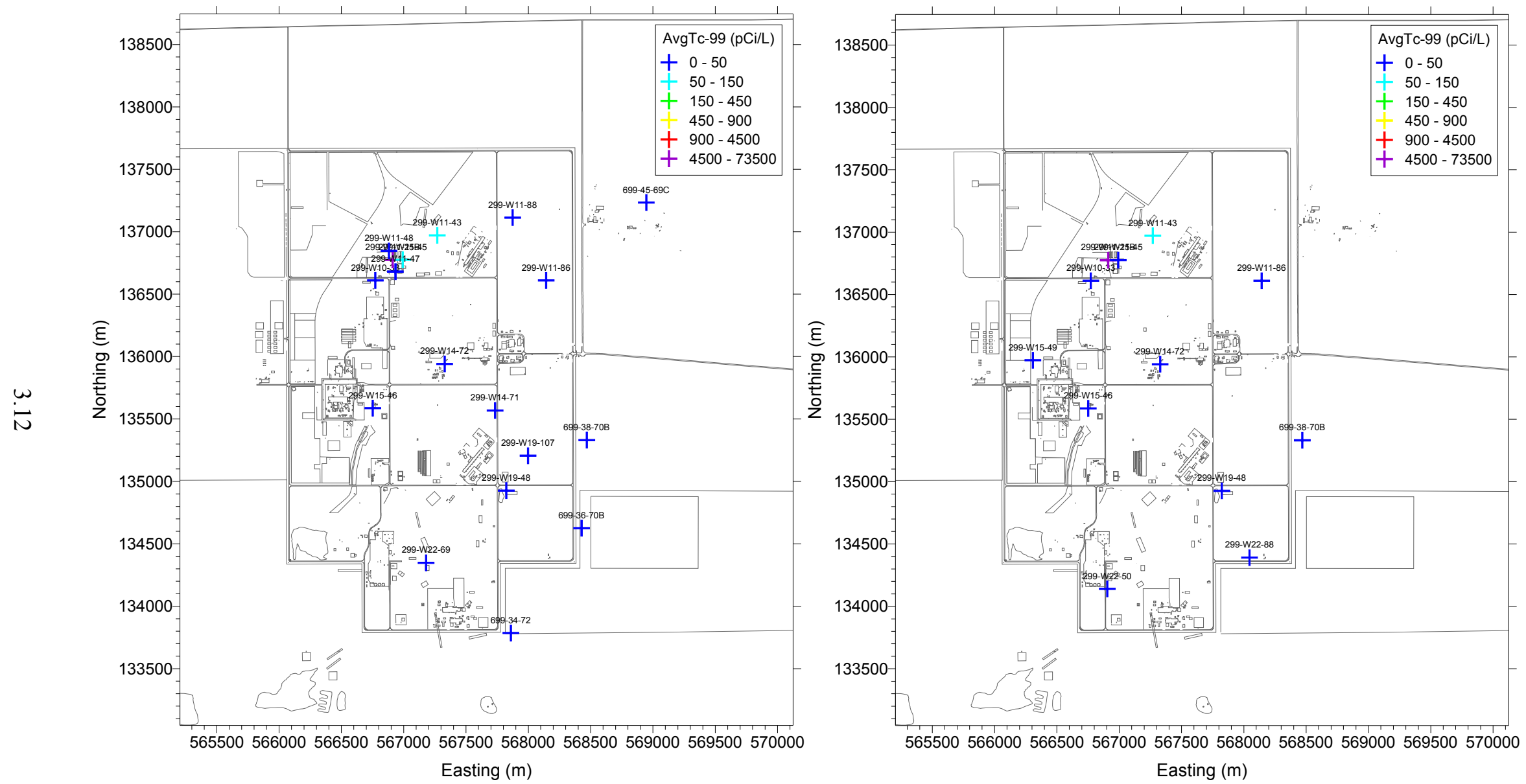

Figure 3.10. Spatial Distribution of Average Tc-99 Activity Data for Intervals from 40 to $50 \mathrm{~m}$ BWT (left) and 50 to $60 \mathrm{~m} \mathrm{BWT}$ (right) 

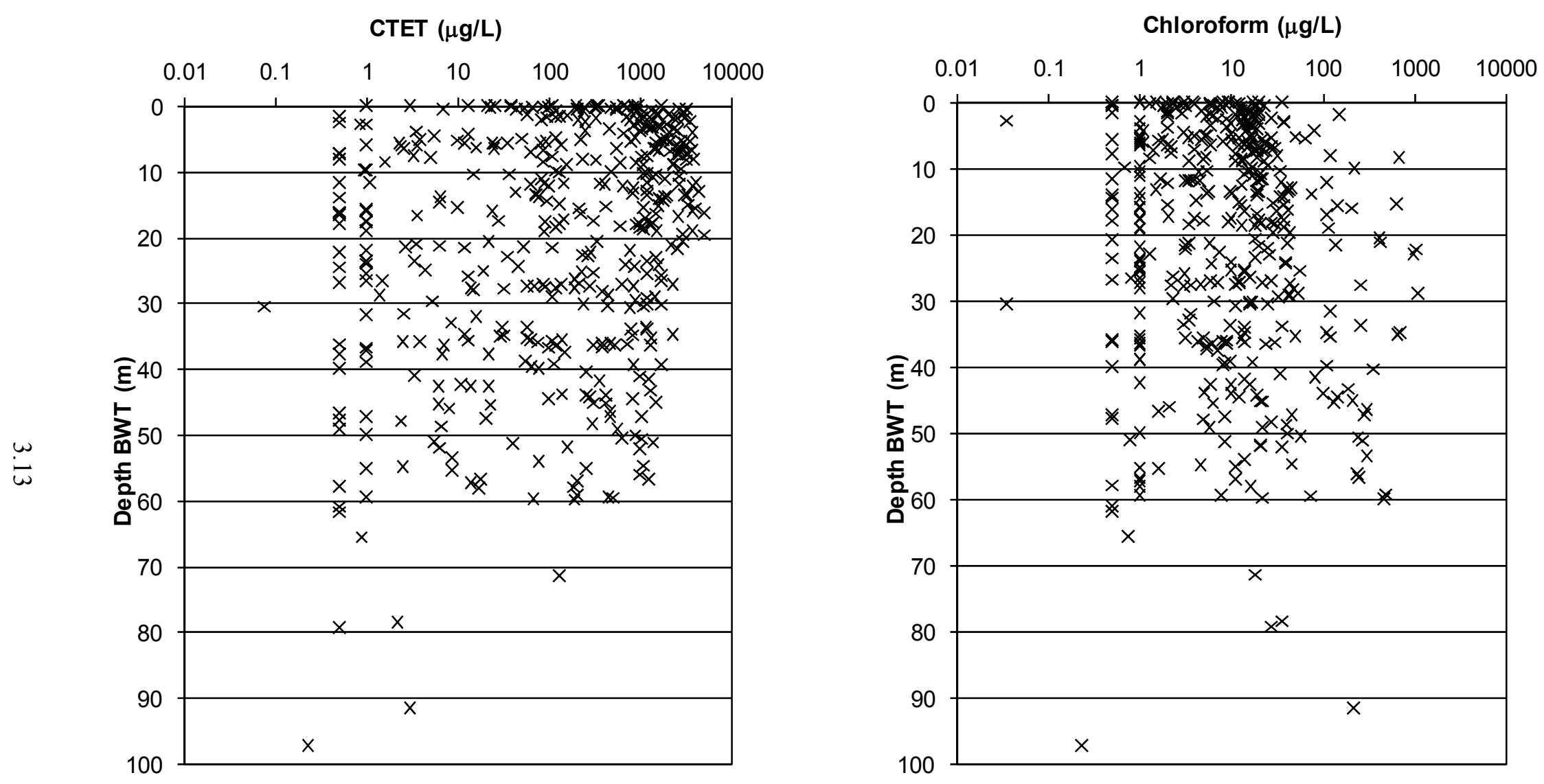

Figure 3.11. Concentrations of CTET (left) and Chloroform (right) as a Function of Depth BWT 


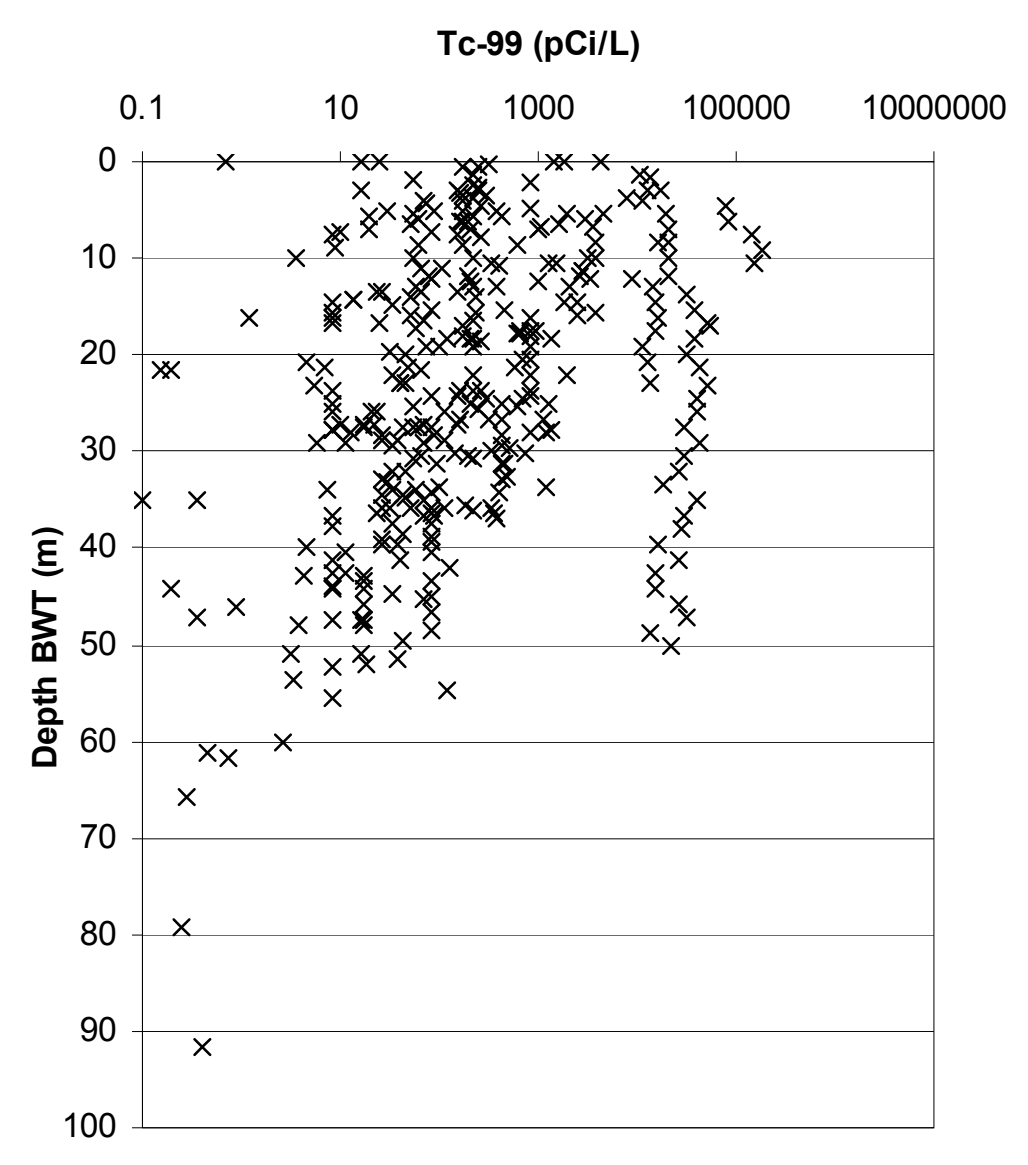

Figure 3.12. Activity of Tc-99 as a Function of Depth BWT

\subsection{Preliminary Conclusions on Spatial Distribution of the COI Data}

The initial spatial analysis of the ZP-1 data set showed that CTET, chloroform, and Tc-99 all could be mapped using the geostatistical methods employed by Murray et al. (2007). This conclusion was already known for CTET and chloroform, both of which had been mapped in 3D for the earlier study. The amount of CTET and chloroform data available for the current study was slightly larger, with the addition of 60 additional point observations and the addition of at least three deep wells with more than five depthdiscrete sample depths per well.

Table 3.2 shows that Tc-99 has fewer observations available than CTET and chloroform, but the decrease is not that large; Tc-99 has about 14\% fewer observations than CTET. Examination of the maps for Tc-99 (Figures 3.8-3.10) suggested that the spatial distribution of the samples in each 10-m interval also was reasonable; samples were distributed evenly across a large portion of the 200 West Area, especially down to a depth of $40 \mathrm{~m} \mathrm{BWT}$, and at least 16 sample locations were present even at 50-60 m BWT. Taken together, the use of geostatistical methods for mapping Tc-99 appeared to be feasible; that was substantiated by the geostatistical mapping of Tc-99 discussed in Section 4. 
However, examination of Table 3.1 suggests that geostatistical mapping in 3D may not be possible for the other COIs. Chromium, I-129, nitrate, TCE, and uranium have $73 \%$ to $85 \%$ fewer depth-discrete data than are available for CTET. This conclusion is mitigated slightly for some of the COIs for which multiple forms and/or measurement units exist in the database, so the final number of depth-discrete data may be slightly higher than suggested by Table 3.1. Additional work will be needed to transform those COIs to common measurement units. Additional work will be needed also to create maps of the depth distributions of the other COIs, similar to Figures 3.2-3.12, to examine the spatial distribution of the samples for each depth level, once that integration is complete.

The correlation between all ZP-1 COIs also should be examined in any future work on the 200-ZP-1 COIs. If high correlations are found between CTET, chloroform, and Tc-99 and any of the remaining COIs, then it is possible that the COI with fewer data might be mapped geostatistically using the COI with a wider distribution of sample locations as secondary data. Geostatistical methods that incorporate secondary data are discussed in Goovaerts (1997). If the geostatistical approach does not appear suitable, it may be necessary to examine other approaches for constructing 3D models of the distribution of the other COIs. 



\subsection{Geostatistical Mapping of COI Data}

The geostatistical method used for 3D mapping of CTET, chloroform, and Tc-99 was sequential Gaussian simulation (Goovaerts 1997). That method is based on use of a normal score transform of the data that transforms the data so that they are normally distributed with a mean of zero and a variance of 1. This transform, which is similar in its effect to a logarithmic transform, adjusts for the positively skewed nature of the COI concentrations but has several advantages over a logarithmic transform. The depthdiscrete data for each COI were converted to normal scores (Goovaerts 1997), and experimental variograms were calculated in three dimensions. Horizontal (2D) variograms also were calculated for the normal scores of the CTET, chloroform, and Tc-99 data sets compiled for the FY 2007 annual groundwater report (Hartman and Webber 2008). Those data sets employ the standard algorithm of selecting the most recent annual average for the period from FY 2005 through FY 2007 for which data are available. The concentration values selected using those criteria (i.e., those data where the zone reported in the HEIS is "TU" or "UU" or "U," or is not specified) are assumed to be representative of conditions in the upper portions of the aquifer (Hartman and Webber 2008). Table 4.1 contains a summary of the models fit to the experimental variograms; details on the modeling and plots of the variograms are included in the section for each COI.

Table 4.1. Variogram Models Fit to the Normal Score Data of the Three COIs

\begin{tabular}{llrccc}
\hline & & & & \multicolumn{2}{c}{ Range $(\mathrm{m})$} \\
\cline { 5 - 6 } \multicolumn{1}{c}{ COI } & Nugget & Sill & Structure & Horizontal & Vertical \\
\hline CTET (3D) & 0.40 & 0.60 & Spherical & 800 & 50 \\
CTET (2D) & 0.08 & 0.92 & Spherical & 1650 & 30 \\
Chloroform & 0.17 & 0.83 & Spherical & 1250 & 70 \\
\multirow{2}{*}{ Tc-99 } & \multirow{2}{*}{0.07} & 0.53 & Spherical & 90 & 90 \\
& & 0.40 & Spherical & 900 & 90 \\
\hline
\end{tabular}

The variogram models shown in Table 4.1 were used to generate a series of realizations of each COI using the SGSIM program included in the GSLIB geostatistical subroutine library (Deutsch and Journel 1998). The data used to condition those realizations were the 3D depth-discrete data, supplemented by the 2D data generated for the FY 2007annual groundwater report (Hartman and Webber 2008). This follows the approach used by Murray et al. (2007). The suites of realizations were then post-processed to retrieve several sets of numerical grids that could be used to represent the spatial distribution of the COIs in the study area.

The grid resolution and origin used for the simulations differ slightly from those used by Murray et al. (2007) in order to fit the needs of a concurrent flow and transport modeling effort using the results of this study to provide 3D input grids for the spatial distribution of the three COIs (M. J. Tonkin, SSPA, personal communication, 2008). For the current study, we used a $60-\mathrm{m}$ x $60-\mathrm{m}$ grid in the horizontal and a 3-m vertical resolution. The simulation grid extended to a depth of $60 \mathrm{~m}$ below the top of the water table. The vertical thickness of the simulation grid was chosen for two reasons. One is that the average thickness of the unconfined aquifer in the study area is approximately $60 \mathrm{~m}$ (Williams et al. 2005). In addition, the number of CTET data decreases with increasing depth below the top of the aquifer, as shown in Figures 3.2 through 3.4; below a depth of $60 \mathrm{~m}$, only two to four data points were present in each 10-m interval. The parameters of the grid are given in Table 4.2, with a total of 167,328 grid nodes in the 3D grid. 
Table 4.2. Grid Parameters Used in Generation of the Geostatistical Realizations

\begin{tabular}{cccccc}
\hline & \multicolumn{5}{c}{ Grid Parameter } \\
\cline { 2 - 6 } & Minimum $(\mathrm{m})$ & Maximum $(\mathrm{m})$ & Length $(\mathrm{m})$ & Spacing $(\mathrm{m})$ & Number \\
\hline $\mathrm{X}$ & 565205 & 570125 & 4920 & 60 & 83 \\
$\mathrm{Y}$ & 133045 & 138745 & 5700 & 60 & 96 \\
$\mathrm{Z}$ & -60 & 0 & 60 & 3 & 21 \\
\hline
\end{tabular}

\subsection{Carbon Tetrachloride}

Two separate variogram models of the spatial distribution of CTET concentrations were generated. The first was based on a variogram model fit to the experimental variogram for the normal scores of the 3D depth-discrete data, and the second was based on the procedure used to estimate the CTET variogram model by Murray et al. (2007).

\subsubsection{D Variogram Model}

Previous attempts to calculate and model variograms of CTET based solely on the 3D depth-discrete data had been unsuccessful, apparently due to the sparse distribution of 3D depth-discrete data (Murray et al. 2007). As discussed in Section 2, the current database includes a much larger set of observations for which the depth is known-436 observations versus 280 in the previous study. There were 39 boreholes with samples from at least five different depths, and another 55 wells with four or fewer observations. With the new data set, an interpretable experimental variogram was calculated for the $3 \mathrm{D}$ depth-discrete CTET concentration data (Figure 4.1), and a variogram model was fit to that experimental variogram; this will be referred to as the $3 \mathrm{D}$ variogram model. The model fit to the horizontal experimental variogram had a shorter range $(800 \mathrm{~m})$ and a higher relative nugget $(0.4)$ than the variogram model used by Murray et al. (2007). A well-defined vertical variogram also was found, with a range of $50 \mathrm{~m}$. This is longer than the vertical range used by Murray et al. (2007), which was $30 \mathrm{~m}$. The final model fit to the depth-discrete CTET data is contained in Table 4.1, labeled CTET (3D).
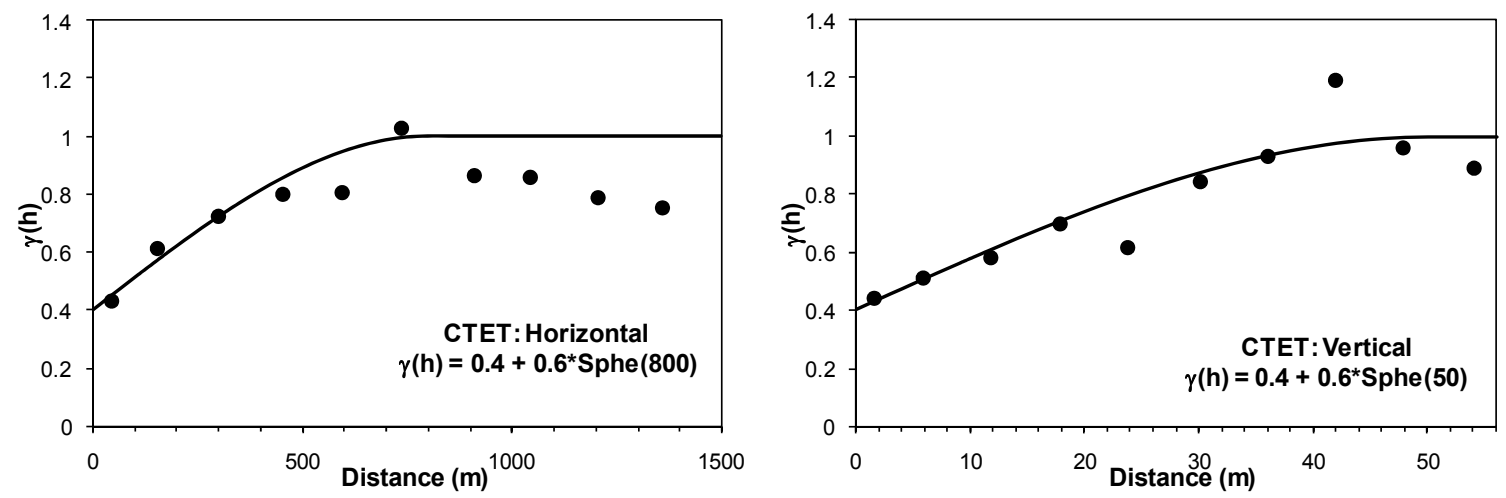

Figure 4.1. Experimental Variogram (dots) and Model (solid lines) for the Depth-Discrete CTET Data. On the left is the horizontal variogram, and on the right is the vertical variogram. 
We used SGSIM to generate 1000 simulations of the CTET concentration using the 3D variogram model. A plot of the variance of the simulated concentration over all realizations versus the number of realizations (Figure 4.2) shows that the variance had stabilized within the first 300 realizations, with only minor fluctuations beyond that point, suggesting that 300 realizations were sufficient to characterize the uncertainty in the CTET concentration. We retained the first 500 realizations for further post-processing. These simulations provide 500 simulated values of the CTET concentration for every node in the 3D grid.

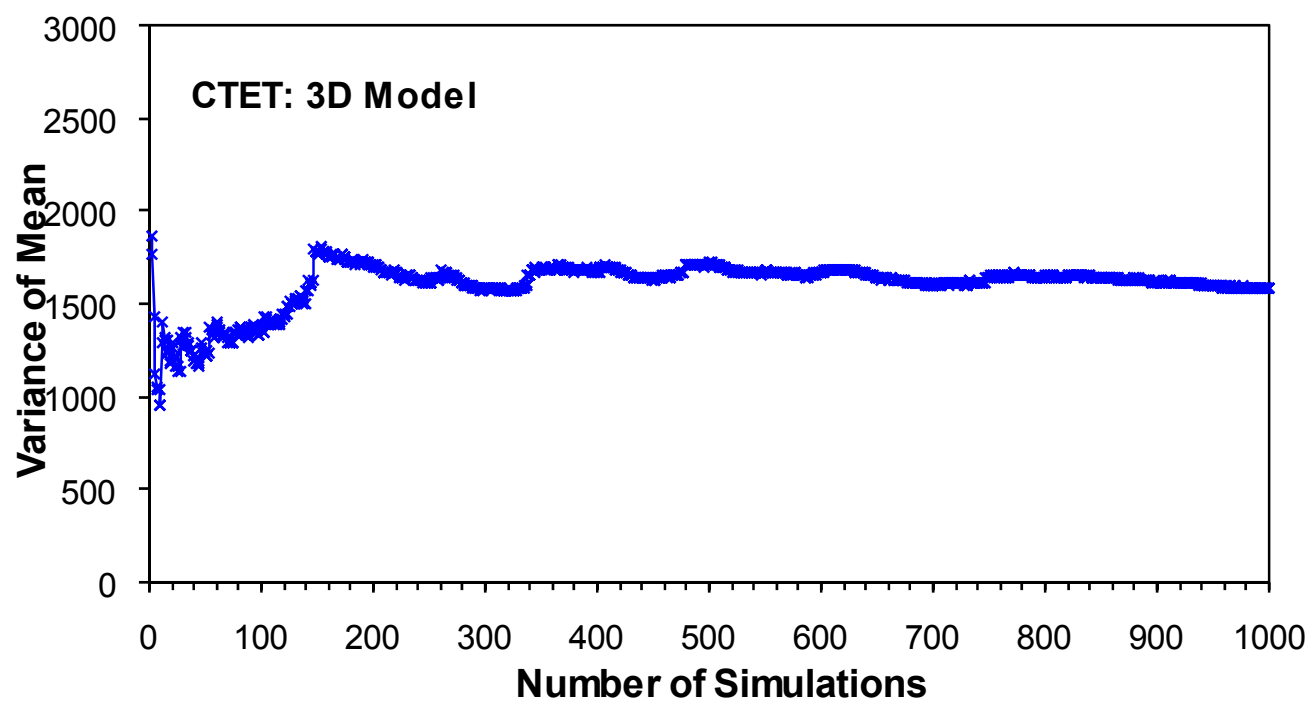

Figure 4.2. Variance of Mean of Simulations vs. the Number of Simulations of CTET. Simulations generated using the 3D variogram model.

One useful way to summarize the concentrations is to calculate the median simulated value at each grid node. The median simulated values were then visualized using Tecplot. Figure 4.3 presents a cutaway $3 \mathrm{D}$ visualization of the median CTET. The cutaway is approximately through the main N-S and E-W centers of the plume. Further visualization of the plume is provided by a series of horizontal slices through the median CT concentration grid. Figures 4.4 through 4.6 present six horizontal slices at 10-m increments through the grid, from depths of 5 to $55 \mathrm{~m} \mathrm{BWT}$. Figures 4.3 and 4.4 suggest that an extension of the plume exists west of the main high concentrations (e.g., in the area west of an easting of $566000 \mathrm{~m}$ and with northing coordinates between $135500 \mathrm{~m}$ and $137500 \mathrm{~m}$ ) that has CTET concentrations between 5 and $100 \mu \mathrm{g} / \mathrm{L}$. This area is expected to be generally up-gradient of the main source area, and CTET concentrations might be expected to be near the detection level. However, the map of CTET concentration data for the interval from 0-10 m DBWT (Figure 4.3) shows that the westernmost wells in that area have CTET concentrations in the range from 5-100 $\mu \mathrm{g} / \mathrm{L}$, so the western edge of the plume in that area is not constrained by the sample concentrations, all of which are above the $5-\mu \mathrm{g} / \mathrm{L}$ drinking water standard. Given the lack of constraint from the well data, the geostatistical algorithm used to generate the simulations would therefore tend to extrapolate the concentrations for the closest nearby wells into that western area. 


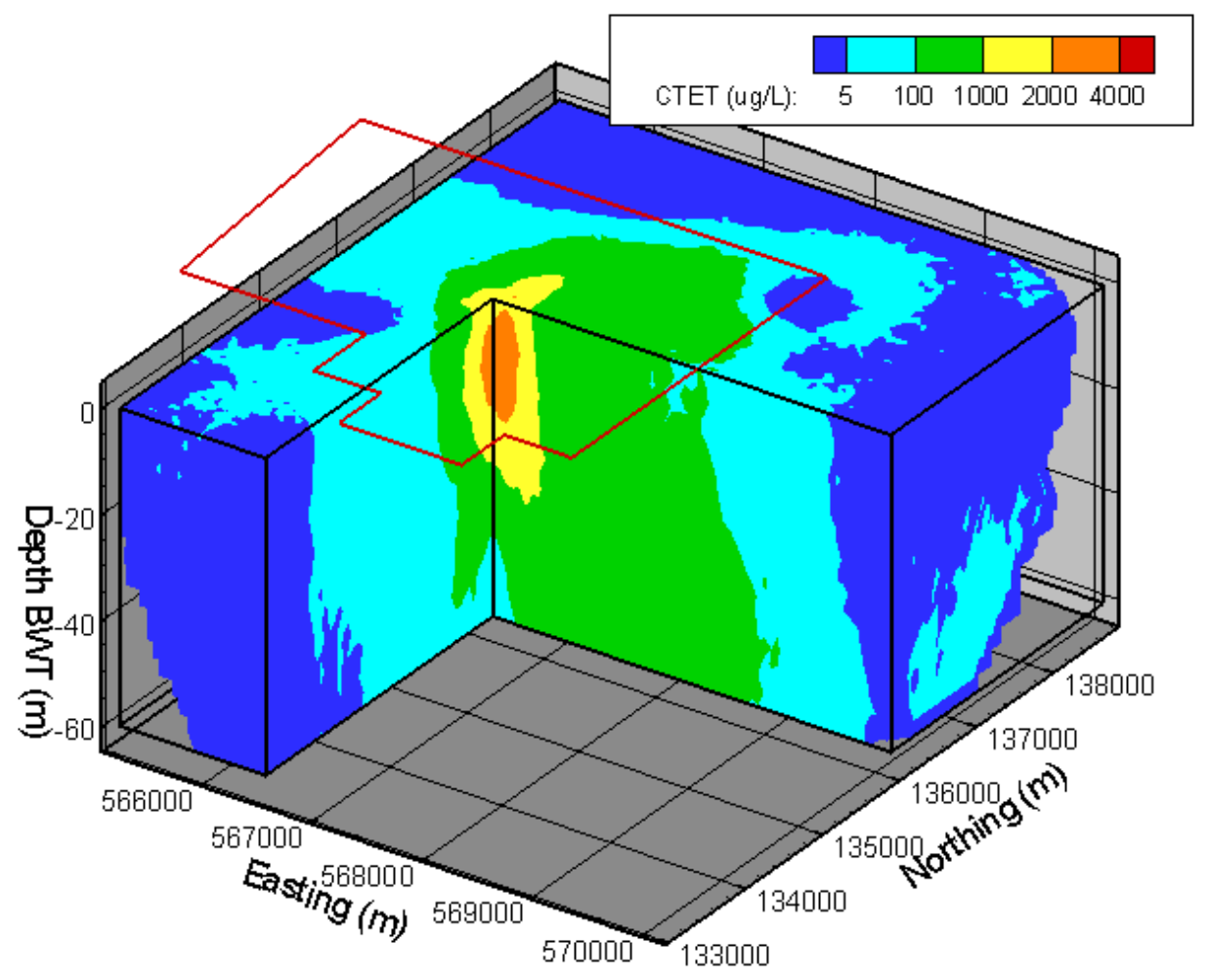

Figure 4.3. Median CTET Concentration of Simulations Based on the 3D Variogram Model. Cutaway at easting from $566525 \mathrm{~m}$ to $570125 \mathrm{~m}$ and northing from $133045 \mathrm{~m}$ to $135985 \mathrm{~m}$. The red line outlines the 200 West Area.

An alternative case provided as a map of the current distribution of CTET in the aquifer is the E-type estimate (Goovaerts 1997), the average of the simulated values of each grid node (Figure 4.7. Because the distribution of the CTET data is highly skewed, the simulated values of CTET at each grid node also tend to be highly skewed. The average of a distribution is strongly affected by the presence of even a small number of high values, whereas the median of a skewed distribution tends to be relatively stable and not affected by the presence of a small proportion of high values (Goovaerts 1997). Therefore, it is not surprising that the E-type estimate tends to estimate higher concentrations across the study area (Figure 4.7) than are reflected in the median estimate (Figure 4.3).

Using the set of 500 realizations, we also calculated 3D probability maps to estimate the probability of exceeding several CTET concentration cutoffs at each grid node. Probability maps were generated for four concentration thresholds: 5, 100, 1000, and $2000 \mu \mathrm{g} / \mathrm{L}$ (Figures 4.8 and 4.9). The probability maps indicate a high probability of encountering high CTET concentrations deep in the aquifer, especially in the eastern portion of the area. This finding agrees with the results found by Murray et al. (2007). The lower boundary of the realizations was set at a depth of $60 \mathrm{~m}$ below the water table because of the sparsity of data below that depth. The presence of relatively high median concentrations between 100 and $1000 \mu \mathrm{g} / \mathrm{L}$ at the base of the simulation zone suggests that the CTET plume extends below that depth in some areas. This conclusion is supported by Figures 2.8-6 and 2.8-7 of Hartman and Webber (2008), which show high concentrations of CTET at depths greater than $60 \mathrm{~m}$ below the water table, especially in areas where the Ringold Lower Mud is thin or missing. 

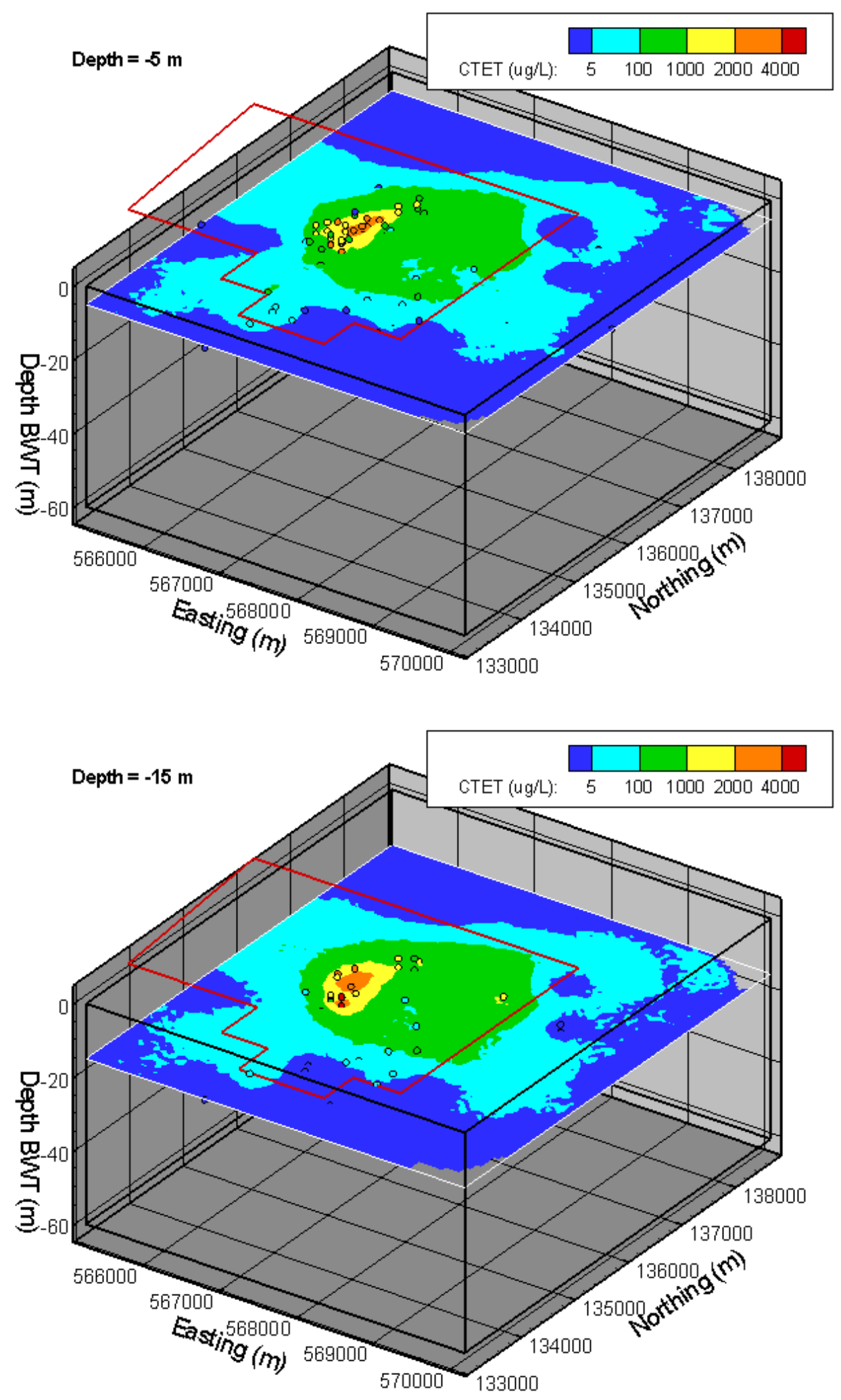

Figure 4.4. Median CTET Concentration Based on 3D Variogram Model at Depth BWT of 5 and $15 \mathrm{~m}$. The well data within $2.5 \mathrm{~m}$ above and below the depths are shown in circles. 

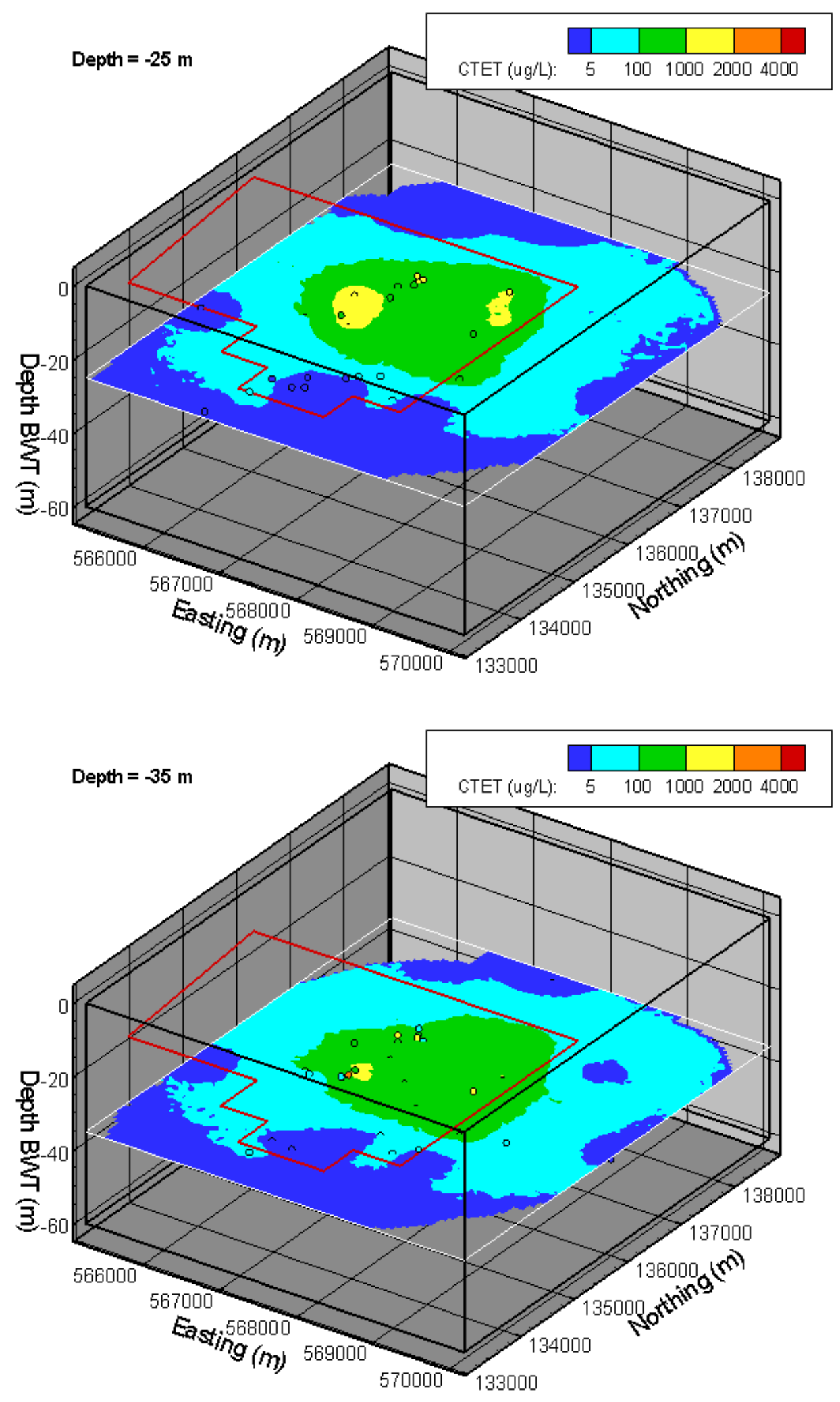

Figure 4.5. Median CTET Concentration Based on 3D Variogram Model at Depth BWT of 25 and $35 \mathrm{~m}$. The well data within $2.5 \mathrm{~m}$ above and below the depths are shown in circles. 

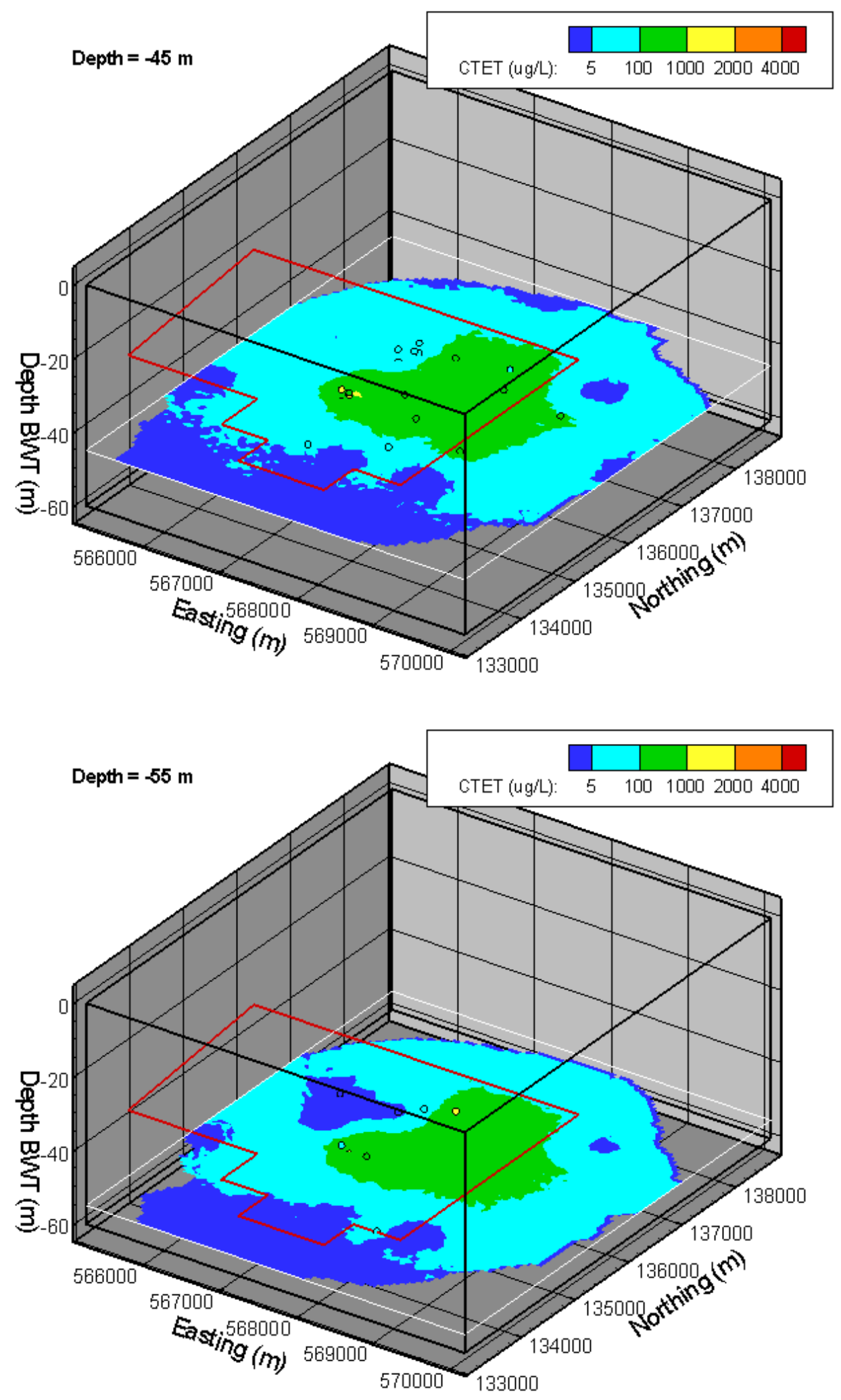

Figure 4.6. Median CTET Concentration Based on 3D Variogram Model at Depth BWT of 45 and $55 \mathrm{~m}$. The well data within $2.5 \mathrm{~m}$ above and below the depths are shown in circles. 


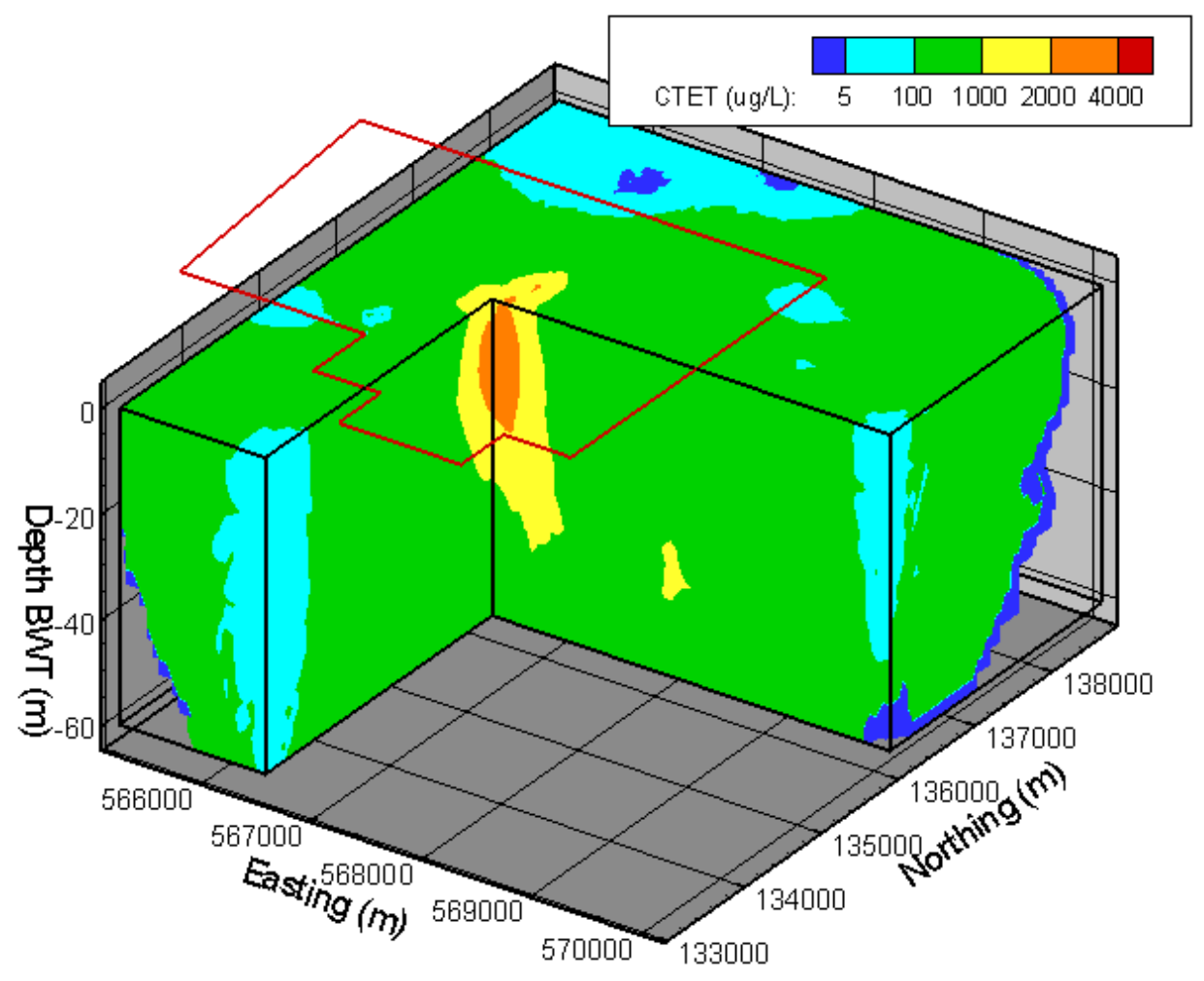

Figure 4.7. E-Type CTET Concentration of Simulations Based on the 3D Variogram Model. Cutaway at easting from $566525 \mathrm{~m}$ to $570125 \mathrm{~m}$ and northing from $133045 \mathrm{~m}$ to $135985 \mathrm{~m}$. The red line outlines the 200 West Area.

An additional form of post-processing applied to the suites of realizations was calculation of the reference uncertainty index (RUI) that accounts specifically for the uncertainty with respect to the cleanup standard. The RUI at a grid node $u_{i}$ can be calculated using the following equation (Kyriakidis 1997):

$$
\operatorname{RUI}\left(u_{i}\right)=\frac{\operatorname{IQR}\left(u_{i}\right)}{\left|C_{\text {med }}\left(u_{i}\right)-C_{t}\right|+1}
$$

where IQR $\left(u_{i}\right)$ and $C_{\text {med }}\left(u_{i}\right)$ are the IQR (interquartile range) and median of the conditional distribution, respectively, and $C_{t}$ is the regulatory threshold in which we are interested. The IQR is a measure of variability defined as the difference between the 75 th and 25 th percentiles of a distribution, and the median is a measure of central tendency defined as the 50th percentile of a distribution. The conditional distribution for each grid node is obtained from the suite of simulated CTET values at each grid node. For this study, we calculated the RUI for two thresholds, $5 \mu \mathrm{g} / \mathrm{L}$ and $100 \mu \mathrm{g} / \mathrm{L}$. A simulated node would have a high RUI value when the spread of the conditional distribution is wide (which would occur if there are few nearby data or those data are highly variable) or the median of the conditional distribution is very close to the regulatory threshold. The farther the median is from the threshold value, the more likely the simulation node would be classified as either clean (if the median is well below the cleanup threshold) or requiring remediation (if the median is above the threshold). On the other hand, the closer the median is to the threshold value, the greater the uncertainty of determining the correct action that should be taken at that grid node. In Figure 4.10, which shows the RUI for $100 \mu \mathrm{g} / \mathrm{L}$, the red and yellow areas indicate those portions of the study area where there is considerable uncertainty about whether the concentration is 

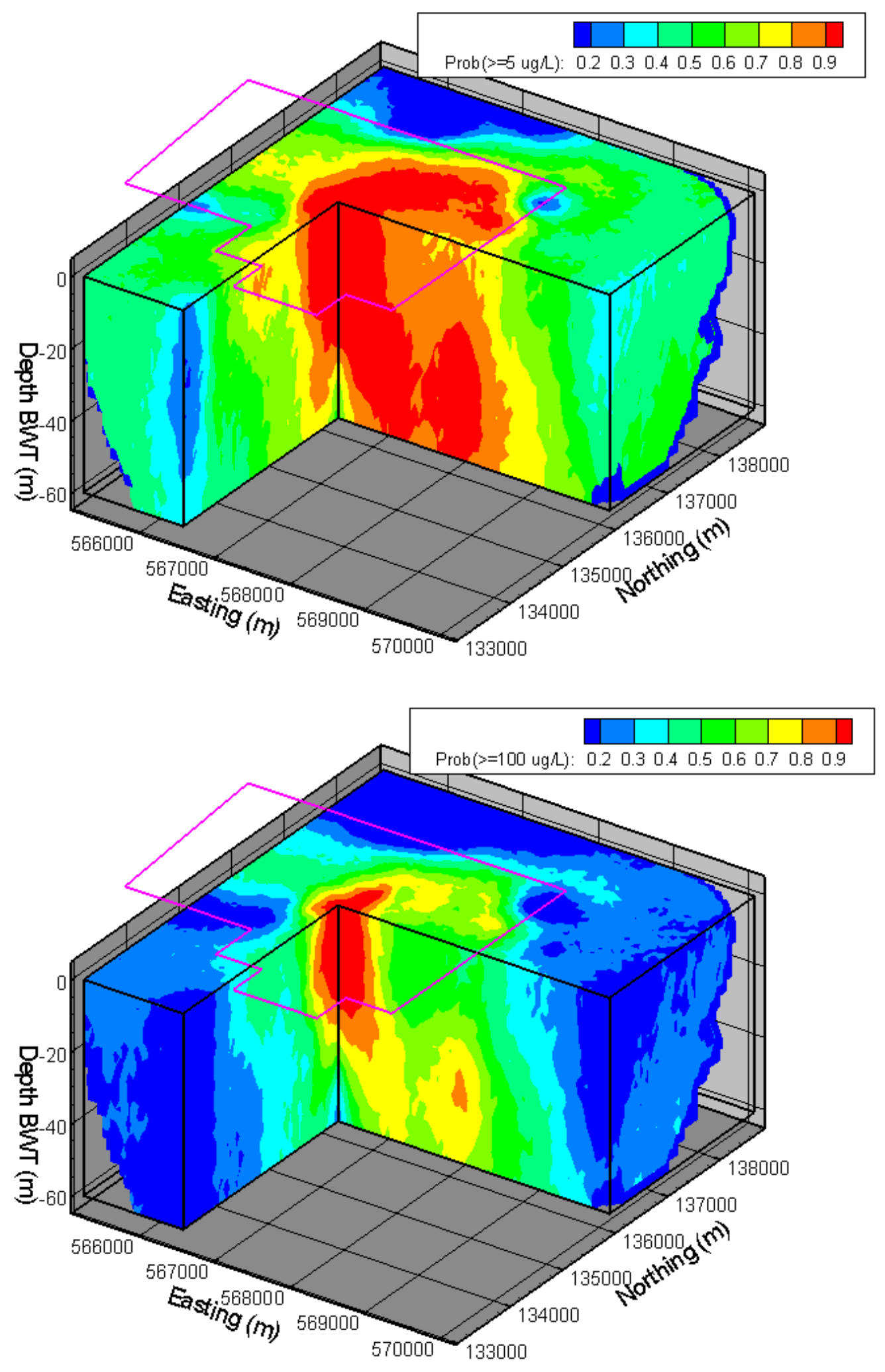

Figure 4.8. Probability of CTET Exceeding $5 \mu \mathrm{g} / \mathrm{L}$ and $100 \mu \mathrm{g} / \mathrm{L}$ for the Simulations Based on the 3D Variogram Model 

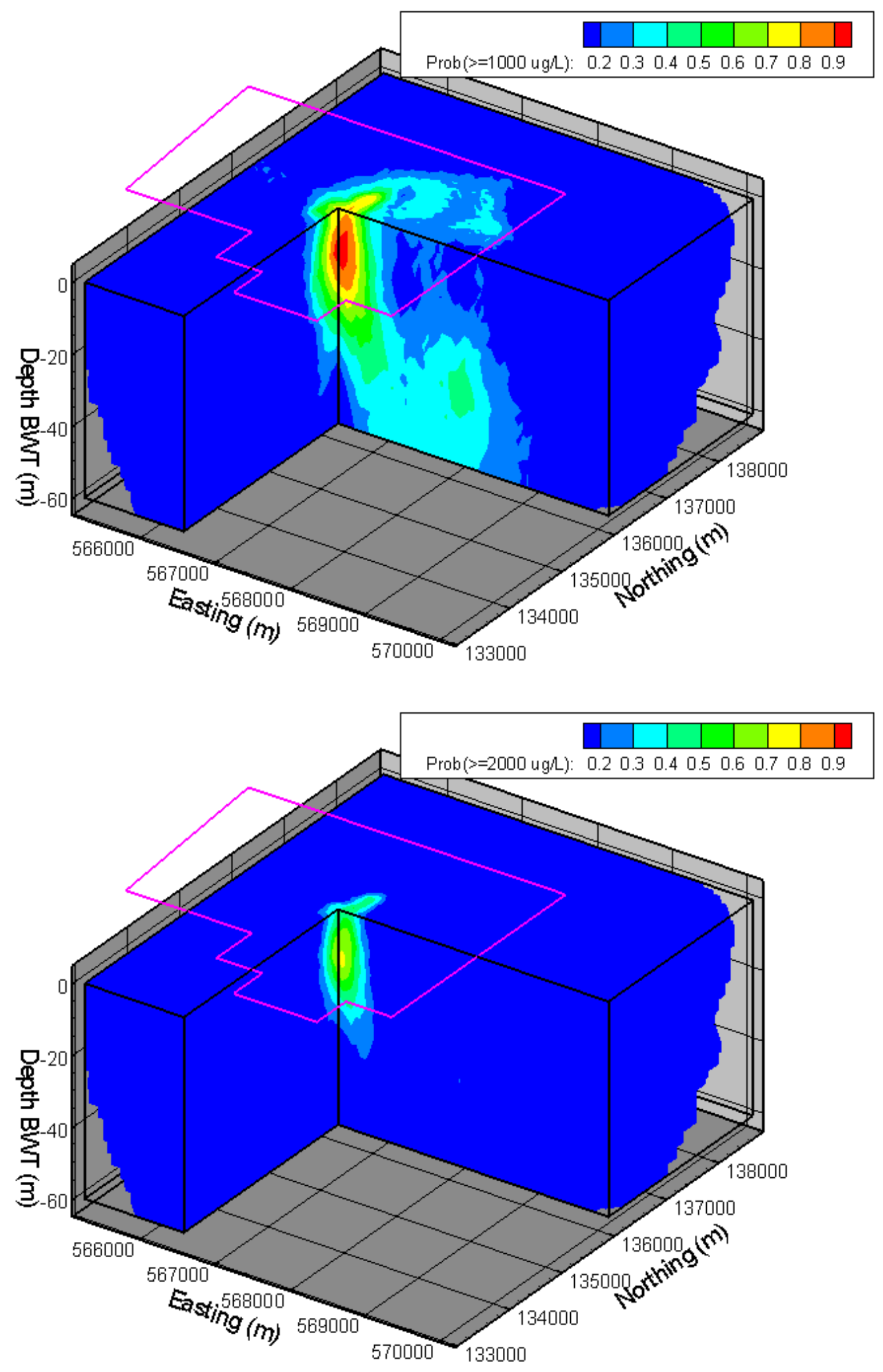

Figure 4.9. Probability of CTET Exceeding $1000 \mu \mathrm{g} / \mathrm{L}$ and $2000 \mu \mathrm{g} / \mathrm{L}$ for the Simulations Based on the 3D Variogram Model 
above or below the $100 \mu \mathrm{g} / \mathrm{L}$ threshold. This includes the area west of the main source area discussed above (i.e., in the area west of an easting of $566000 \mathrm{~m}$ and with northing coordinates between $135500 \mathrm{~m}$ and $137500 \mathrm{~m}$ ), plus the upper $25 \mathrm{~m}$ in the area on the east-west portion of the cutaway in Figure 4.10 between an easting of approximately 567000 and 568500 . The RUI grid could be used to identify or confirm candidate well locations for additional sample collection.

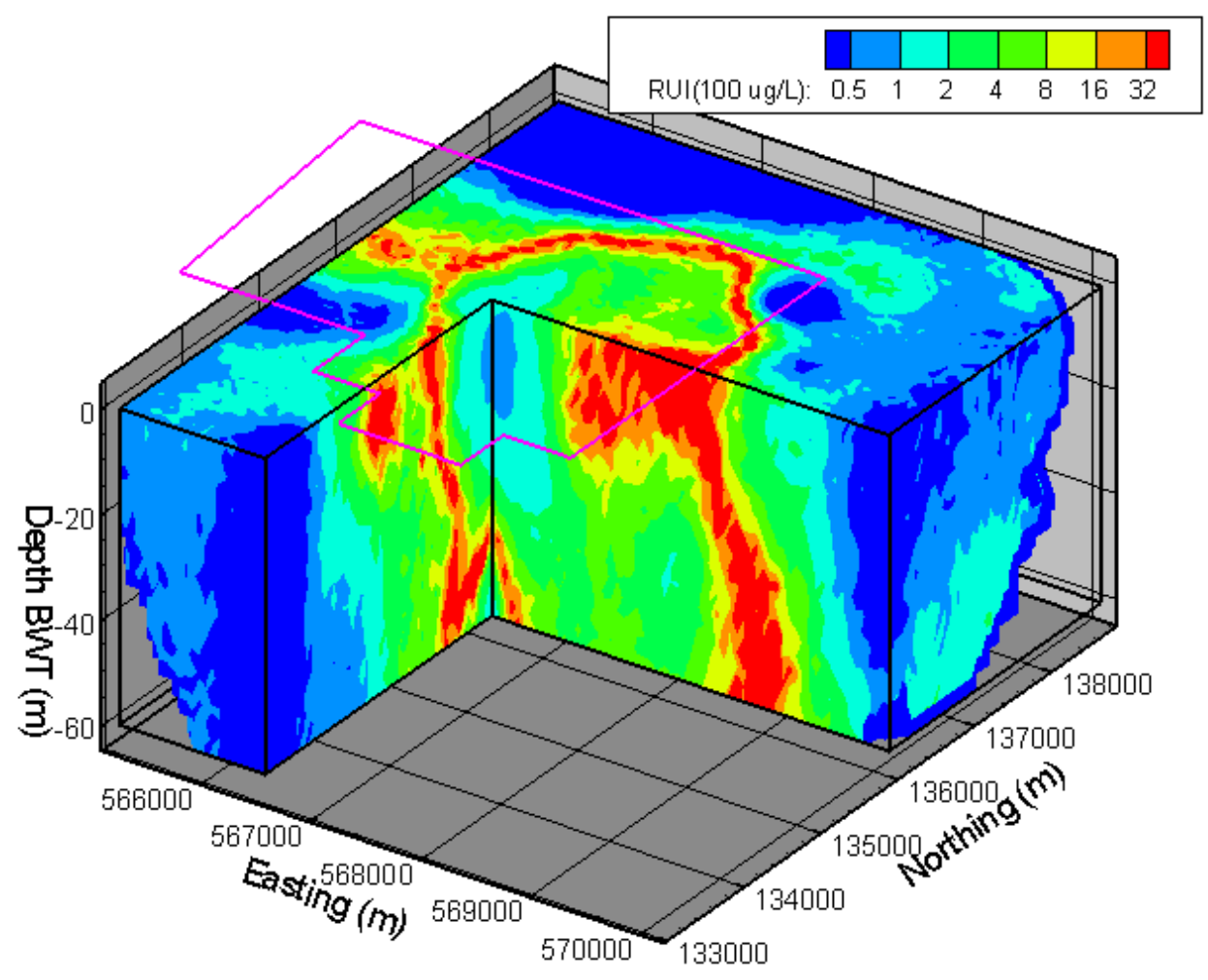

Figure 4.10. RUI with Respect to a Threshold of $100 \mu \mathrm{g} / \mathrm{L}$ as Based on 500 Realizations of CTET Generated Using the 3D Variogram Model. Cutaway at easting from $566525 \mathrm{~m}$ to $570125 \mathrm{~m}$ and northing from $133045 \mathrm{~m}$ to $135985 \mathrm{~m}$.

The median simulated value shown in Figure 4.3 provides a reasonable estimate for an input concentration distribution that could be used as initial conditions for a flow and transport model. We also ranked the set of realizations in order to identify a subset of realizations with high mean concentrations of CTET that could be used as alternative input concentration fields for the flow and transport modeling. The ranking method consisted of counting the number of cells in each realization with a concentration greater than $100 \mu \mathrm{g} / \mathrm{L}$. The six realizations chosen as alternative realizations ranked as $25 \mathrm{th}, 30 \mathrm{th}, 35 \mathrm{th}$, 40th, 45th, and 50th in terms of the volume (i.e., number of interpolated cells) that exceed a cutoff of $100 \mu \mathrm{g} / \mathrm{L}$ for CTET. These ranked as approximately the 95th, 94th, 93rd, 92nd, 91st, and 90th percentiles of the set of realizations, based on that criteria. Note that although these realizations would provide an estimate of the uncertainty with respect to the flow and transport predictions, that these realizations are from a relatively restricted range of the suite of realizations (the 90th to 95th percentiles), and were chosen so that they would be near the upper end of the range in terms of the mass of CTET present within the study area. 


\subsubsection{D Variogram Model}

As an alternative conceptual model for the spatial variability of CTET, we also used the variogram fitting procedure followed by Murray et al. (2007). That consisted of fitting a model to the horizontal variogram calculated using the data set compiled for the FY 2007 annual groundwater report (Hartman and Webber 2008) and then assuming a 30-m vertical range based on the estimated average plume thickness shown in cross sections (Hartman and Webber 2008, Figures 2.8-5 through 2.8-7) and on examination of well data that suggested that the plume thickness averages about $30 \mathrm{~m}$. The variogram model was assumed to have geometric anisotropy (i.e., although the ranges in horizontal and vertical directions are different, the sills in the horizontal and vertical directions were assumed the same). The variogram model fit to the 2D FY 2007 data (Figure 4.11), hereafter referred to as the 2D variogram model, had a small relative nugget (0.08) similar to that found by Murray et al. (2007) for the FY 2005 data but with a longer range $(1650 \mathrm{~m}$ versus $1300 \mathrm{~m})$. Table 4.1 gives the variogram model fit using this process, labeled CTET (2D).

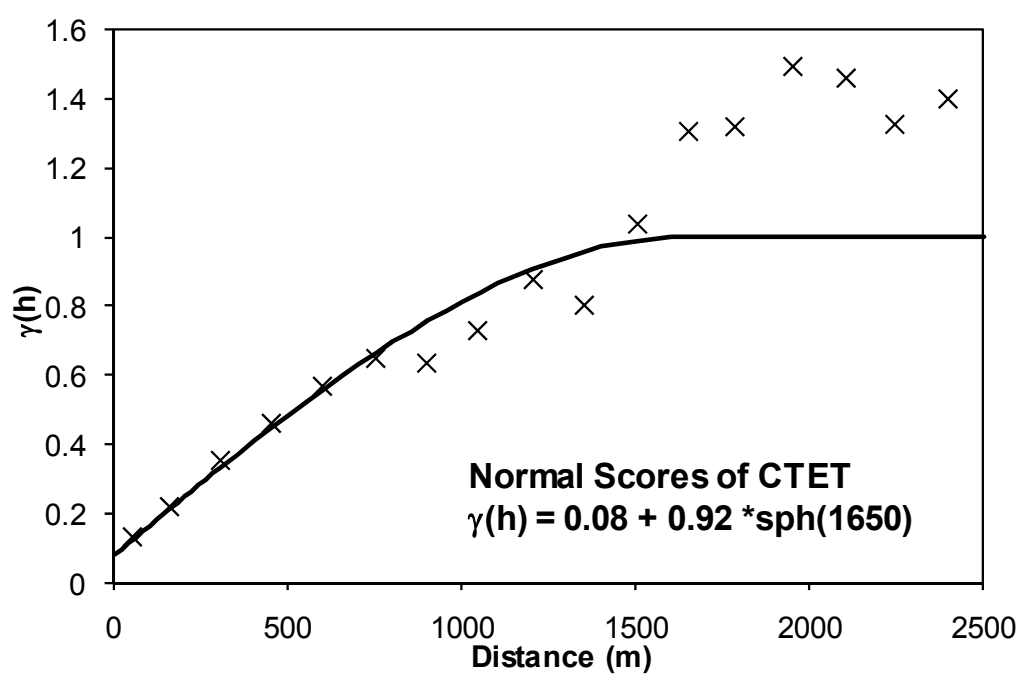

Figure 4.11. Experimental Variogram (dots) and Model (solid lines) for the 2D Horizontal Variogram Based on CTET Data from the FY 2007 Annual Groundwater Report (Hartman and Webber 2008)

A suite of 500 stochastic realizations of CTET was generated using SGSIM and the 2D variogram model. At first glance, a plot of the median simulated value for the suite of realizations generated using the 2D variogram model (Figure 4.12) does not appear to be significantly different from that created using the 3D variogram model (Figure 4.3). However, analysis of several measures indicate that the concentrations of the realizations generated using the 3D variogram model are significantly higher than those generated using the $2 \mathrm{D}$ variogram model. For example, comparison of the global average concentrations for each realization indicates that the averages for the 3D model are about $50 \%$ higher (Figure 4.13 and Table 4.3). Several other metrics, including the median simulated value of each realization and the number of cells above a given threshold also indicated that the concentrations of realizations generated using the 3D variogram model were significantly higher than those generated using the 2D model. 


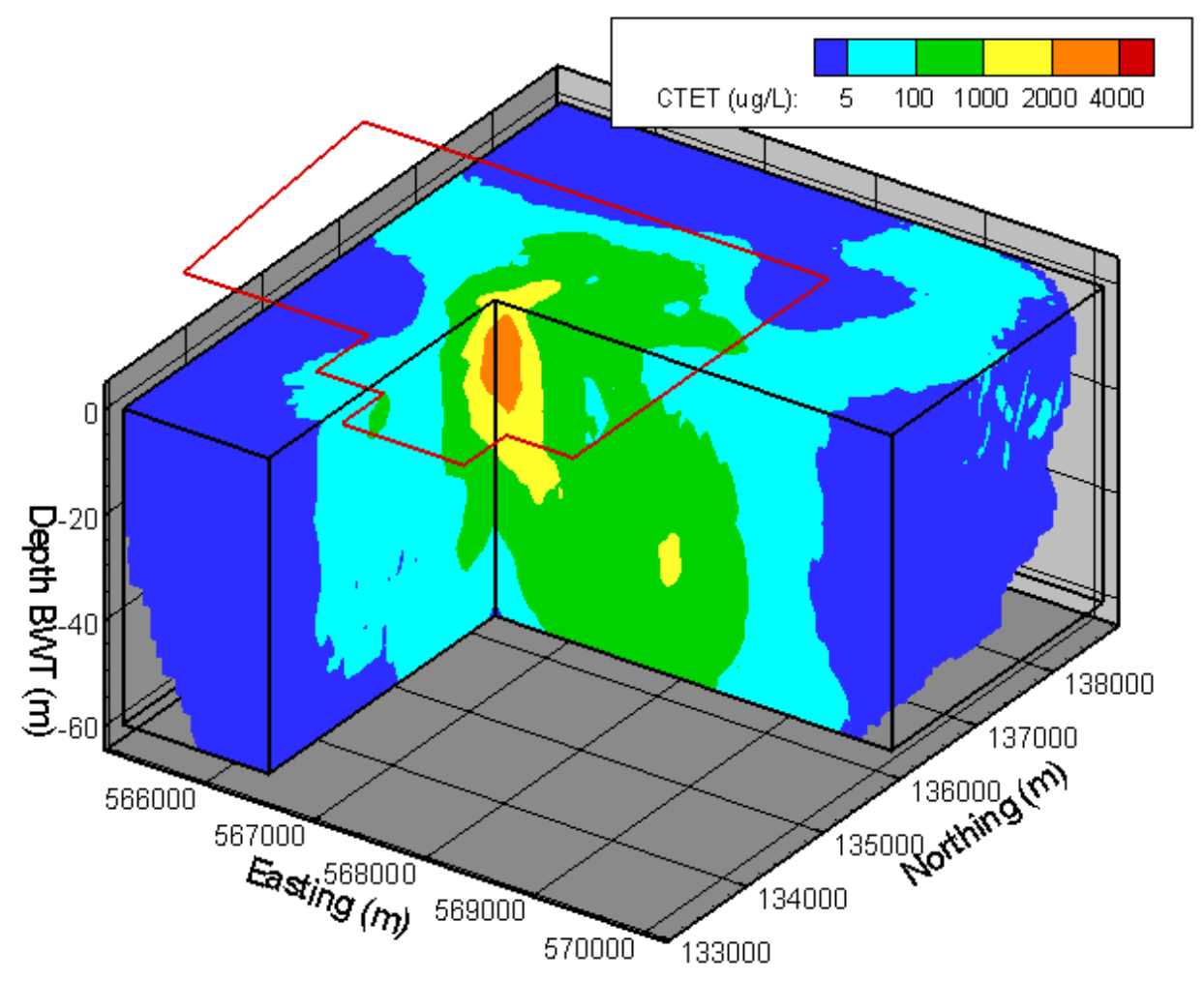

Figure 4.12. Median CTET Concentration of Simulations Based on the Variogram Model of 2D Data. Cutaway at easting from $566525 \mathrm{~m}$ to $570125 \mathrm{~m}$ and northing from $133045 \mathrm{~m}$ to $135985 \mathrm{~m}$.

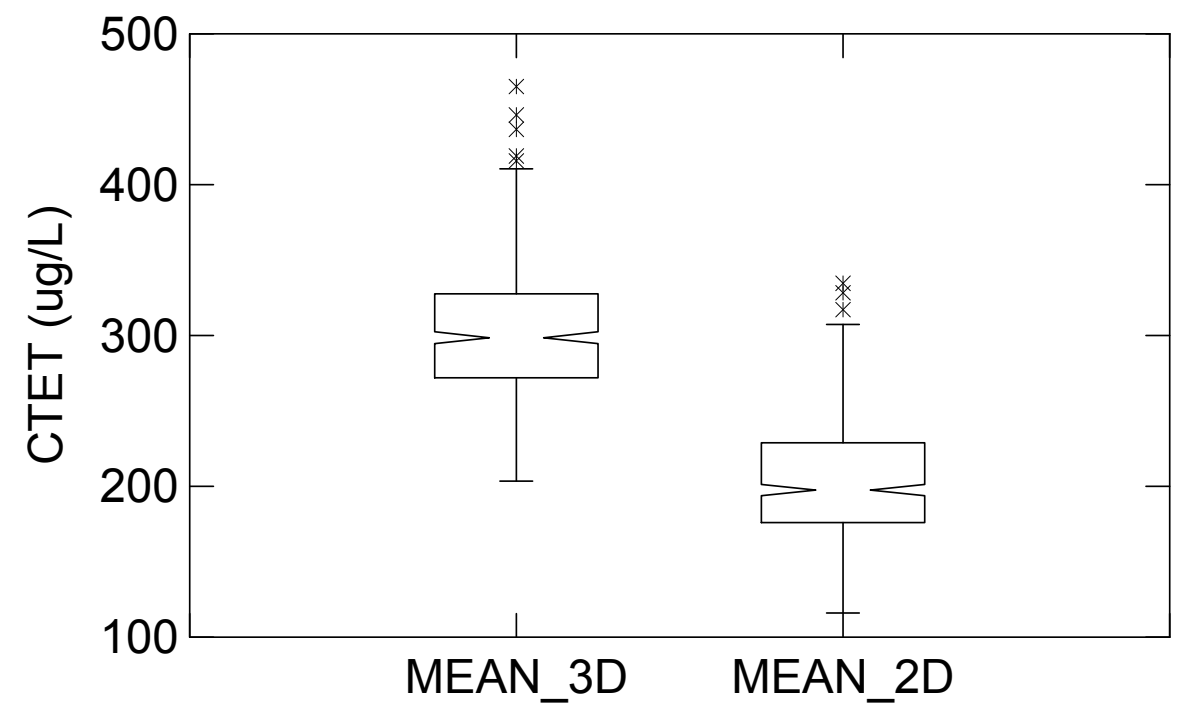

Figure 4.13. Comparison of Global Average Concentrations for Realizations Generated Using the 3D and 2D Variogram Models. The medians of the distributions are shown as the center of the notches, and the lower and upper quartiles as the bottom and top of the boxes, respectively. The notches represent an approximate 95\% confidence interval around the median (McGill et al. 1978). Asterisks represent outlier data points at 1.5 and 3.0 times the interquartile range, respectively. 
Table 4.3. Statistics for Global Means of CTET Realizations Generated Using the 3D and 2D Variogram Models

\begin{tabular}{lcc}
\hline & \multicolumn{2}{c}{ Global Mean of Realizations } \\
\cline { 2 - 3 } \multicolumn{1}{c}{ Statistic } & 3D Model & 2D Model \\
\hline Mean & 302.15 & 203.92 \\
Median & 298.59 & 197.57 \\
Standard deviation & 41.51 & 37.69 \\
Coefficient of variation & 0.137 & 0.185 \\
Range & 261.59 & 218.45 \\
Minimum & 203.47 & 116.16 \\
Maximum & 465.05 & 334.61 \\
Count & 500 & 500 \\
\hline
\end{tabular}

Because the global statistics for the 3D model were approximately $50 \%$ higher, and the $3 \mathrm{D}$ variogram model is tied more directly to the depth-discrete CTET concentration data, we concluded that the 3D model should be considered the base case for CTET. This would provide a conservative base case concentration distribution to provide initial conditions for the flow and transport modeling.

Because the 3D variogram model was chosen as the base case, the post-processing for the $2 \mathrm{D}$ variogram model was not as extensive as it was for the 3D variogram model. However, the appendix does contain the grid of median simulated values for the $2 \mathrm{D}$ variogram model as well as the 500 stochastic realizations that support it. This provides the material that would be needed to evaluate an alternative case based on the 2D variogram model.

\subsection{Chloroform}

Experimental variograms were calculated for the depth-discrete chloroform data (Figure 4.14). The experimental variogram for the vertical dimension was well behaved, with a simple monotonic increase in the experimental variogram for the first several lags. The model fit to the vertical experimental variogram had a relative nugget of 0.17 and a range of $70 \mathrm{~m}$. The horizontal variogram of the depth-discrete chloroform data, however, was much noisier, and the behavior of the variogram near the origin could not be determined with any degree of confidence. For that reason, the horizontal variogram was based on the model fit to the experimental variogram of the 2D data used for mapping chloroform in the FY 2007 annual groundwater report (Figure 4.15). The experimental variogram for that data had a relative nugget of 0.17 , the same as that fit to the vertical variogram, and a horizontal range of $1250 \mathrm{~m}$.

Another option that could be considered would be to adopt the CTET 3D variogram model parameters (i.e., nugget, sill, and range) for simulation of chloroform because their spatial distributions are similar and one possible source of chloroform is biodegradation of CTET (Hartman and Webber 2008). However, the variogram models for the FY 2007 2D data sets of CTET and chloroform had different ranges, by several hundred meters, suggesting the spatial distributions are not that similar, a conclusion supported by examination of the FY 2005 variogram models. For that reason, the CTET and chloroform distributions were modeled and mapped independently. 

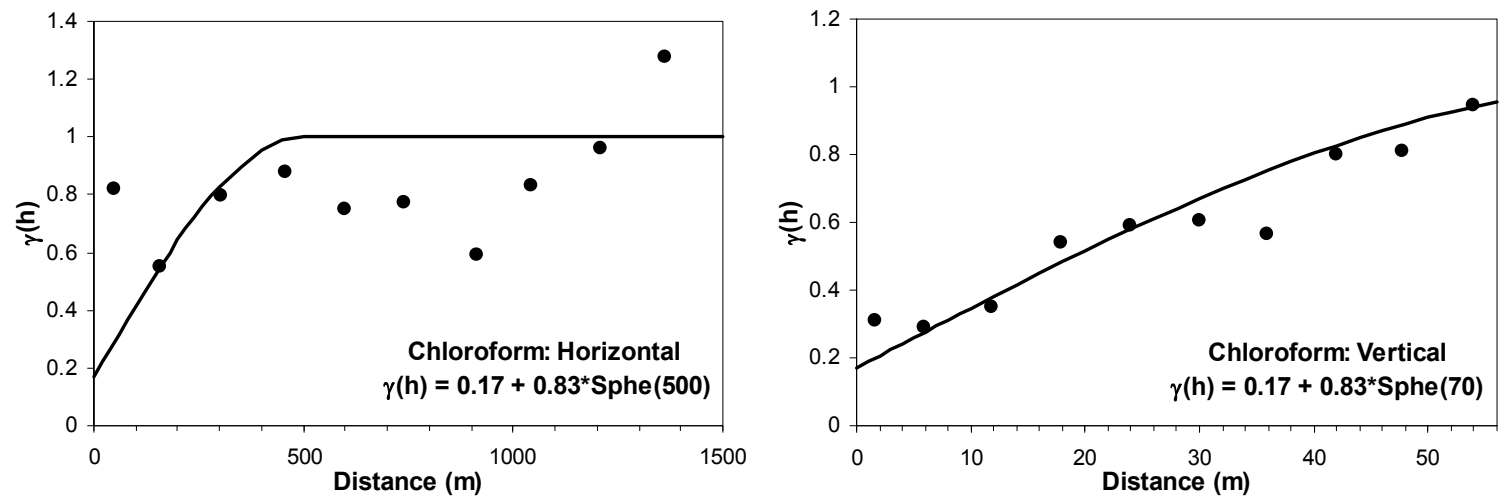

Figure 4.14. Experimental Variograms (dots) and Fitted Models (solid lines) for the Normal Scores of the Depth-Discrete Chloroform Data

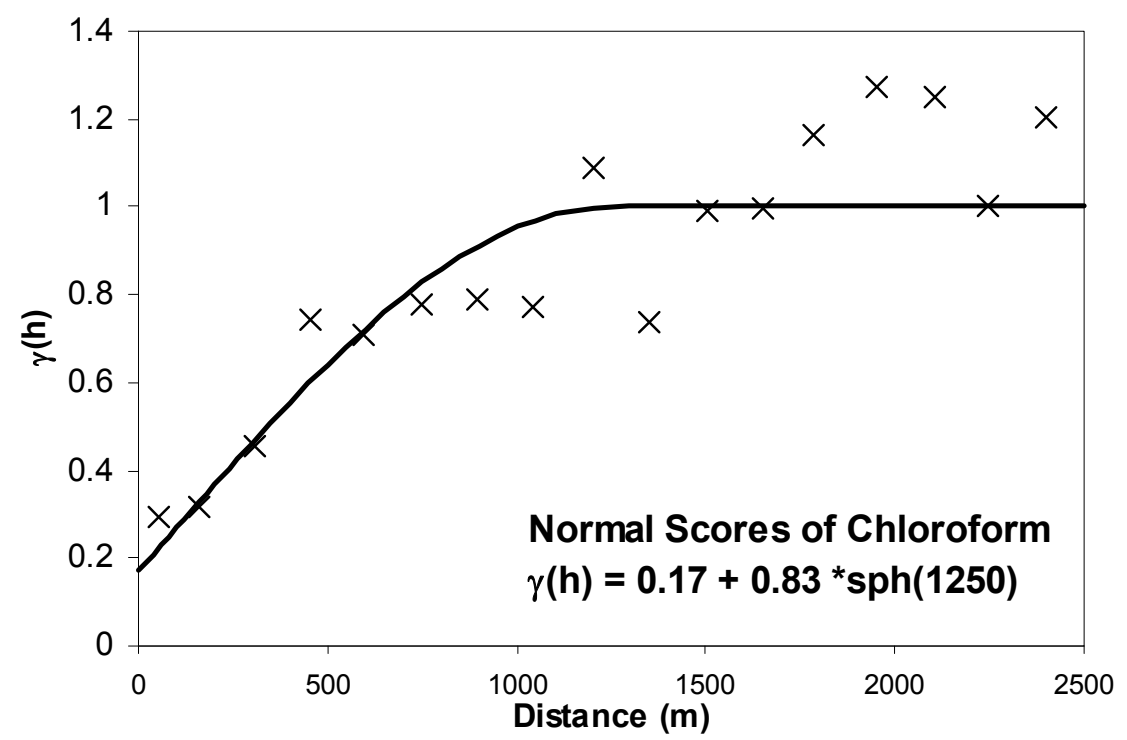

Figure 4.15. Experimental Variogram (Xs) and Fitted Model (solid line) for 2D Chloroform Data

Geostatistical realizations of the chloroform distribution were generated using the vertical and horizontal variogram models described above. The median simulated concentrations of chloroform (Figures 4.16-4.19) shows the same general form as the CTET distribution, with relatively deep penetration of a high-concentration zone near the center of the cutaway and a deeper zone of high concentrations to the east. The grid of median simulated chloroform concentrations as well as the 500 realizations used to generate that grid are included in the appendix. 


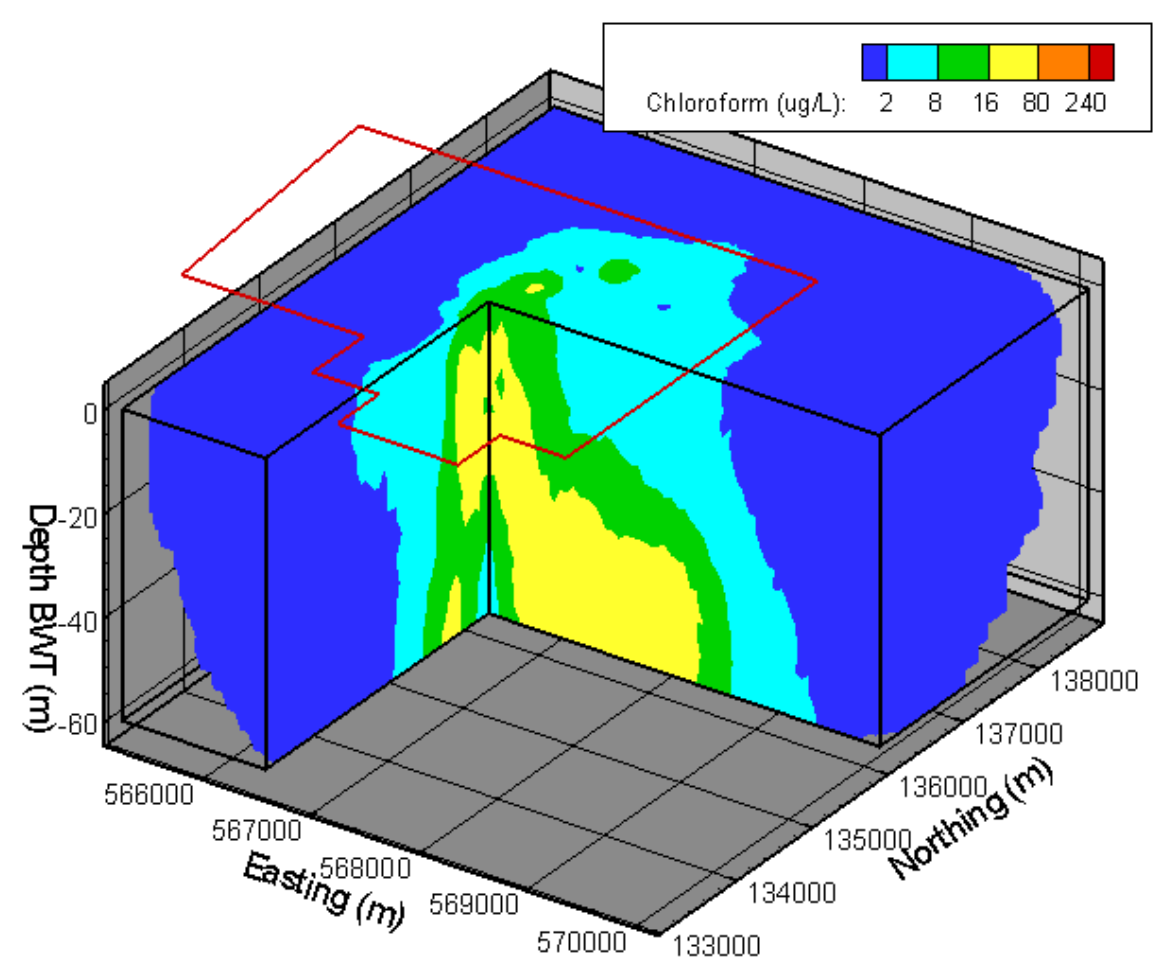

Figure 4.16. Median Simulated Chloroform Concentration over 500 Realizations. Cutaway at easting from $566525 \mathrm{~m}$ to $570125 \mathrm{~m}$ and northing from $133045 \mathrm{~m}$ to $135985 \mathrm{~m}$.

\subsection{Technetium-99}

Experimental variograms were calculated for the depth-discrete Tc-99 data (Figure 4.20). As with chloroform, the vertical experimental variogram was well behaved, with a simple monotonic increase in the experimental variogram for the first several lags. The model fit to the vertical experimental variogram had a relative nugget of 0.07 and a range of $90 \mathrm{~m}$. The horizontal variogram of the depth-discrete Tc-99 data, however, was very noisy, and the behavior of the variogram near the origin was uncertain. For that reason, the horizontal variogram was based on the model fit to the experimental variogram of the 2D data used for mapping Tc-99 in the FY 2007 annual groundwater report (Figure 4.20, bottom). The experimental variogram for the horizontal data suggested that about $60 \%$ of the variability in the horizontal was accounted for in the first $90 \mathrm{~m}$, so a nested model was fit to the experimental variogram. The range for the second spherical structure was $900 \mathrm{~m}$. The nested variogram model for Tc-99 is listed in Table 4.1.

Geostatistical realizations of the Tc-99 distribution were generated using SGSIM and the variogram model described above. The median simulated concentrations of Tc-99 are shown in Figures 4.21 through 4.24, with the E-type estimate plotted in Figure 4.25. The Tc-99 plumes illustrated by the median concentration maps suggest that Tc-99 occurs as isolated small plumes and that the concentration decreases substantially with depth. This tendency for the concentration to decrease with depth is suggested also by maps of the probability of exceeding $900 \mathrm{pCi} / \mathrm{L}$ for depths from 5 to $35 \mathrm{~m} \mathrm{BWT}$ (Figures 4.26 and 4.27), where the probability of exceeding the $900 \mathrm{pCi} / \mathrm{L}$ threshold has decreased to very low levels by a depth of $35 \mathrm{~m}$ BWT. This is quite different from the behavior noted for CTET and chloroform, in which substantial contamination was mapped for depths from $30 \mathrm{~m}$ to $60 \mathrm{~m}$ BWT. 

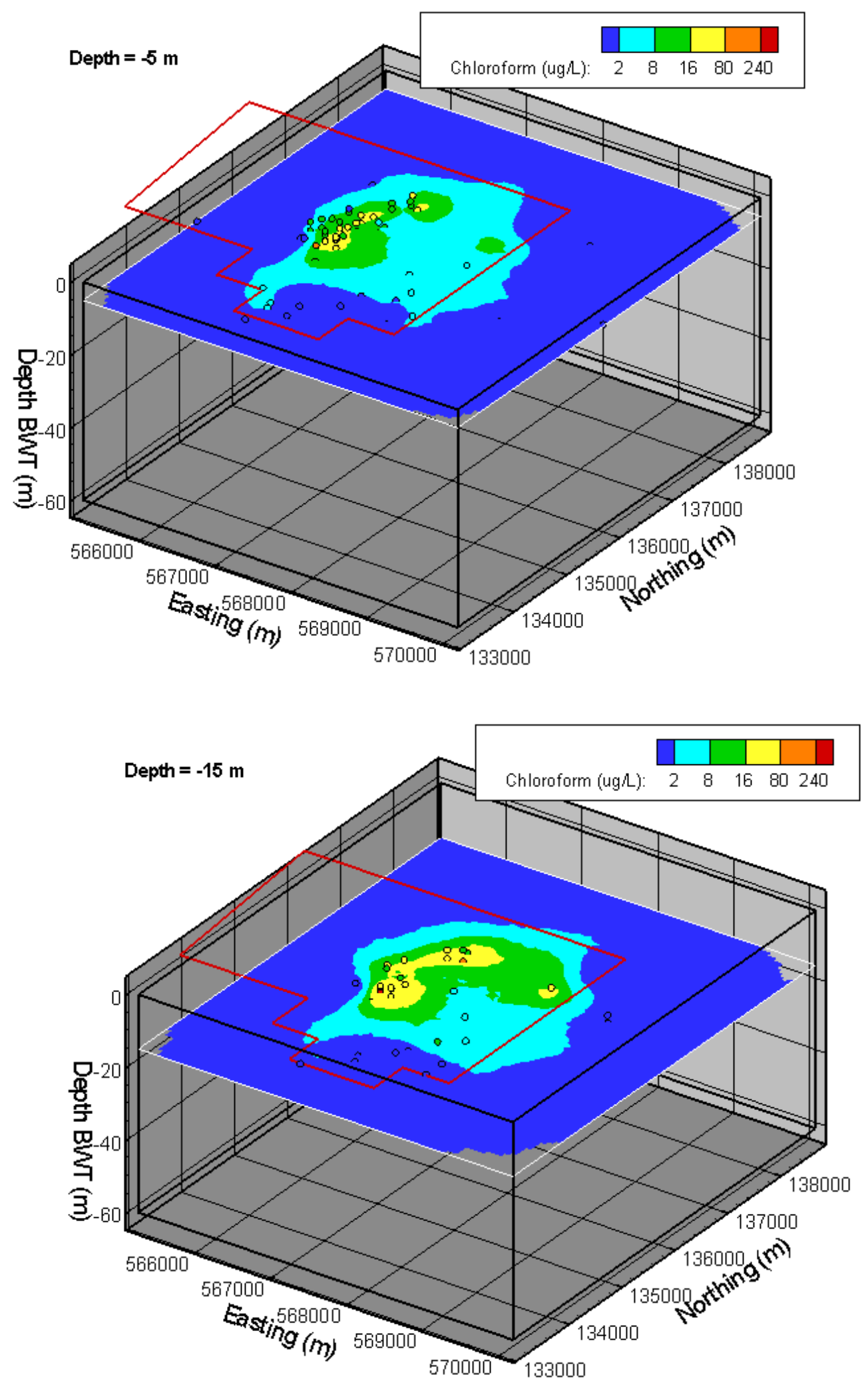

Figure 4.17. Median Chloroform Concentration at Depth BWT of 5 and $15 \mathrm{~m}$. The well data within $2.5 \mathrm{~m}$ above and below the depths are shown in circles. 

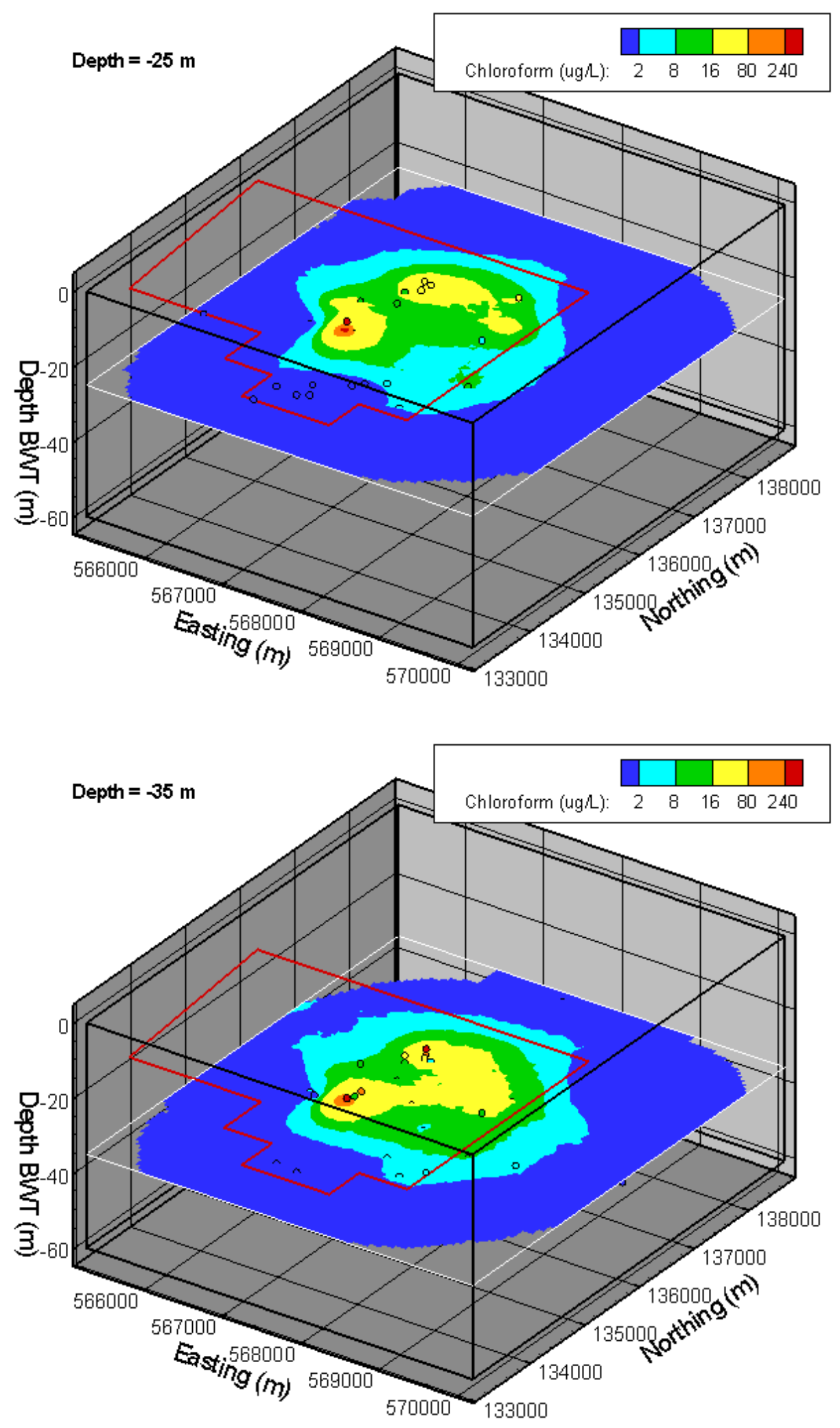

Figure 4.18. Median Chloroform Concentration at Depth BWT of 25 and $35 \mathrm{~m}$. The well data within $2.5 \mathrm{~m}$ above and below the depths are shown in circles. 

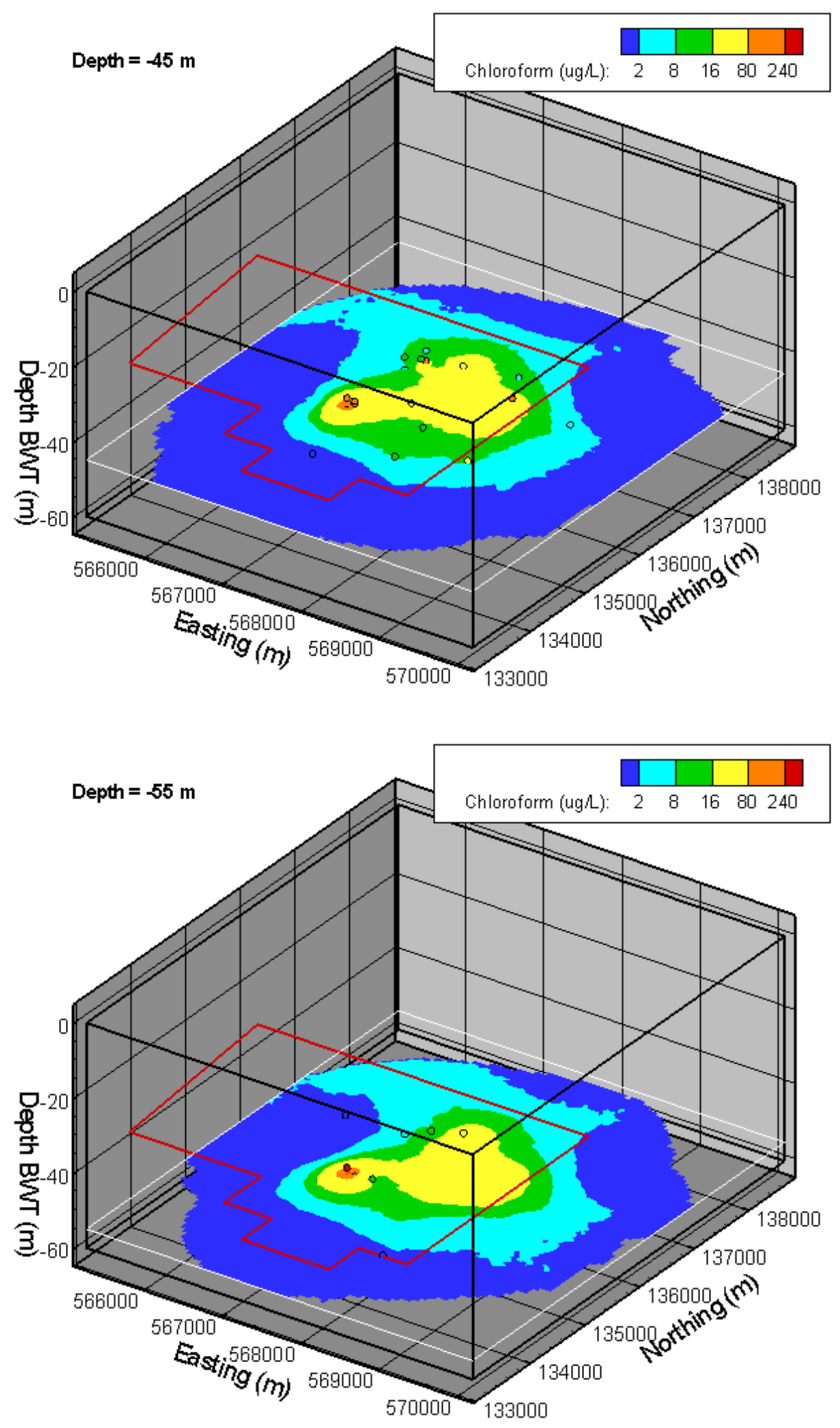

Figure 4.19. Median Chloroform Concentration at Depth BWT of 45 and $55 \mathrm{~m}$. The well data within $2.5 \mathrm{~m}$ above and below the depths are shown in circles. 
The Tc-99 realizations show greater variability than the realizations generated for the 3D CTET model. For example, the maximum of the global means of the Tc-99 realizations is five times larger than the minimum (Table 4.4), while that ratio is only 2.3 for the 3D CTET realizations (Table 4.3). Similarly, the coefficient of variation (i.e., the ratio of the standard deviation to the mean) for the global means of the Tc-99 realizations is almost twice as large as that for the 3D CTET realizations. The greater variability for the Tc-99 realizations, which should lead to higher uncertainty for Tc-99 flow and transport predictions, is probably due to several factors, including 1) the presence of $17 \%$ more depth-discrete data for CTET than there is for Tc-99 (Table 3.2); 2) the apparent patchiness of the Tc-99 plumes relative to the CTET plumes, e.g., in the median maps (Figures 4.22 through 4.24); and 3) the presence of a greater degree of variability in the univariate distributions of the two variables, with the Tc-99 data ranging over more than five orders of magnitude versus less than four orders of magnitude for the CTET data

(Table 3.2).

Table 4.4. Statistics of Global Means for 500 Tc-99 Realizations

\begin{tabular}{lc}
\hline \multirow{1}{*}{ Statistic } & Global Mean \\
\cline { 2 - 2 } Mean & Tc-99 $(\mathrm{pCi} / \mathrm{L})$ \\
\hline Median & 770.09 \\
Standard deviation & 742.35 \\
Coefficient of variation & 204.42 \\
Range & 0.265 \\
Minimum & 1440.95 \\
Maximum & 350.58 \\
Count & 1791.54 \\
\hline
\end{tabular}



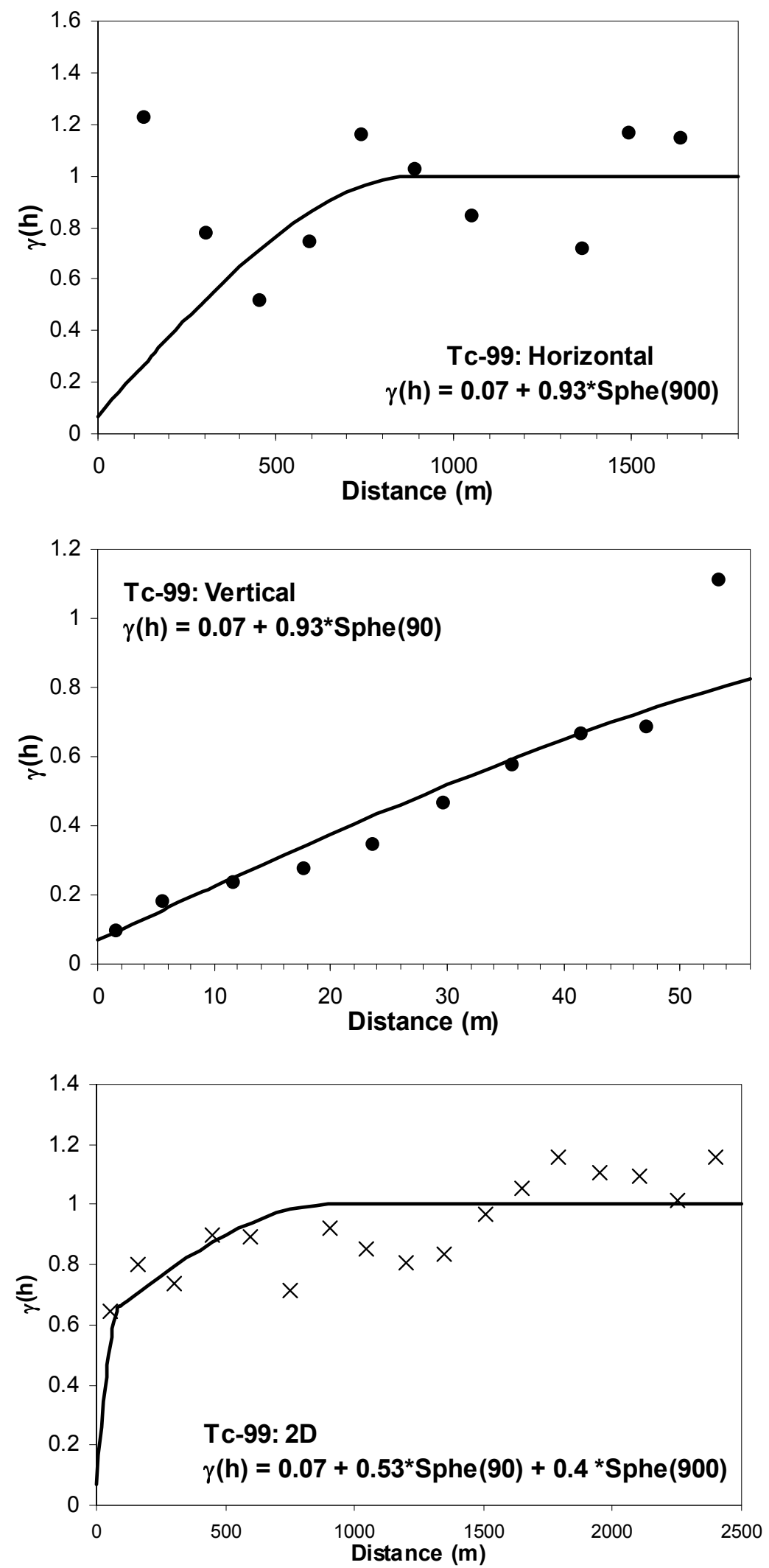

Figure 4.20. Experimental Variograms and Models for the Normal Scores of 3D Tc-99 Data (top and middle) and the Horizontal Variogram Model for 2D Tc-99 Data (bottom) 


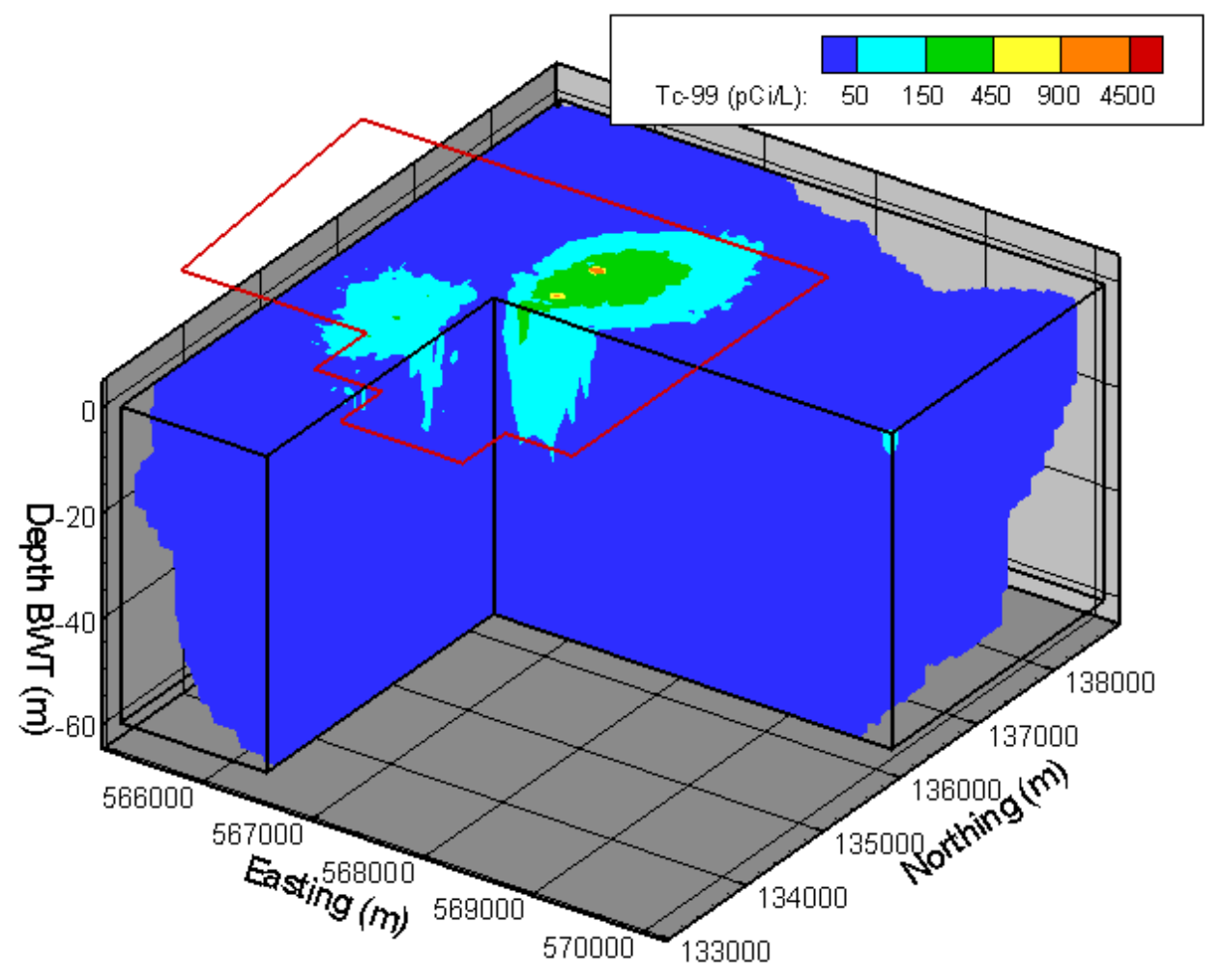

Figure 4.21. Median Tc-99 Concentration of 500 Simulations. Cutaway at easting from $566525 \mathrm{~m}$ to $570125 \mathrm{~m}$ and northing from $133045 \mathrm{~m}$ to $135985 \mathrm{~m}$. 

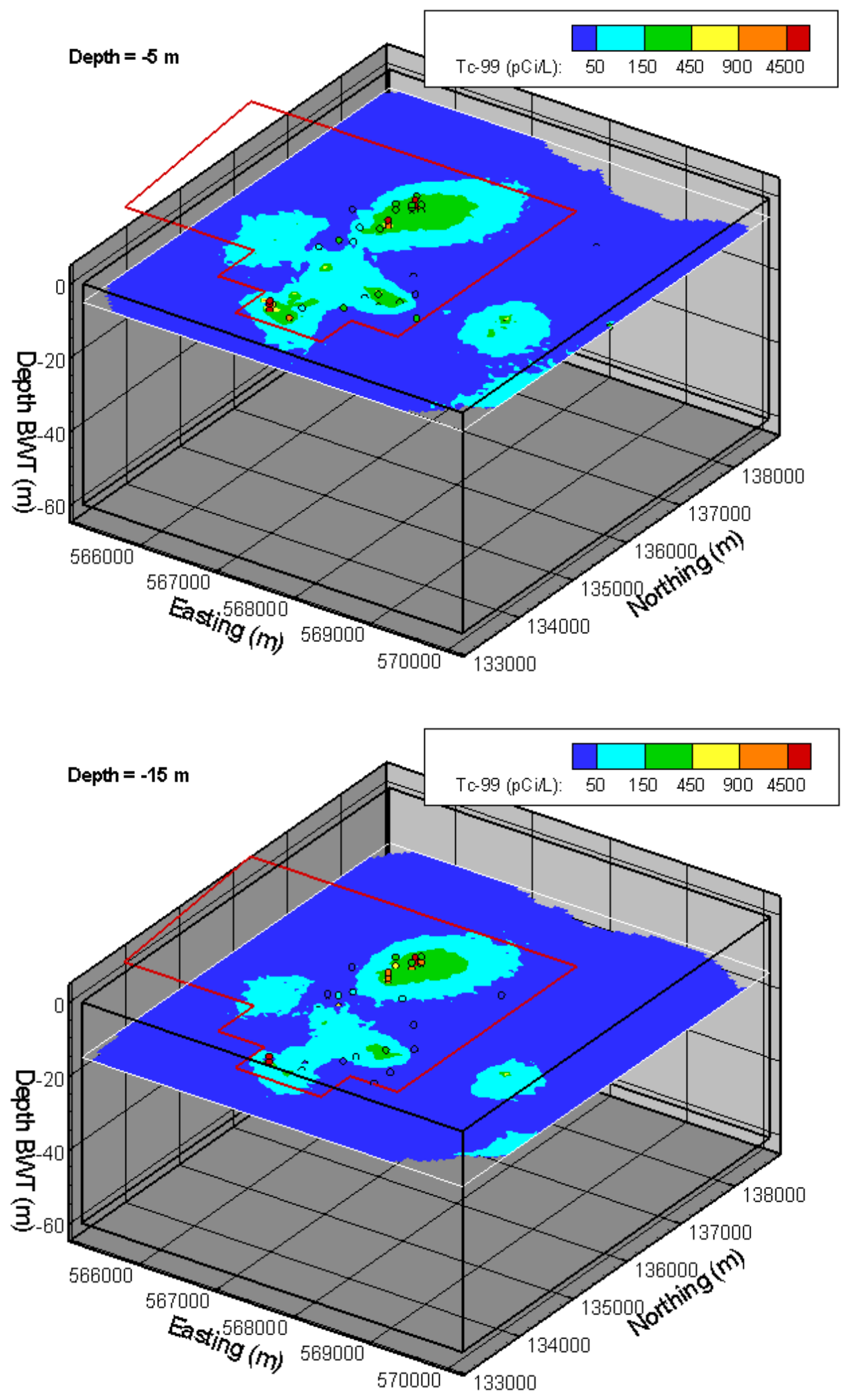

Figure 4.22. Median Tc-99 Concentration at Depth BWT of 5 and $15 \mathrm{~m}$. The well data within $2.5 \mathrm{~m}$ above and below the depths are shown in circles. 

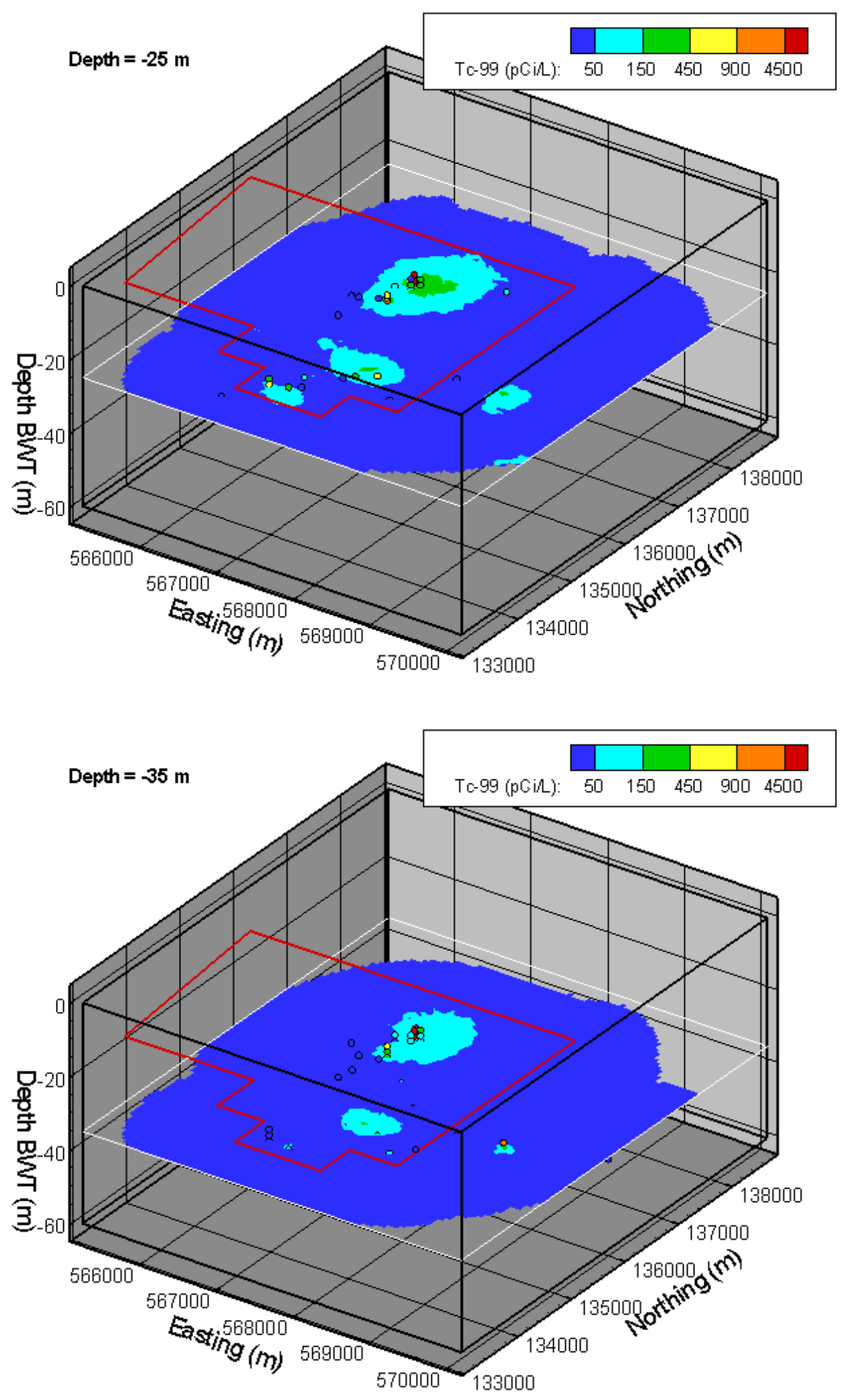

Figure 4.23. Median Tc-99 Concentration at Depth BWT of 25 and $35 \mathrm{~m}$. The well data within $2.5 \mathrm{~m}$ above and below the depths are shown in circles. 

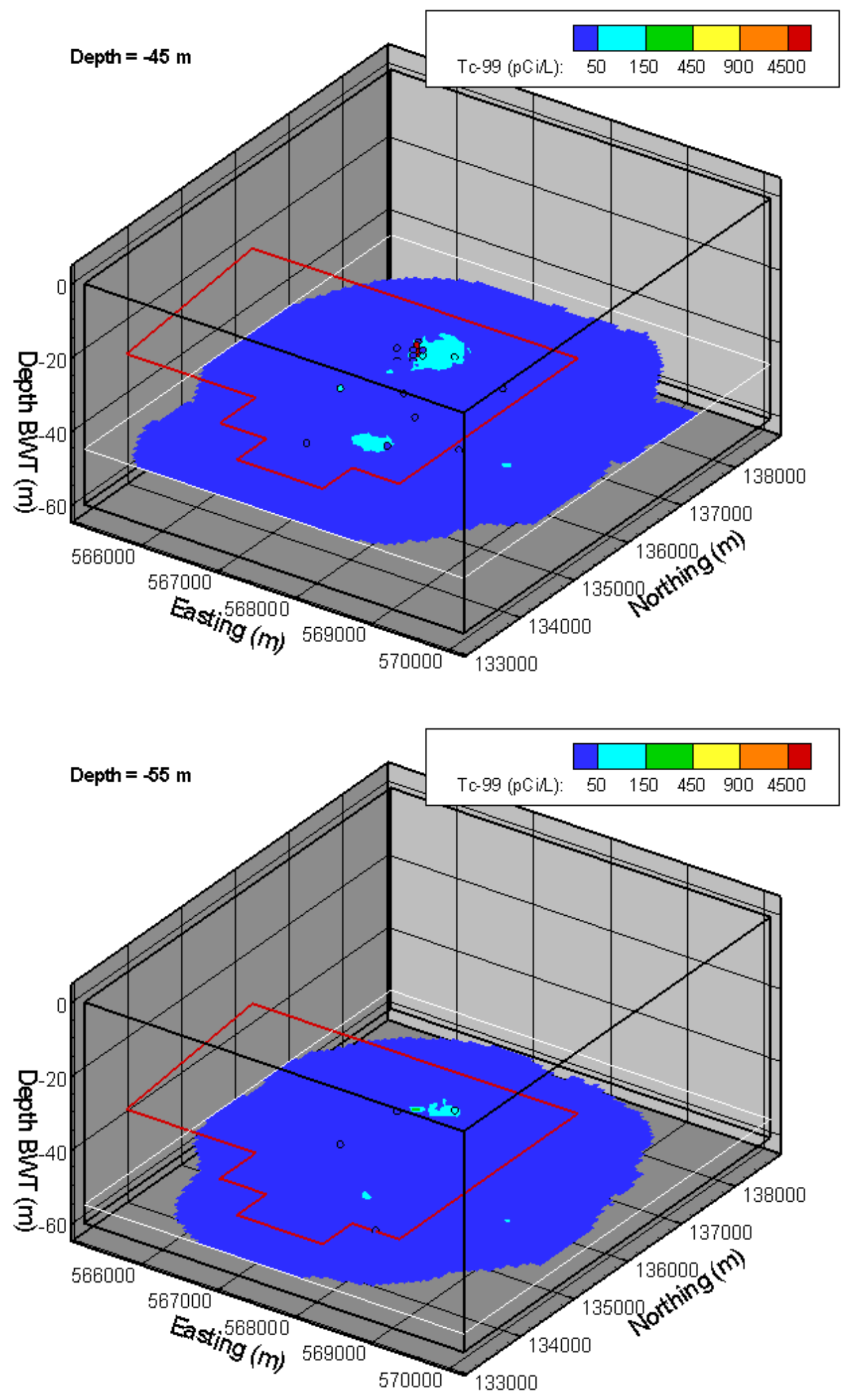

Figure 4.24. Median Tc-99 Concentration at Depth BWT of 45 and $55 \mathrm{~m}$. The well data within $2.5 \mathrm{~m}$ above and below the depths are shown in circles. 


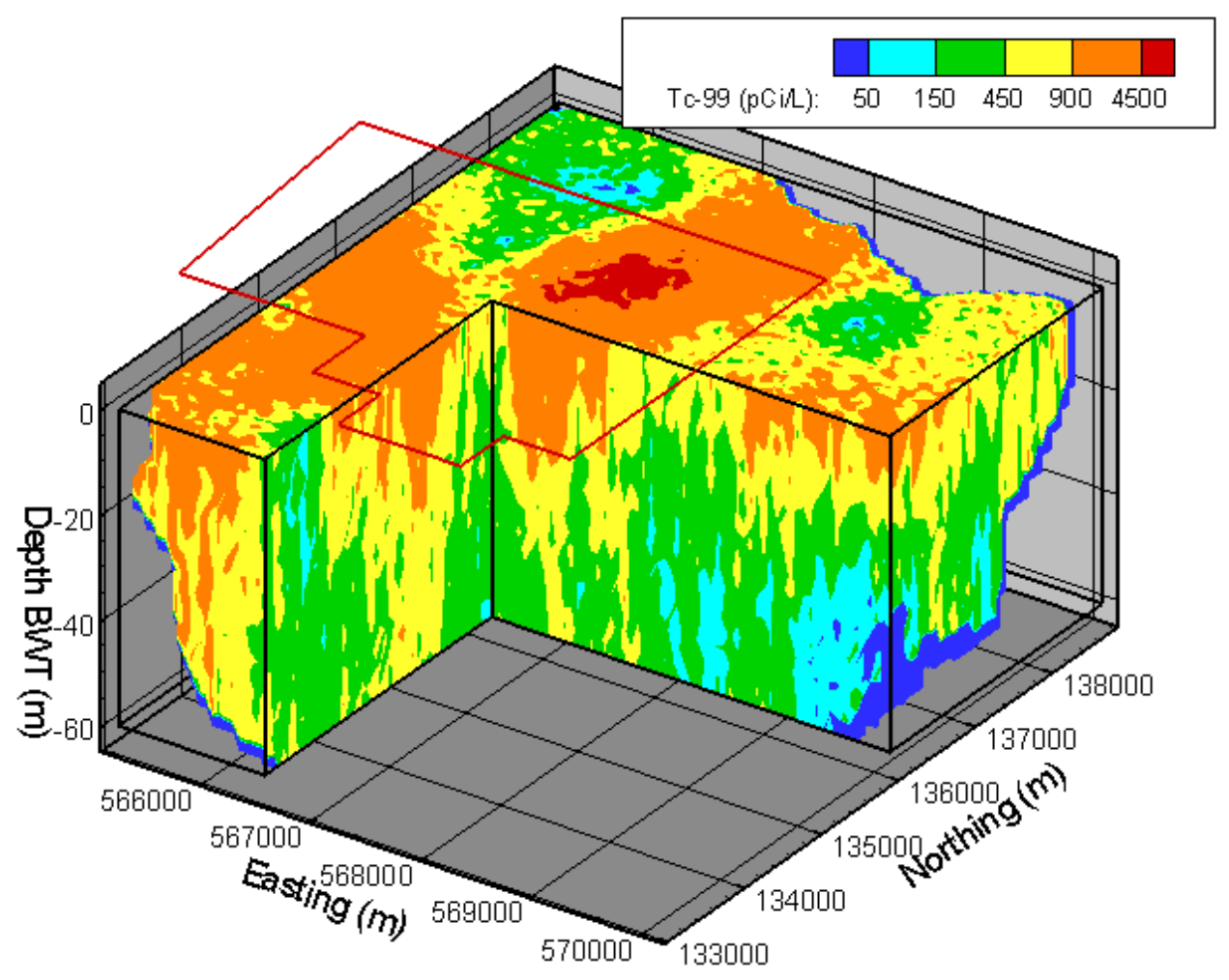

Figure 4.25. E-type Tc-99 Concentration for 500 Simulations. Cutaway at easting from $566525 \mathrm{~m}$ to $570125 \mathrm{~m}$ and northing from $133045 \mathrm{~m}$ to $135985 \mathrm{~m}$. 

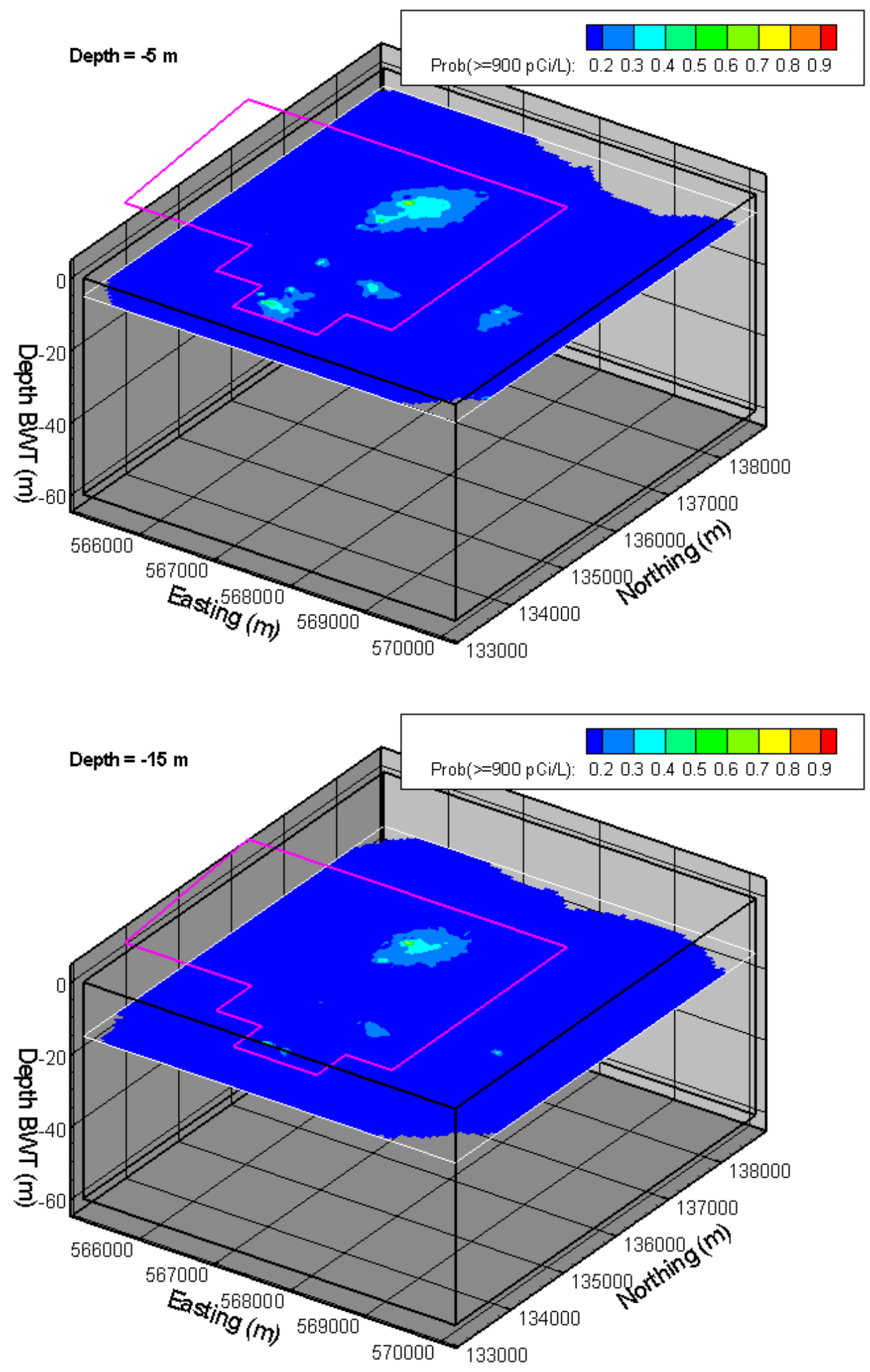

Figure 4.26. Probability of Tc-99 Exceeding $900 \mathrm{pCi} / \mathrm{L}$ from the Suite of Realizations for Depths BWT of 5 and $15 \mathrm{~m}$ 

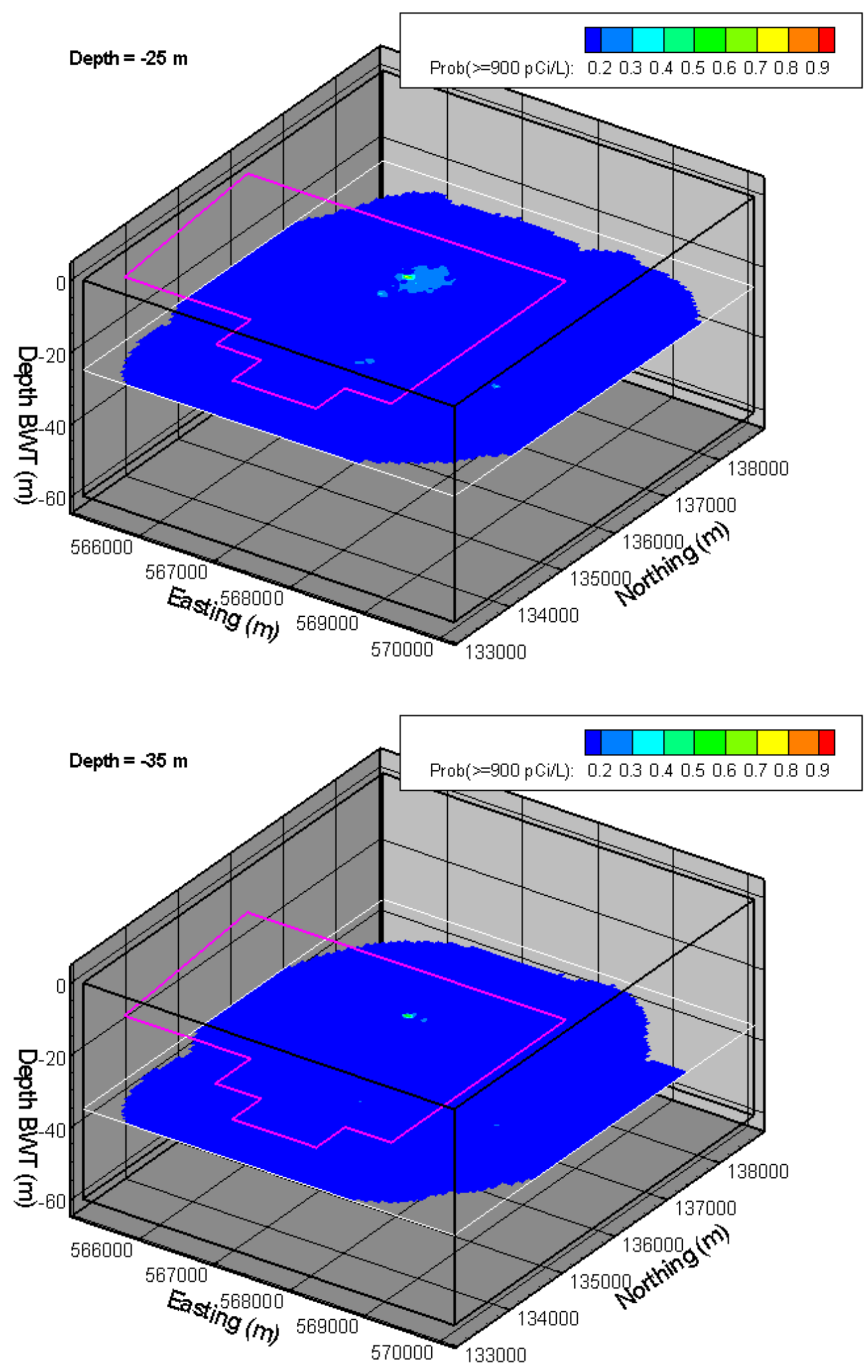

Figure 4.27. Probability of Tc-99 Exceeding $900 \mathrm{pCi} / \mathrm{L}$ from the Suite of Realizations for Depths BWT of 25 and $35 \mathrm{~m}$ 


\subsection{References}

Deutsch CV and AG Journel. 1998. GSLIB: Geostatistical Software Library and User's Guide. Oxford University Press, New York.

Gilbert RO. 1987. Statistical Methods for Environmental Pollution Monitoring. Van Nostrand Reinhold, New York.

Goovaerts P. 1997. Geostatistics for Natural Resources Evaluation. Oxford University Press, New York.

Hartman MJ and WD Webber (eds). 2008. Hanford Site Groundwater Monitoring for Fiscal Year 2007. DOE/RL-2008-01, Rev. 0, U.S. Department of Energy, Richland Operations Office, Richland, Washington.

Kyriakidis PC. 1997. "Selecting Panels for Remediation in Contaminated Soils via Stochastic Imaging." In Geostatistics Wollongong 96, EY Baafi and NA Schofield (eds), pp. 973-983. Kluwer Academic Publishers, Dordrecht, the Netherlands.

McGill JR, JW Tukey, and JW Larsen. 1978. "Variations of Box Plots." American Statistician 32:12-16.

Murray CJ, Y Bott, and MJ Truex. 2007. Geostatistical Analyses of the Persistence and Inventory of Carbon Tetrachloride in the 200 West Area of the Hanford Site. PNNL-16509, Pacific Northwest National Laboratory, Richland, Washington.

Williams BA, FA Spane, VJ Rohay, and DB Erb. 2005. "Characterization of the Vertical Distribution of Carbon Tetrachloride Contamination in Hanford Site Groundwater." Presented to the Washington State 5th Annual Hydrogeology Symposium, April 12, 2005, Tacoma, Washington. Abstract accessed online at http://www.ecy.wa.gov/events/hg/PastSymposia/abstracts2005.pdf (December 2008). 



\section{Appendix}

\section{Electronic Files for}

Contaminant Database and Geostatistical Mapping 



\section{Appendix}

\section{Electronic Files for Contaminant Database and Geostatistical Mapping}

This appendix, contained on the two compact discs (CDs) inside the back cover of this report, includes electronic files produced in the course of the mapping study. The files are in several folders on the CDs, including folders for the draft database and its associated documentation files; a folder containing the grids of the median simulated values; a folder with the grids of the average simulated value (i.e., E-type estimate) for the CTET 3D model and Tc-99; a folder containing the alternative realizations for the CTET 3D model and Tc-99 selected using the ranking method described in Section 4.1.1; and simulation folders for each variable with the SGSIM parameter files, data files, and executable files used to generate the realizations. In addition, the simulation subfolders include archived copies of the 500 realizations retained for each variable.

The files are archived on two CDs. A listing of the files included on the CDs follows. Disc 1 contains the following files:

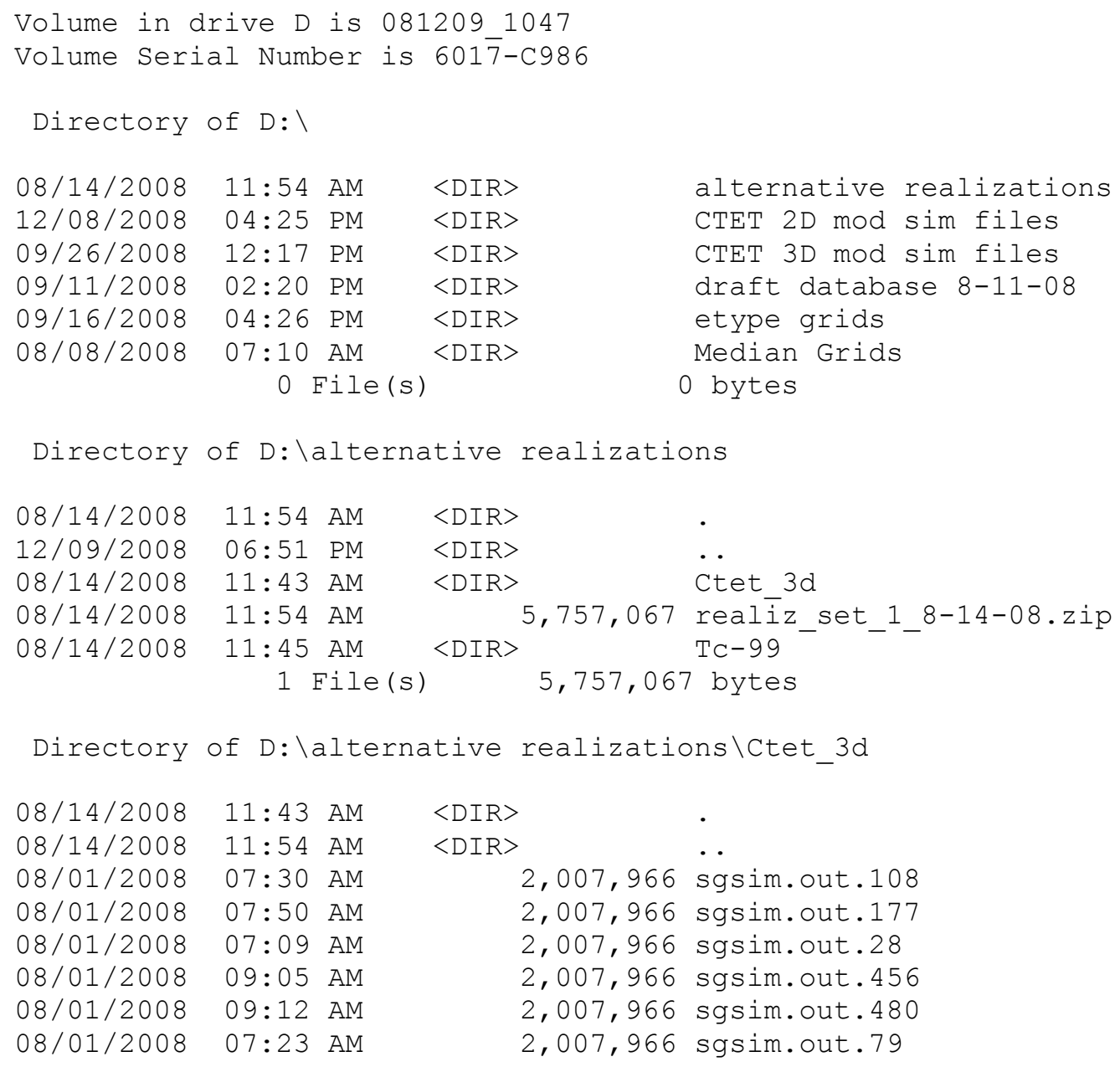




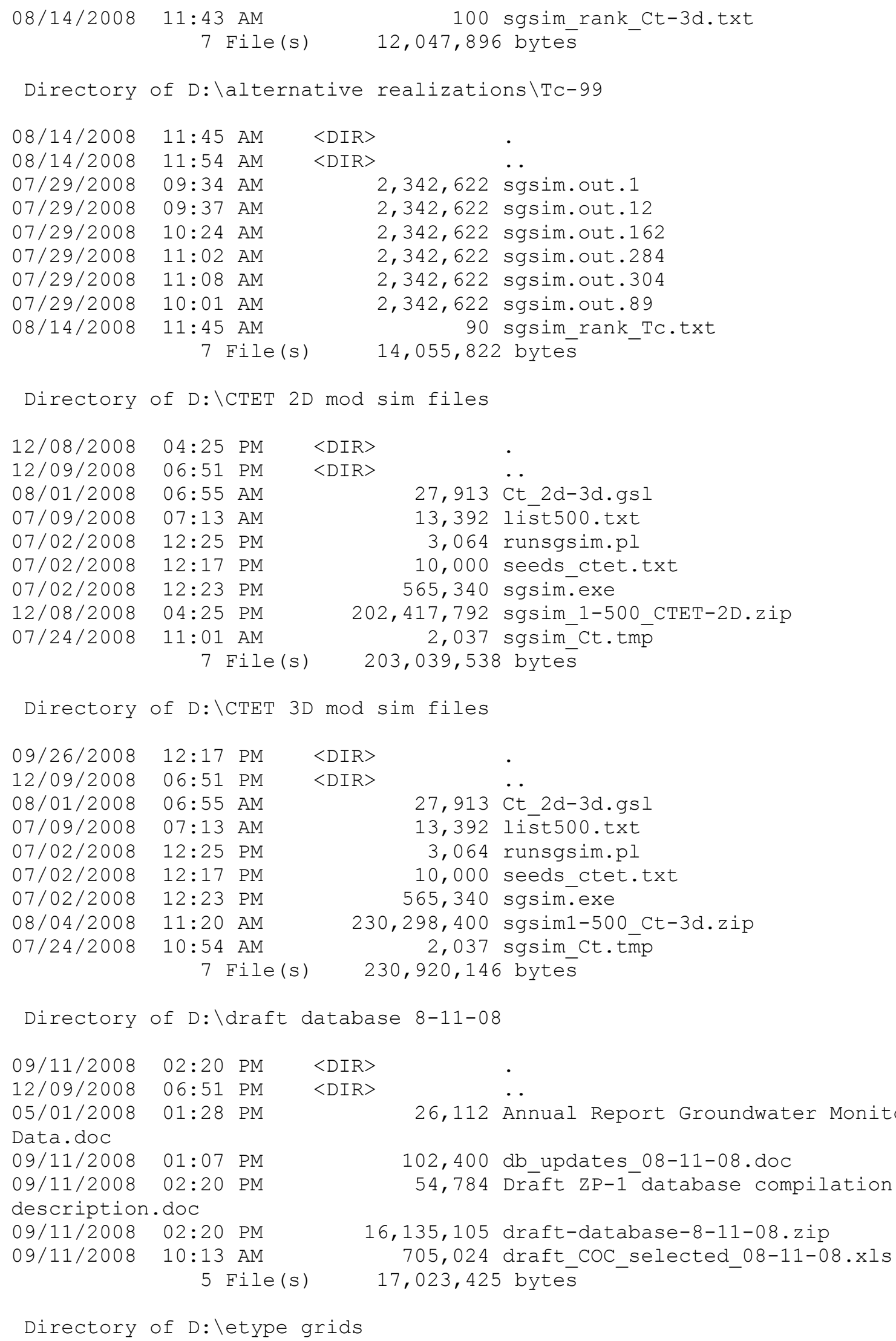

Directory of D: letype grids 


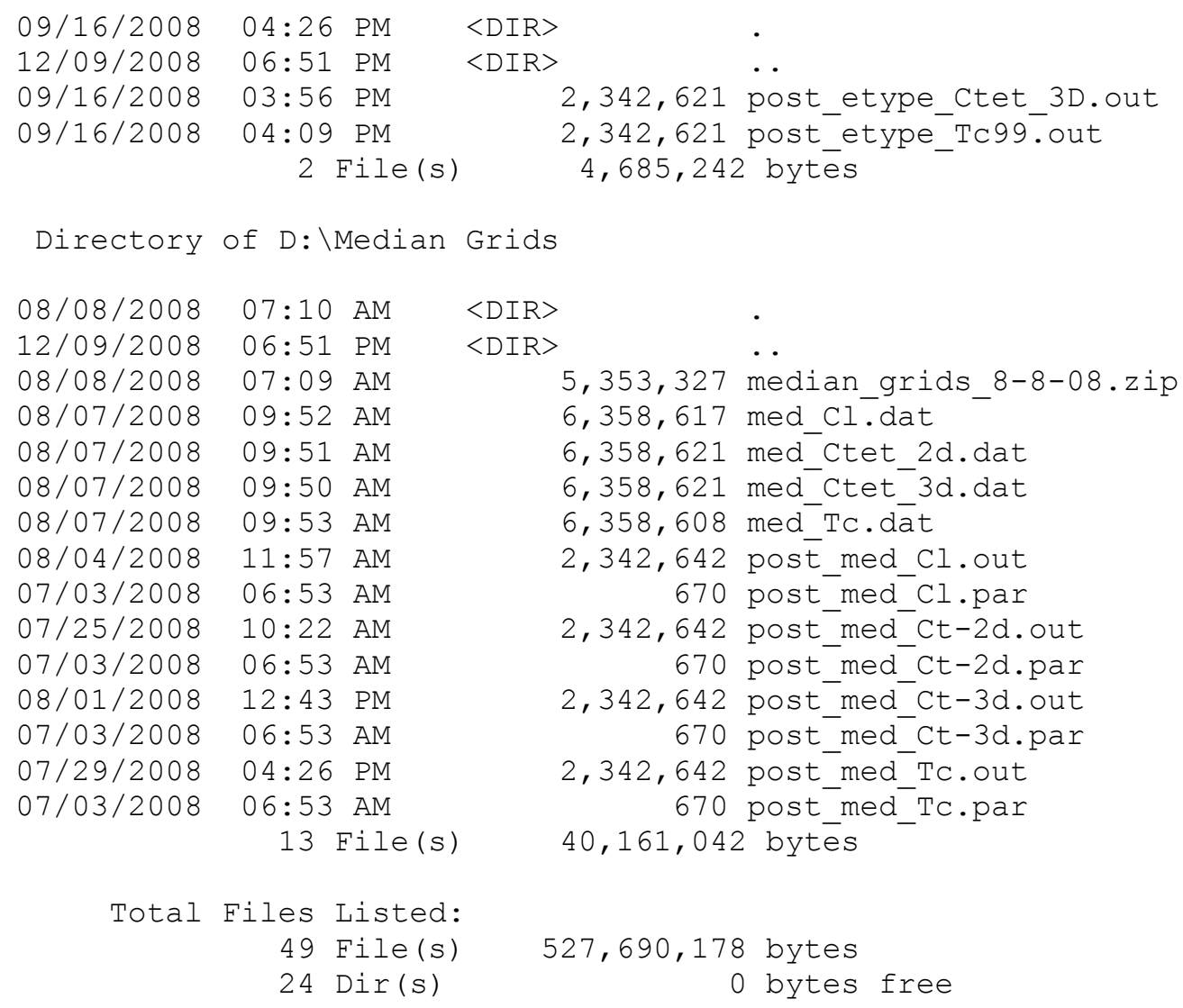

Disc 2 contains the following files:

Volume in drive D is 0812091054

Volume Serial Number is $800 \overline{0}-42 \mathrm{DD}$

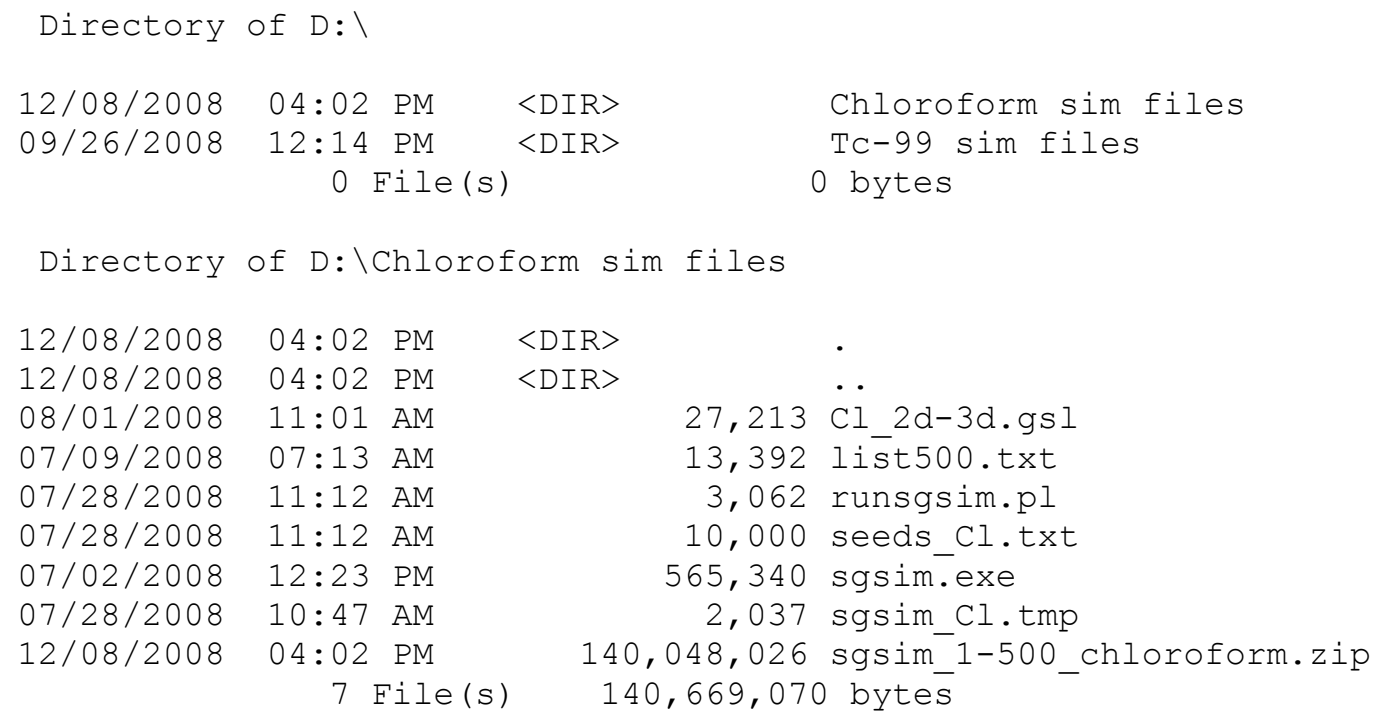




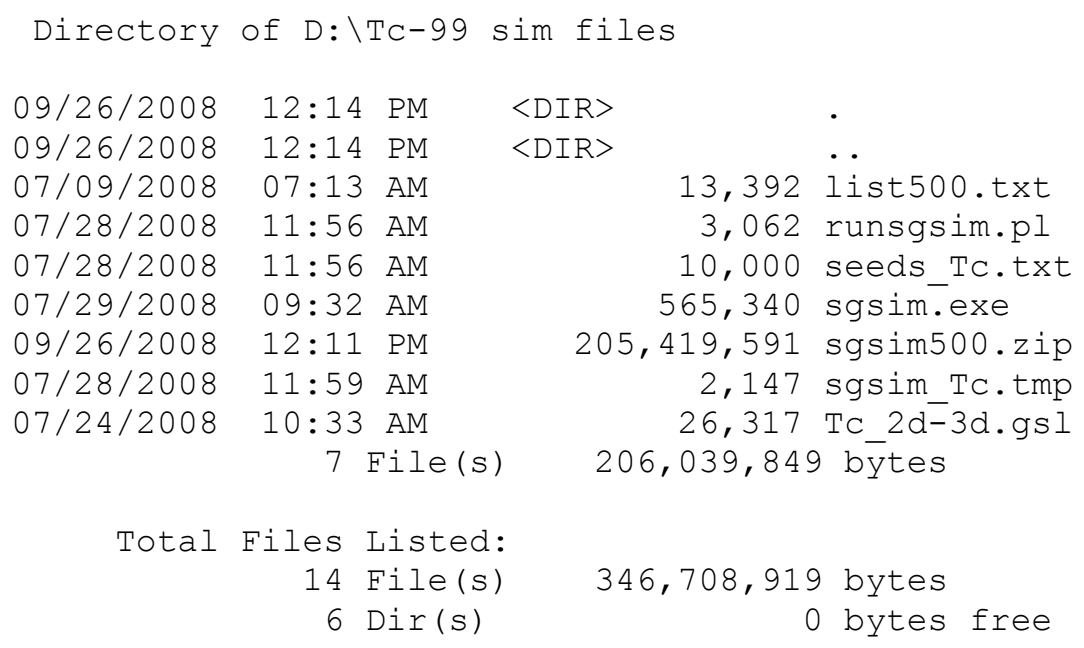




\section{Distribution}

No. of

Copies

M. J. Tonkin

S.S. Papadopulos \& Assoc., Inc.

7944 Wisconsin Avenue

Bethesda, MD 20814

R. Dinicola

U.S. Geological Survey

Washington Water Science Center

934 Broadway, Suite 300

Tacoma, WA 98402

Vista Engineering Technologies LLC

1355 Columbia Park Trail

Richland, WA 99352

Attn: W. Bratton

C. Arola
OFFSITE

No. of

Copies

20 CH2M HILL Plateau

Remediation Company

R Biggerstaff E6-35

ME Byrnes E6-44

KM Davis E6-44

WS Elliott E6-44

DB Erb E6-35

GG Kelty E6-35

DS Miller E6-44

K Moser E6-44

RW Oldham E6-35

SW Petersen E6-35

RS Popielarczyk E6-35

VJ Rohay (5) E6-44

AJ Rossi R3-60

SA Simmons $\quad$ E6-44

LC Swanson B6-06

BH Von Bargen R3-19

\section{ONSITE}

\section{DOE-Richland Operations Office}

AC Tortoso

A6-38

JG Morse

A6-38

BL Charboneau
U.S. Environmental Protection Agency

DA Faulk

B1-46

12 Pacific Northwest National Laboratory

GV Last

K6-81

CJ Murray (5)

K6-81

M Oostrom

K9-33

ML Rockhold

K9-36

FA Spane

K6-96

MJ Truex

K6-96

Hanford Technical Library (2)
P8-55 




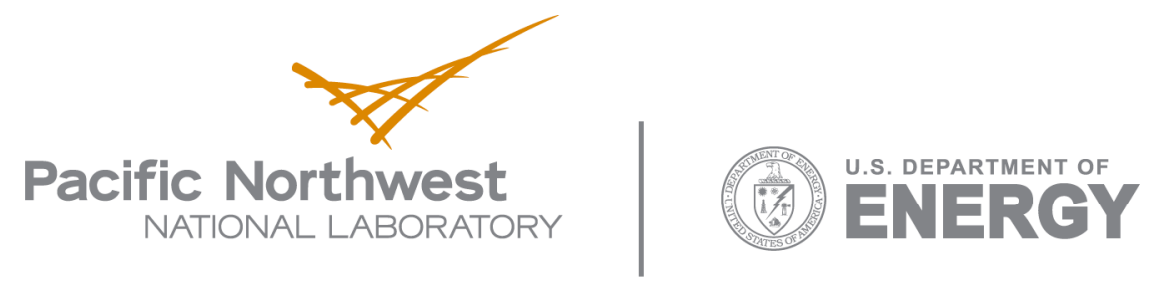

902 Battelle Boulevard

P.O. Box 999

Richland, WA 99352

1-888-375-PNNL (7665)

www.pnl.gov 